\title{
Fire Performance of Cold-formed Steel Wall Panels and Prediction of their Fire Resistance Rating
}

Shanmuganathan Gunalan and Mahen Mahendran

\begin{abstract}
Recent research at the Queensland University of Technology has investigated the structural and thermal behaviour of load bearing Light gauge Steel Frame (LSF) wall systems made of $1.15 \mathrm{~mm}$ G500 steel studs and varying plasterboard and insulation configurations (cavity and external insulation) using full scale fire tests. Suitable finite element models of LSF walls were then developed and validated by comparing with test results. In this study, the validated finite element models of LSF wall panels subject to standard fire conditions were used in a detailed parametric study to investigate the effects of important parameters such as steel grade and thickness, plasterboard screw spacing, plasterboard lateral restraint, insulation materials and load ratio on their performance under standard fire conditions. Suitable equations were proposed to predict the time-temperature profiles of LSF wall studs with eight different plasterboard-insulation configurations, and used in the finite element analyses. Finite element parametric studies produced extensive fire performance data for the LSF wall panels in the form of load ratio versus time and critical hot flange (failure) temperature curves for eight wall configurations. This data demonstrated the superior fire performance of externally insulated LSF wall panels made of different steel grades and thicknesses. It also led to the development of a set of equations to predict the important relationship between the load ratio and the critical hot flange temperature of LSF wall studs. Finally this paper proposes a simplified method to predict the fire resistance rating of LSF walls based on the two proposed set of equations for the load ratio-hot flange temperature and the time-temperature relationships.
\end{abstract}

Keywords: Cold-formed steel wall panels, Light gauge steel frame, Load bearing walls, Critical temperature, Steel studs, Plasterboards, Insulation, Standard fire. 


\section{Introduction}

Cold-formed steel sections are commonly used in various combinations to provide loadbearing Light gauge Steel Framed (LSF) wall systems in buildings (Figure 1). Under fire conditions, cold-formed steel stud sections heat up quickly as they are thin-walled, resulting in fast reduction to their strength and stiffness. Therefore these stud sections are commonly used in planer structural wall systems with plasterboard on both sides as fire protection. Plasterboards protect the steel studs by delaying the temperature rise in the studs during building fires. Since the LSF walls are often subjected to fire on one side, non-uniform temperature distributions will develop across the depth of LSF wall studs. This will induce additional bending moments on the studs due to thermal bowing, neutral axis shift and magnification effects. Hence the thin-walled steel studs will be subjected to combined actions of axial compression and bending moment during a fire event. This fire behaviour of LSF wall panels has been investigated by many researchers in the past [1-10] and several fire design rules have been proposed [1-3,5,6,9,10]. Klippstein [1] and Gerlich et al. [2] developed their fire design rules based on AISI design provisions [11] while Alfawakhiri's [5] study was based on Canadian cold-formed steel design rules. Ranby [3], Kaitila [6], Feng and Wang [9] and Zhao et al. [10] developed their fire design rules based on Eurocode 3 Part 1.3 [12]. These design rules are complex and time consuming and hence do not suit routine design purposes.

In order to overcome this problem related to the need for simplified design rules and to address the lack of research data on Australian LSF wall systems, a detailed investigation based on full scale fire tests and finite element analyses was conducted on both conventional Australian LSF walls with and without the use of cavity insulation and the new composite panel system developed recently at the Queensland University of Technology. Details of 10 full scale fire tests and their results including the temperature and deflection profiles measured during the tests are presented in $[13,14]$ along with the failure times and modes. A suitable finite element model of LSF wall studs subject to fire conditions was then developed using ABAQUS, and validated using the results of fire tests [14].

In this paper idealised time-temperature profiles were first proposed for LSF wall studs based on the results from the full scale fire tests. These idealised time-temperature profiles were then used in a detailed finite element analysis based parametric study of LSF wall studs under 
fire conditions. The validated finite element models were used in this parametric study to investigate the behaviour of LSF walls. This study included the effects of various parameters such as steel grade, steel thickness, screw spacing, plasterboard restraint, various insulation materials and load ratios. Finally, a simple design method was proposed based on the parametric study results to predict the fire resistance rating of LSF wall panels with varying wall configurations (single and double layers of plasterboards, cavity and externally insulated) and structural parameters (steel grade and thickness) under varying load ratios.

\section{Experimental Study}

This section provides brief details of the series of full scale fire tests of LSF walls conducted first to evaluate the fire resistance rating (FRR) of load bearing LSF wall assemblies. One wall specimen was tested to failure under an axial compression load at room temperature while ten wall specimens subjected to a constant axial compression load were exposed to standard fire conditions on one side to evaluate their fire performance (Table 1). Conventional Australian LSF wall panels lined with single or double layers of plasterboard with or without cavity insulation were considered. A new LSF wall system based on a composite panel was also included in which a $25 \mathrm{~mm}$ external insulation was sandwiched between the two plasterboards [13,14]. The plasterboards used in the study were $1200 \mathrm{~mm}$ in width by $2400 \mathrm{~mm}$ in length with a thickness of $16 \mathrm{~mm}$ and density of $13 \mathrm{~kg} / \mathrm{m}^{2}$. The densities of glass, rockwool and cellulose fibre insulations used in this study were 13.88 $\mathrm{kg} / \mathrm{m}^{3}, 100 \mathrm{~kg} / \mathrm{m}^{3}$ and $100-110 \mathrm{~kg} / \mathrm{m}^{3}$, respectively. Their thermal conductivity, specific heat and relative density at ambient and elevated temperatures are given in [15].

All the steel frames used in the load bearing LSF wall panels were built to a height of 2400 $\mathrm{mm}$ and a width of $2400 \mathrm{~mm}$ as shown in Figure 1. The studs and tracks used in the test frames were fabricated from G500 galvanized steel sheets with a nominal base metal thickness of $1.15 \mathrm{~mm}$, a yield strength of $569 \mathrm{MPa}$ and an elastic modulus of $213520 \mathrm{MPa}$ at ambient temperature. Their dimensions are shown in Figure 1. Test frames were lined on both sides by single or double layers of $16 \mathrm{~mm}$ gypsum plasterboards manufactured by Boral Plasterboard. Table 1 shows the details of the 10 LSF wall specimens used in this study with two load ratios. 
The furnace was designed to deliver heat based on the standard fire curve given in [16]. The loading frame was designed to load the individual studs of LSF wall specimens in compression from the bottom side (Figure 2) using hydraulic jacks. The axial shortenings of the studs and the out-of-plane movements of the wall specimen were measured using Linear Variable Displacement Transducers. K type thermocouples were used to measure the temperature development across the wall specimens. The stud (hot flange, web and cold flange) temperatures were measured at three levels for interior studs, namely, at $0.25 \mathrm{H}, 0.50$ $\mathrm{H}$ and $0.75 \mathrm{H}$, and at mid-height for exterior studs.

In each fire test an axial compression load of $15 \mathrm{kN}$ (for a load ratio of about 0.2 ) or $30 \mathrm{kN}$ (for a load ratio of about 0.4) was applied to each stud (ie. 0.2 or 0.4 times the ultimate capacity of each stud at room temperature obtained from [13]. The load was held constant at room temperature before the furnace was started and then maintained throughout the fire test. During the fire test, the furnace temperature was regulated to follow the standard timetemperature curve. The test was stopped immediately after one or more of the wall studs failed, and the time to failure was recorded. Figure 2 (b) shows the LSF wall panel and the studs after failure. Table 1 shows the failure times obtained from the experimental study. Further details are given in $[13,14]$.

\section{Idealised Time-Temperature Profiles}

Table 1 shows the LSF wall test configurations and insulations used in the experimental study. The new externally insulated wall panels with glass and rock fibres were tested under two load ratios of 0.2 and 0.4 . Hence these 10 full scale fire tests were essentially conducted using eight different wall configurations (Table 2). Therefore idealised time-temperature profiles were developed for these eight configurations using the measured hot and cold flange temperature distributions along the wall stud. In the development of idealised timetemperature profiles of studs with externally insulated glass and rock fibres, the average temperature values of the two fire tests were used (load ratios of 0.2 and 0.4 - Tests $1 \& 2$; Tests $\left.3 \& 6^{*}\right)$. The critical stud in a LSF wall panel was the stud with the vertical plasterboard joint against it. The temperature values of this stud were high compared to other studs due to the opening of this vertical joint at higher temperatures. Therefore the average temperatures along this stud were considered in the development of all the idealised timetemperature profiles for LSF wall studs under standard fire conditions. 
When the LSF wall was subject to standard fire conditions, the hot and cold flange temperatures of the steel stud were $20^{\circ} \mathrm{C}$ for the initial few minutes. They then increased gradually to reach $100^{\circ} \mathrm{C}$ and remained at the same temperatures during the plasterboard dehydration process. After this the steel temperatures increased rapidly with time. Table 2 shows the time-temperature values of hot and cold flanges up to $100^{\circ} \mathrm{C}$. A linear variation of temperature distribution was assumed between these times. Beyond $100^{\circ} \mathrm{C}$, Equations 1 to 8 represent the idealised time-temperature profiles for the LSF wall panels with eight configurations shown in Table 2, where $\mathrm{T}_{\mathrm{HF}}$ and $\mathrm{T}_{\mathrm{CF}}$ are the average hot and cold flange temperatures in ${ }^{\circ} \mathrm{C}$ and $\mathrm{t}$ is the time in minutes.

1) LSF wall lined on both sides by a single layer of plasterboard (Test $1 *$ ).

$$
\begin{array}{ll}
T_{H F}=-0.1066 t^{2}+20.17 t-165 & (15 \leq t) \\
T_{C F}=10.29 t-125 & (22 \leq t \leq 50) \\
T_{C F}=29.35 t-1090 & (50<\mathrm{t} \leq 60) \\
T_{C F}=T_{H F} & (60<t)
\end{array}
$$

2) LSF wall lined on both sides by two layers of plasterboard (Test $2^{*}$ ).

$$
\begin{array}{ll}
T_{H F}=6.35 t-160 & (42 \leq t \leq 110) \\
T_{H F}=12.11 t-790 & (110<t) \\
T_{C F}=6.07 t-230 & (55 \leq t)
\end{array}
$$

3) LSF wall lined on both sides by two layers of plasterboard with glass fibre used as cavity insulation (Test $3 *$ ).

$$
\begin{array}{ll}
T_{H F}=11.17 t-490 & (53 \leq t) \\
T_{C F}=4.92 t-225 & (66 \leq t \leq 96) \\
T_{C F}=12.04 t-915 & (96<t)
\end{array}
$$

4) LSF wall lined on both sides by two layers of plasterboard with rock fibre used as cavity insulation (Test $\left.4^{*}\right)$.

$$
\begin{aligned}
& T_{H F}=10.2 t-435 \\
& T_{C F}=4.06 t-165
\end{aligned}
$$

5) LSF wall lined on both sides by two layers of plasterboard with cellulose fibre used as cavity insulation (Test $\left.5^{*}\right)$.

$$
\begin{array}{ll}
T_{H F}=8.94 t-360 & (53 \leq t \leq 106) \\
T_{H F}=19.83 t-1530 & (106<t)
\end{array}
$$


$T_{C F}=3.83 t-150$

$(66 \leq t \leq 106)$

$T_{C F}=17 t-1550$

$(106<t)$

6) LSF wall lined on both sides by two layers of plasterboard with glass fibre used as external insulation (Tests $1 \& 2$ ).

$T_{H F}=0.001007 t^{3}-0.1605 t^{2}+12.15 t-205$

$T_{C F}=0.0904 t^{2}-9.56 t+350$

7) LSF wall lined on both sides by two layers of plasterboard with rock fibre used as external insulation (Test $3 \& 6^{*}$ ).

$T_{H F}=-0.000212 t^{3}+0.0931 t^{2}-5.47 t+100 \quad(71 \leq t)$

$T_{C F}=0.0586 t^{2}-6.69 t+260$

8) LSF wall lined on both sides by two layers of plasterboard with cellulose fibre used as external insulation (Test $7 *$ ).

$T_{H F}=-0.000286 t^{3}+0.1024 t^{2}-2.92 t-100$

$T_{C F}=0.0846 t^{2}-9.5 t+320$

Figures 3 (a) to (h) show the measured and idealised time-temperature profiles of hot and cold flanges. The idealised profiles were based on the equations proposed in this study. Equation 1 (a) was used to represent the hot flange temperature values in Wall Configuration 1. The limit given as $15 \leq t$ indicates that after 15 minutes the hot flange temperature increased rapidly from $100^{\circ} \mathrm{C}$. Similarly, the cold flange temperature increased rapidly after 22 minutes according to Equation 1 (b). After 50 minutes the fire side plasterboard has fallen off and hence the cold flange was also exposed to severe fire due to the heat transmitted into the cavity. Therefore the cold flange temperature increased rapidly and the temperature difference across the stud was reduced as shown in Figure 3 (a). It is unsafe to neglect this phase in the fire design of LSF wall panels and hence this phase is included using Equation 1 (c). A similar argument was used to develop the idealised time-temperature profiles of all other wall configurations. Therefore additional equations were proposed for the final phases of Wall Configurations 2, 3 and 5 (Figures 3 (b), (c) and (e)). In Wall Configuration 1, the cold flange temperature is expected to reach the hot flange temperature after a few minutes from the plasterboard fall off time. This is possible in LSF wall panels where both sides are lined with only a single layer of plasterboard. Hence an upper limit is proposed for Equation 1 (c) as 60 minutes. After 60 minutes it is expected that the cold flange temperatures will be the same as hot flange temperatures. 
Figures 3 (a) to (h) show a close agreement between the measured and idealised timetemperature profiles. Hence Equations 1 to 8 were used in the finite element parametric study. It is also observed that the hot flange temperatures of cavity insulted wall panels (Figures 3 (c) to (e)) increased rapidly compared to externally insulated wall panels (Figures 3 (f) to (h)). In addition to this the difference between the hot and cold flange temperatures also increased rapidly in cavity insulated wall panels compared to externally insulated wall panels. This implies that the cavity insulated wall panels will be subjected to larger bending moment effects and earlier failure times compared to externally insulated wall panels. This will be further discussed in this paper.

\section{Finite Element Models and Validation}

A finite element model of LSF wall studs (Figure 4(a)) was developed with appropriate thermal and structural boundary conditions to simulate the behaviour of LSF wall studs under standard fire conditions and to determine the FRR. Finite element analyses were conducted under steady state conditions. Here, the non-uniform temperature distributions in the steel stud cross-section were raised to the target levels at any given time during the standard fire and then maintained. A load was then applied in increments until the failure of stud.

\subsection{Parameters Used}

S4R shell element type with a $4 \mathrm{~mm} \times 4 \mathrm{~mm}$ mesh size was selected based on detailed convergence studies (Figure 4(b)). The measured mechanical properties of steel were used to enable the comparison of FEA and test results of LSF wall studs. Poisson's ratio of steel was assumed as 0.3 . The yield strength and elastic modulus reduction factors at elevated temperatures and the stress-strain curves were based on the predictive equations developed in [17]. The coefficient of thermal expansion given in [18] was used.

\subsection{Boundary Conditions}

Based on other numerical studies and the experimental behaviour of LSF wall studs $[13,14]$, one of the two central studs that had the vertical plasterboard joint against it was considered in the analyses. In practical construction, tracks of LSF walls are fixed to floors or ceilings using screw fasteners or bolts at $600 \mathrm{~mm}$ spacing while studs are fixed to tracks through their flanges using one screw fastener on each side. These types of connection can be 
conservatively assumed to provide pinned supports to LSF wall studs. Hence in the numerical study pinned support conditions were simulated for studs using rigid plates while an axial compressive load was applied at the section centroid at one end as shown in Figure 4(b). It was assumed that the plasterboards screw-fixed to both flanges provided sufficient lateral restraint until the failure of studs $[6,7,10]$.

\subsection{Temperature Distributions}

The measured temperature profiles obtained from the fire tests were used for validation purposes as was done by other researchers $[6,10]$. The temperatures of the studs were measured at mid-height and quarter points throughout the fire tests $[13,14]$. Therefore the average values of the measured temperatures were used over the entire stud length. A simplified non-uniform temperature distribution was considered across the stud as shown in Figure 4(c).

\subsection{Initial Geometric Imperfections and Residual Stresses}

The local web buckling near the support was predominant in the first eigen mode of the elastic buckling analyses and also in the test results [13]. Therefore this eigen mode was used to introduce the initial geometric imperfection with an amplitude of $0.006 \mathrm{~b}$ [19]. The effect of residual stress on the ultimate capacity of LSF wall stud was found to be small at ambient temperature. It will be even more insignificant at elevated temperatures. Hence residual stresses were not considered in the modelling of studs under fire conditions $[6,7,10]$.

\subsection{Validation}

The results from finite strip analyses (CUFSM) and tests [13] were used to validate the results of finite element analyses (FEA) at ambient temperature. The elastic buckling loads from CUFSM and FEA were $39.5 \mathrm{kN}$ and $39.8 \mathrm{kN}$, respectively. The ultimate failure loads from the full scale test and FEA also agreed well $(79.0 \mathrm{kN}$ and $77.3 \mathrm{kN})$. The studs failed due to local buckling of web and flanges in the test [13], which was confirmed by FEA.

Under fire conditions, many steady state analyses conducted in close time intervals led to a load ratio (ultimate load of stud in fire conditions / ambient temperature capacity) versus failure time (FRR) curve for the LSF wall systems. Figure 5 (a) shows this curve for the case of LSF wall with glass fibre external insulation while Figure 5 (b) shows the variation of load 
ratio with respect to the hot flange temperature at failure. As shown in these figures, the failure time and the critical hot flange temperature for Test 1 with a load ratio of 0.2 were obtained as 115 minutes and $600^{\circ} \mathrm{C}$. The main advantage of FEA with steady state conditions is that figures such as Figure 5 (a) can now be used to obtain the fire resistance rating (failure time) for any given load ratio. Table 1 gives the failure times predicted by FEA under steady state conditions for all the tests. These comparisons show that the developed finite element model accurately predicts the elastic buckling and ultimate capacities and failure modes of LSF wall studs subjected to axial compression under standard fire conditions. Further details on the development and validation of the finite element model can be found in [14].

\section{Fire Performance of LSF Wall Panels based on Parametric Study}

\subsection{Finite Element Analyses}

The validated finite element model was used in a detailed parametric study into the fire performance of LSF wall panels using a 90x40x15 stud section. Table 3 lists the five different cases with varying screw spacing, plasterboard restraint, steel grade and thickness considered in this study. Nominal mechanical properties and idealised time-temperature profiles using the predictive equations developed in Section 3 were used (compare Case 1 and FEA Validation columns in Table 3). The strain hardening material model was used for steels with gradual yielding type stress-strain curve except for $\mathrm{G} 250$ steels at $100^{\circ} \mathrm{C}$ and $200^{\circ} \mathrm{C}$ for which an elastic-perfect plastic material model was used [17] as they had a well defined yield point. Case 1 results were used with those of Cases 2 to 4 to investigate the effect of screw spacing, plasterboard fall off and steel grades, respectively. Similarly, Cases 4 and 5 results were used to study the effect of varying steel thickness. This section presents the results from the parametric study.

\subsection{Influence of Screw Spacing}

The influence of screw spacing on the fire performance of LSF walls was investigated for $1.15 \mathrm{~mm}$ G500 steel studs using three different screw spacings $(300 \mathrm{~mm}, 600 \mathrm{~mm}$ and 1200 $\mathrm{mm}$ ). Elastic buckling modes for these screw spacings remained the same. Figure 6 (a) shows the ultimate failure mode of the LSF wall stud with $300 \mathrm{~mm}$ screw spacing. A similar ultimate failure mode was observed for $600 \mathrm{~mm}$ and $1200 \mathrm{~mm}$ screw spacings. A slight bending about the minor axis was also observed when the screw spacing was increased to 1200 mm (Figure 6 (b)). 
Table 4 and Figure 7 show the variation of ultimate load of LSF wall stud with time during a standard fire event as obtained from FEA of $1.15 \mathrm{~mm}$ G500 steel studs lined on both sides by two layers of plasterboard with glass fibre used as external insulation and different screw spacings. The ultimate load did not reduce much when the screw spacing was increased from $300 \mathrm{~mm}$ to $600 \mathrm{~mm}$. However, it reduced considerably when the screw spacing was increased to $1200 \mathrm{~mm}$. Tables 5 to 12 present the load ratios for the LSF wall studs with screw spacings of $300 \mathrm{~mm}$ and $600 \mathrm{~mm}$ (Cases 1 and 2) for the eight wall configurations chosen in this study. The difference in the load ratio was small when the screw spacing was increased although the ultimate load was reduced. Figures 8 (a) to (h) also show that there is not much difference in the failure time when a different screw spacing is used. Figure 8 (f) includes the screw spacing of $1200 \mathrm{~mm}$ in addition to $300 \mathrm{~mm}$ and $600 \mathrm{~mm}$. It also shows that the failure time does not change when the screw spacing is varied. However, these FEA values were obtained by assuming that the plasterboard integrity was maintained at elevated temperatures. Hence the lateral restraint provided by the plasterboard was considered to be always effective. However, practically it is not possible to maintain the integrity of plasterboards when larger screw spacings are used. The plasterboards are likely to fall off prematurely when a screw spacing of $1200 \mathrm{~mm}$ is used. Therefore the failure time will also be considerably reduced for $1200 \mathrm{~mm}$ screw spacing unlike what is predicted by FEA.

\subsection{Validity of Plasterboard Restraint to Hot Flanges under Fire Conditions}

The screw-fixed plasterboards provide lateral restraint to the LSF wall studs. However, with increasing temperatures during fire events they calcinate and lose their strength. Many cracks will be developed in these calcinated plasterboards and eventually the fire side plasterboards are likely to fall off. Therefore the lateral restraint may not be available on the hot flange of the studs during the later stages of a fire event. This leads to a sudden reduction to their axial compression capacities and thus a collapse of the LSF wall. The stud temperature at which the fire side plasterboards fall off was found to vary in the previous studies $[2,6,20]$.

Gerlich et al. [2] stated that the fire exposed side plasterboard will reduce its ability to prevent buckling of the studs when steel temperatures reach critical levels $\left(>300-400^{\circ} \mathrm{C}\right)$. It is believed that these temperatures are the average stud temperatures. Gerlich et al. [2] also recommended a $3 \mathrm{~mm}$ thickness of undamaged gypsum to be retained to provide lateral 
restraint. However, it is not practical to measure this thickness in a full scale fire test. Sultan [20] reported that plasterboard fall-off occurs when the unexposed face of the board reaches about $600^{\circ} \mathrm{C}$. This temperature must be the hot flange temperature of the stud. Kaitila [6] investigated the torsional-flexural buckling mode when the temperature during the fire test was above the level of calcination of the plasterboards. He recommended a value of $550^{\circ} \mathrm{C}$ as an approximate limit. Klippstein [1] assumed that the failure by weak axis flexural buckling or torsional buckling is prevented by the gypsum boards on the internal and external faces of the wall. Alfawakhiri [5] assumed that the flexural-torsional and weak axis buckling failure modes are prevented by bridging and blocking. In the studies of $[7,10]$ the fire side plasterboards were assumed to provide lateral restraint to the studs throughout the test. Hence the question of lateral restraint provided by plasterboards was not discussed in $[1,5,7,10]$.

In the current experimental study the lateral or torsional buckling failure modes were not observed in most of the tests. This may suggest that the plasterboards did not fully calcinate to lose its ability in providing lateral restraint to the hot flanges until failure. This is quite possible for the composite panel where two plasterboards are used with insulation sandwiched between them. The hot flange temperature of the stud reached more than $600^{\circ} \mathrm{C}$ at failure for the load ratio of 0.2. Hence conservatively a hot flange temperature value of $600^{\circ} \mathrm{C}$ is recommended here as the limit beyond which the plasterboard restraint is considered to be not effective.

Local buckling was observed as the ultimate failure mode in FEA when both flanges are restrained by plasterboards (Figure 9 (a)). When it was assumed that the fire side plasterboards have fallen off and that the lateral restraint to the hot flange is not effective, as expected the flexural-torsional buckling failure mode was observed (Figure 9 (b)).

Tables 5 to 12 show the FEA results of LSF wall studs with varying plasterboard restraint conditions (Cases 1 and 3). The load ratio was calculated in the usual way when the stud was restrained along both flanges. However, a different method was used when only the cold flange was restrained. Here the load ratio was equal to the case where both flanges were restrained until the hot flange temperature was $600^{\circ} \mathrm{C}$. When this temperature was more than $600^{\circ} \mathrm{C}$, the load ratio was calculated by finding the ratio between the ultimate load at elevated temperature when only the cold flange was restrained and the load at ambient temperature 
when both flanges were restrained. Therefore the calculated load ratios show a sudden drop when the temperature increases beyond $600^{\circ} \mathrm{C}$, representing the plasterboard fall off.

Figures 10 (a) to (h) show the variation of load ratio with time when different hot flange temperature limits $\left(500^{\circ} \mathrm{C}, 550^{\circ} \mathrm{C}\right.$ and $\left.600^{\circ} \mathrm{C}\right)$ were assumed. At higher load ratios, the load ratio versus time curves remained the same irrespective of the temperature limits. However, the load ratio curves start to deviate when the load ratio is about 0.2 .

Table 13 shows the failure times of LSF wall panels when different hot flange temperature limits were used. The failure time did not vary much when the load ratio was larger than 0.4. When the load ratio was about 0.2 , the failure time did not change much if a hot flange temperature limit of $600^{\circ} \mathrm{C}$ was used. A slight variation in failure time ( $\leq 6$ mins.) was observed when the hot flange temperature limit was used as $500^{\circ} \mathrm{C}$. However, this variation is small compared to the complexity involved in the fire design of LSF walls and the variables within LSF wall panel construction. Therefore it is concluded that the plasterboard restraint can be assumed to be effective throughout the failure time in routine fire design calculations. This is particularly valid for LSF walls with double plasterboard linings.

\subsection{Influence of Steel Grade}

This section investigates the effect of studs made of a high grade of G500 and a low grade of G250. Tables 5 to 12 (Cases 1 and 4) show the ultimate loads and the load ratios of LSF wall studs made of these steels. As expected the ultimate load was reduced considerably when the low grade steel was used. Figures 11 (a) to (h) show the variation of load ratios with time for these steel grades. The G500 load ratio curve was expected to be above the G250 load ratio curve. However, a rapid reduction was observed in the G500 load ratio curve with increasing stud temperatures. The temperature difference across the stud increased rapidly and hence thermal bowing was developed. The bending moment generated by this thermal bowing was directly proportional to the applied load. Therefore the G500 steel stud experienced a larger bending moment and its capacity was reduced rapidly during this stage. This phase is longer for cavity insulated wall panels (Figures 11 (c) to (e)) and on the other hand shorter for externally insulated wall panels (Figures 11 (f) to (h)). This is due to the ever rising temperature difference across the studs in the cavity insulated wall panels. 
In the next phase the axial compression capacity of the stud was reduced with time due to the effects of elevated temperatures. Therefore the above mentioned rapid reduction was not possible for G500 steel with a small load. Further the cold flange temperature was approaching the hot flange temperature and the temperature difference across the stud was reduced, especially for externally insulated wall panels. Hence G500 load ratio curve was above the G250 load ratio curve during this phase.

In the final phase of all these figures, the G500 load ratio curve is below that of G250 steel. This is explained by the reduction factors recommended in [17]. Beyond about $540^{\circ} \mathrm{C}$ the reduction factor for G500 steel is less than that for G250 steel. This corresponds well with the final phase of the two curves.

\subsection{Influence of Steel Thickness}

This section investigates the fire performance of LSF wall studs with varying steel thicknesses (1.15 to $1.95 \mathrm{~mm})$. The ultimate failure modes for $1.15 \mathrm{~mm}$ and $1.95 \mathrm{~mm}$ G250 steel studs are local buckling and flexural buckling about the major axis, respectively (Figures 12 (a) and (b)).

Tables 5 to 12 (Cases 4 and 5) show the axial compressive capacity and the load ratio of LSF wall studs at elevated temperatures. As expected the axial compressive capacity of $1.95 \mathrm{~mm}$ studs is higher than that of $1.15 \mathrm{~mm}$ studs. However, the load ratio is reduced rapidly with time for $1.95 \mathrm{~mm}$ studs compared to $1.15 \mathrm{~mm}$ studs. This is explained by the bending moment developed by the higher load and thermal bowing deflection. The bending moment generated by the magnified thermal bowing is directly proportional to the applied load. Therefore $1.95 \mathrm{~mm}$ studs experienced a greater bending moment due to the higher load and hence the capacity was reduced rapidly during this stage. The variation of yield stress reduction factors did not influence the load ratio curves since the same steel grade (G250) was used in this case. Therefore the load ratio curve of $1.95 \mathrm{~mm}$ stud was always located below the load ratio curve of $1.15 \mathrm{~mm}$ stud. Figures 13 (a) to (h) show the variations of load ratio with time for 1.15 and $1.95 \mathrm{~mm}$ studs. 


\section{Simplified Design Method Based on the Critical Hot Flange Temperature}

Lawson [21] adopted the so-called limiting temperature method used for hot-rolled steel structures [22] to cold-formed thin-walled steel structures. In this method the limiting temperature is defined as a function of the load ratio of the structural member. The load ratio is the ratio between the load on the member at the fire limit state and the load carrying capacity of that member under ambient conditions. Kolarkar [13] proposed simple design rules to determine the failure times of LSF walls by combining the yield stress reduction factors proposed in [17] and idealised time-temperature profiles. The critical temperature (ie. the maximum hot flange temperature at failure) corresponding to a load ratio (strength reduction factor) was used with idealised time-temperature profiles to obtain the approximate failure times of each type of wall specimen.

In this study FEA results of Cases 1, 4 and 5 for eight wall configurations were used to determine the critical temperature of LSF wall studs. Figures 14 to 16 show the variation of load ratio with hot flange temperature at failure. Figures 14 (a) and (b) show the variation of load ratios for LSF walls with single and double layers of plasterboard, respectively. Figure 14 (c) was plotted using the FEA results of LSF wall panels with glass fibre, rock fibre and cellulose fibre cavity insulations. It is interesting to note the plots for different insulations merged together. This clearly indicates that the failure temperature of LSF wall studs does not depend on the type of insulation. In other words the effect of using different types of insulation is simply to delay the time to reach the same hot flange temperatures in the LSF wall studs. Figure 14 (d) was plotted with FEA results for LSF wall panels with glass fibre, rock fibre and cellulose fibre external insulation. The close agreement in this figure also confirms the above finding. The results of cavity and externally insulated wall panels did not merge when they were plotted together. This indicates that the arrangement of insulations and plasterboards influences the failure temperature although the type of insulation does not. Figures 15 (a) to (d) and 16 (a) to (d) were obtained for LSF wall studs made of $1.15 \mathrm{~mm}$ and $1.95 \mathrm{~mm}$ Grade 250 steel, respectively. They also confirmed the same observations.

The limiting temperature methods proposed in $[13,18,21]$ are also shown in these figures for comparison purposes. Kolarkar's [13] method gave arbitrary observations and hence this method cannot be used in the fire design of LSF walls. Lawson's [21] method was found to be unsafe in all the cases as shown in Figures 14 to 16. Eurocode 3 [18] recommends a 
limiting temperature value of $350^{\circ} \mathrm{C}$ irrespective of the load ratio as shown by a horizontal line in these figures. This also did not agree with the FEA results. Therefore it was decided to propose a new set of equations (Equations 9 to 20) to determine the critical hot flange temperatures at failure for the above mentioned 12 sets (3 LSF wall stud cases with 4 wall configurations). These equations represent the temperature values ranging from $100^{\circ} \mathrm{C}$ to $800^{\circ} \mathrm{C}$ where $T$ is the hot flange temperature in ${ }^{\circ} \mathrm{C}$ and $L R$ is the load ratio. The load ratio was more than 0.90 when the hot flange temperature was below $100^{\circ} \mathrm{C}$. Similarly the load ratio was less than 0.10 when the hot flange temperature was above $800^{\circ} \mathrm{C}$. They were not included in the proposed equations.

$1.15 \mathrm{~mm}$ G500 steel studs lined on both sides by

a single layer of plasterboard $T=1298 L R^{3}-1894 L R^{2}-14 L R+708$

two layers of plasterboard $T=-527 L R^{3}+895 L R^{2}-1166 L R+825$

two layers of plasterboard with cavity insulation $T=196 L R^{3}+428 L R^{2}-1379 L R+854$

two layers of plasterboard with external insulation $T=870 L R^{3}-1291 L R^{2}-260 L R+768$

$1.15 \mathrm{~mm} \mathrm{G} 250$ steel studs lined on both sides by

a single layer of plasterboard $T=-1300 L R^{3}+2312 L R^{2}-1927 L R+934$

two layers of plasterboard $T=-1113 L R^{3}+2583 L R^{2}-2367 L R+968$

two layers of plasterboard with cavity insulation $T=863 L R^{3}-990 L R^{2}-581 L R+804$

two layers of plasterboard with external insulation $T=314 L R^{2}-1136 L R+891$

$1.95 \mathrm{~mm} \mathrm{G} 250$ steel studs lined on both sides by

a single layer of plasterboard $T=866 L R^{2}-1712 L R+938$

two layers of plasterboard $T=5455 L R^{4}-10681 L R^{3}+6727 L R^{2}-2244 L R+868$

two layers of plasterboard with cavity insulation $T=-1162 L R^{3}+2085 L R^{2}-1811 L R+920$ (19)

two layers of plasterboard with external insulation $T=-708 L R^{3}+1846 L R^{2}-1995 L R+921$ (20)

In the simplified method proposed here to predict the fire resistance rating of LSF wall systems, Equations 9 to 20 predicting the limiting hot flange temperature of LSF wall studs are used with Equations 1 to 8 giving the idealised hot flange time-temperature profiles. For one of the 24 LSF wall systems considered here (3 LSF wall stud cases with 8 wall configurations) with a given load ratio (LR), the limiting hot flange temperature can be found first by using Equations 9 to 20, which can then be used in Equations 1 to 8 to find the time 
required to reach the calculated limiting hot flange temperature. This is the fire resistance rating in minutes (stud failure time) for the selected wall system.

\section{Discussions}

\subsection{Failure Times from Test, FEA and the Simplified Method}

Tables 14 to 16 show the fire resistance rating (failure times) of LSF walls with different steel grades and thicknesses predicted by the simplified method proposed in the last section and the corresponding FEA and test results. These tables show that the results agree well. They clearly indicate the superior performance of externally insulated LSF wall panels. Table 17 shows the percentage increase in fire resistance rating when external insulations are used compared to non-insulated wall panels. When cavity insulation was used, the fire resistance rating is mostly reduced compared to the non-insulated wall panels. The adverse effect of cavity insulation is that it will reflect back the heat and hence the hot flange temperature of the stud will increase rapidly. The other problem associated with cavity insulation is the thermal bowing and magnification effects due to high temperature gradient across the stud. These unfavourable effects will reduce the fire resistance rating of LSF wall panels considerably.

The studs withstand higher temperatures when they are subjected to lower load ratios. However, at these higher temperatures the glass fibre melts and hence it is ineffective. Therefore at a load ratio of 0.2 when glass fibre was used as external insulation the failure time did not change much compared to the non-insulated wall panels. Hence glass fibre is not recommended in LSF wall panels when it is subjected to lower load ratios. Further, the fire resistance rating was reduced when glass fibre was used as cavity insulation (Tables 14 to 16). The reason is that the glass fibre was protected by two plasterboards when it is placed in the cavity. Therefore the glass fibre will not melt fully and the adverse effects of cavity insulation will be still valid.

\subsection{Failure Temperatures from FEA}

Table 18 shows the FEA failure temperatures of LSF wall studs with different steel grades and thicknesses for three load ratios. The failure temperature is the hot flange temperature of the wall stud at failure for a given load ratio. The $1.15 \mathrm{~mm} \mathrm{G} 250$ steel studs withstood higher 
temperatures compared to $1.95 \mathrm{~mm} \mathrm{G} 250$ steel studs for any given load ratio as explained in Section 5.5.

The failure temperatures of $1.15 \mathrm{~mm} \mathrm{G500} \mathrm{and} \mathrm{G250} \mathrm{steel} \mathrm{studs} \mathrm{did} \mathrm{not} \mathrm{follow} \mathrm{a} \mathrm{similar}$ pattern as explained before. In this case, when lower load ratios are considered the failure temperature is influenced mainly by yield stress reduction patterns. This is because the loads are not large enough in this case to influence the failure temperature compared to the yield stress reduction pattern.

When the load ratio is 0.2 , the corresponding steel temperatures should be used to determine the yield stress. However, it should be noted that all the temperatures listed in Table 18 for the load ratio of 0.2 are greater than $530^{\circ} \mathrm{C}$. At temperatures beyond $530^{\circ} \mathrm{C}$ the reduction in yield stress at elevated temperatures for G500 steel is higher than that for G250 steel (Figure 17). Therefore Grade 500 steel studs withstood only lower temperatures compared to G250 grade steel at a load ratio of 0.2 . When the load ratio is 0.4 , all the temperatures listed in Table 18 are less than $530^{\circ} \mathrm{C}$. At temperatures below $530^{\circ} \mathrm{C}$, the reduction in yield stress is less for G500 steel compared to G250 steel (Figure 17). Therefore Grade 500 steel studs withstood larger temperatures compared to G250 grade steel studs at a load ratio of 0.4 .

When higher load ratios are considered (0.7), the failure temperature is dominated by the bending moment due to eccentricity. Therefore the failure temperatures of G500 steel studs were less than those of G250 steel studs as explained earlier (Table 18).

\section{Conclusions}

This paper has presented the details of an investigation into the fire performance of LSF wall panels based on an extensive finite element analysis based parametric study. The LSF wall panels with eight different plasterboard-insulation configurations were considered under standard fire conditions. Effects of varying steel grades, steel thicknesses, screw spacing, plasterboard restraint, insulation materials and load ratio on the fire performance of LSF walls were investigated and the results of extensive fire performance data are presented in the form of load ratio versus time and critical hot flange (failure) temperature curves for LSF walls with eight plasterboard-insulation configurations. Important findings based on this data are: 
- External insulation provided superior fire performance of LSF walls made of steel studs with different thickness and yield stress.

- The material yield stress reduction pattern at elevated temperatures had a major influence on the fire performance of LSF walls.

- The failure temperature of LSF walls did not depend on the type of insulation. The effect of using different types of insulation is simply to delay the time to reach the same hot flange temperatures in the wall stud.

- It is recommended that glass fibre insulation is not used in LSF wall panels subjected to lower load ratios.

- The plasterboard restraint can be assumed to be effective until failure in routine fire design calculations.

This paper has proposed two sets of equations to predict (1) the hot flange temperature as a function of time during a standard fire and (2) the critical (failure) hot flange temperature as a function of load ratio for LSF wall systems with varying steel stud and plasterboardinsulation configurations. It then proposes a simplified design method to predict their fire resistance rating based on these two sets of equations.

\section{Acknowledgements}

The authors would like to thank Australian Research Council for their financial support and the Queensland University of Technology for providing the necessary facilities and support to conduct this research project.

\section{References}

[1] Klippstein, K.H. (1980), Strength of Cold-Formed Studs Exposed to Fire, American Iron and Steel Institute. Washington DC, USA

[2] Gerlich, J.T., Collier, P.C.R. and Buchanan, A.H. (1996), Design of Steel-framed Walls for Fire Resistance, Fire and Materials, Vol.20, No.2, pp.79-96.

[3] Ranby, A. (1999), Structural Fire Design of Thin Walled Steel Sections, Licentiate Thesis, Department of Civil and Mining Engineering, Lulea University of Technology, Stockholm, Sweden. 
[4] Kodur, V.R. and Sultan, M.A. (2001), Factors governing fire resistance of load-bearing steel stud walls, Proceedings of the Fifth AOSFST International Conference, Newcastle, Australia, pp.1-2.

[5] Alfawakhiri, F. (2001), Behaviour of Cold-formed-Steel-framed Walls and Floors in Standard Fire Resistance Tests, PhD Thesis. Carleton University, Ottawa, Ontario, Canada.

[6] Kaitila, O. (2002), Finite Element Modelling of Cold-formed Steel Members at High Temperatures, Licentiate Thesis, Helsinki University of Technology, Espoo, Finland.

[7] Feng, M., Wang, Y.C. and Davies, J.M. (2003), Axial strength of cold-formed thin-walled steel channels under non-uniform temperatures in fire, Fire Safety Journal, Vol.38, pp.679-707.

[8] Feng, M. and Wang, Y.C. (2005a), An Experimental Study of Loaded Full-Scale ColdFormed Thin-Walled Steel Structural Panels Under Fire Conditions, Fire Safety Journal, Vol. 40, pp. 43-63.

[9] Feng, M. and Wang, Y.C. (2005b), An analysis of the structural behaviour of axially loaded full-scale cold-formed thin-walled steel structural panels tested under fire conditions, Thin-Walled Structures, Vol. 43, pp. 291-332.

[10] Zhao, B., Kruppa, J., Renaud, C., O’Connor, M., Mecozzi, E., Apiazu,. W., Demarco, T., Karlstrom, P., Jumppanen, U., Kaitila, O., Oksanen, T. and Salmi, P. (2005), Calculation rules of lightweight steel sections in fire situations, Technical steel research, European Union, France.

[11] American Iron and Steel Institute (AISI) (2007), Specifications for the cold-formed steel structural members, Cold-formed Steel Design Manual, Washington, USA. 
[12] EN 1993-1-3 (2006), Eurocode 3: Design of Steel Structures. Part 1-3: General Rules Supplementary Rules for Cold-formed Members and Sheeting, European Committee for Standardization, Brussels.

[13] Kolarkar, P.N. (2010), Structural and Thermal Performance of Cold-formed Steel Stud Wall Systems under Fire Conditions, PhD Thesis, Queensland University of Technology, Brisbane, Australia.

[14] Gunalan, S. (2011), Structural Behaviour and Design of Cold-formed Steel Wall Systems under Fire Conditions, PhD Thesis, Queensland University of Technology, Brisbane, Australia.

[15] Keerthan, P. and Mahendran, M. (2012), Thermal Performance of Composite Panels under Fire Conditions Using Numerical Studies, Plasterboards, Rockwool, Glass Fibre and Cellulose Insulations, Fire Technology, Vol. 49, pp. 329-356.

[16] Standards Australia (SA) (2005), Methods for fire tests on building materials, components and structures, Part 4: Fire-resistance tests of elements of building construction, AS 1530.4, Sydney, Australia.

[17] Dolamune Kankanamge, N. and Mahendran, M. (2011), Mechanical properties of coldformed steels at elevated temperatures, Thin-Walled Structures, Vol. 49, pp. 26-44.

[18] EN 1993-1-2 (2005), Eurocode 3: Design of steel structures. Part 1-2: General Rules Structural Fire Design, European Committee for Standardization, Brussels.

[19] Schafer, B. and Pekoz, T. (1998), Direct Strength Prediction Of Cold-Formed Steel Members Using Numerical Elastic Buckling Solutions, Proceedings, Second International Conference on Thin-Walled Structures, Thin Walled Structures, Research and Development, Singapore, pp. 137-144. 
[20] Sultan, M.A. (1996), A Model for Predicting Heat through Non-insulated Unloaded Steel-Stud Gypsum Board Wall Assemblies Exposed to Fire, Fire Technology, Vol. 32, No. 3, pp. 239-259.

[21] Lawson, R.M. (1993), Building design using cold formed steel sections: fire protection. The Steel Construction Institute, Publication P129, London, UK.

[22] British Standards Institute (BSI) (1990), Structural Use of Steelwork in Building, BS 5950, Part 8 Code of Practice for Fire Resistance Design, London, UK. 
Table 1: LSF Wall Systems Considered in Fire Tests

\begin{tabular}{|c|c|c|c|c|c|c|c|}
\hline \multirow{3}{*}{ Test } & \multirow{3}{*}{ Index } & \multirow{3}{*}{ Configuration } & \multicolumn{2}{|c|}{ Insulation } & \multirow{3}{*}{$\begin{array}{l}\text { Load } \\
\text { Ratio }\end{array}$} & \multirow{2}{*}{\multicolumn{2}{|c|}{$\begin{array}{l}\text { Failure Time } \\
\text { (min.) }\end{array}$}} \\
\hline & & & \multirow{2}{*}{ Material } & \multirow{2}{*}{ Location } & & & \\
\hline & & & & & & Test & FEA \\
\hline 1 & CP-GF & 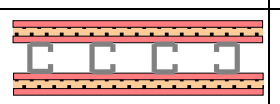 & $\begin{array}{l}\text { Glass } \\
\text { Fibre }\end{array}$ & External & 0.2 & 118 & 115 \\
\hline 2 & CP-GF & $\begin{array}{lll} \\
\end{array}$ & $\begin{array}{l}\text { Glass } \\
\text { Fibre }\end{array}$ & External & 0.4 & 108 & 110 \\
\hline 3 & CP-RF & 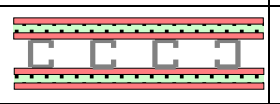 & $\begin{array}{l}\text { Rock } \\
\text { Fibre }\end{array}$ & External & 0.4 & 134 & 131 \\
\hline $1 *$ & $1 \times 1$ & $\left.\begin{array}{lllll} & {[} & {[} & 1\end{array}\right]$ & None & - & 0.2 & 53 & 53 \\
\hline $2^{*}$ & $2 \times 2$ & 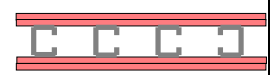 & None & - & 0.2 & 111 & 115 \\
\hline $3 *$ & CI-GF & Alar & $\begin{array}{l}\text { Glass } \\
\text { Fibre }\end{array}$ & Cavity & 0.2 & 101 & 100 \\
\hline $4^{*}$ & CI-RF & A & $\begin{array}{l}\text { Rock } \\
\text { Fibre }\end{array}$ & Cavity & 0.2 & 107 & 105 \\
\hline $5^{*}$ & CI-CF & 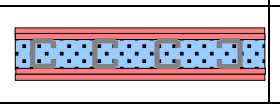 & $\begin{array}{l}\text { Cellulose } \\
\text { Fibre }\end{array}$ & Cavity & 0.2 & 110 & 109 \\
\hline $6^{*}$ & $\mathrm{CP}-\mathrm{RF}$ & 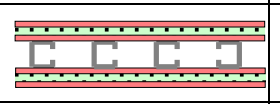 & $\begin{array}{l}\text { Rock } \\
\text { Fibre }\end{array}$ & External & 0.2 & $136^{\#}$ & 154 \\
\hline $7 *$ & $\mathrm{CP}-\mathrm{CF}$ & 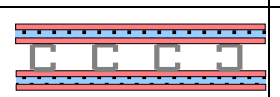 & $\begin{array}{l}\text { Cellulose } \\
\text { Fibre }\end{array}$ & External & 0.2 & 124 & 129 \\
\hline
\end{tabular}

( 1 - 3 ) - Tests conducted by Gunalan [14]; ( $\left.1^{*}-7^{*}\right)$ - Tests conducted by Kolarkar [13]; (\# ) Earlier failure time due to lack of space for thermal expansion; Cavity - Insulation is placed within the LSF frame; External - Insulation is placed outside the LSF frame. 
Table 2: Idealised Time - Temperature Values up to $100^{\circ} \mathrm{C}$

\begin{tabular}{|c|c|c|c|c|c|c|c|}
\hline $\mathrm{W} / \mathrm{C}$ & Index & Configuration & Insulation & $\begin{array}{l}\text { Time } \\
(\min .)\end{array}$ & $\begin{array}{l}\text { HFT } \\
\left({ }^{\circ} \mathrm{C}\right)\end{array}$ & $\begin{array}{l}\text { Time } \\
(\min .)\end{array}$ & $\begin{array}{l}\text { CFT } \\
\left({ }^{\circ} \mathrm{C}\right)\end{array}$ \\
\hline \multirow{3}{*}{1} & \multirow{3}{*}{$1 \times 1$} & \multirow{3}{*}{$\begin{array}{lllll} & {[} & {[} & 1 \\
\end{array}$} & \multirow{3}{*}{ None } & 2 & 20 & 2 & 20 \\
\hline & & & & 6 & 100 & 11 & 100 \\
\hline & & & & 14 & 100 & 21 & 100 \\
\hline \multirow{3}{*}{2} & \multirow{3}{*}{$2 \times 2$} & \multirow{3}{*}{$\left.\begin{array}{llll}5 & 5 & 5 & \end{array}\right]$} & \multirow{3}{*}{ None } & 2 & 20 & 2 & 20 \\
\hline & & & & 25 & 100 & 35 & 100 \\
\hline & & & & 41 & 100 & 54 & 100 \\
\hline \multirow{3}{*}{3} & \multirow{3}{*}{ CI-GF } & \multirow{3}{*}{ का } & \multirow{3}{*}{$\begin{array}{l}\text { Glass } \\
\text { Fibre }\end{array}$} & 6 & 20 & 6 & 20 \\
\hline & & & & 20 & 100 & 50 & 100 \\
\hline & & & & 52 & 100 & 65 & 100 \\
\hline \multirow{3}{*}{4} & \multirow{3}{*}{ CI-RF } & \multirow{3}{*}{ al } & \multirow{3}{*}{$\begin{array}{l}\text { Rock } \\
\text { Fibre }\end{array}$} & 6 & 20 & 6 & 20 \\
\hline & & & & 25 & 100 & 50 & 100 \\
\hline & & & & 52 & 100 & 65 & 100 \\
\hline \multirow{3}{*}{5} & \multirow{3}{*}{$\mathrm{CI}-\mathrm{CF}$} & \multirow{3}{*}{ - } & \multirow{3}{*}{$\begin{array}{l}\text { Cellulose } \\
\text { Fibre }\end{array}$} & 6 & 20 & 6 & 20 \\
\hline & & & & 25 & 100 & 50 & 100 \\
\hline & & & & 52 & 100 & 65 & 100 \\
\hline \multirow{3}{*}{6} & \multirow{3}{*}{ CP-GF } & \multirow{3}{*}{ 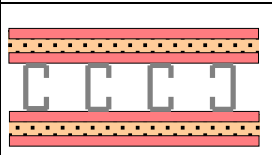 } & \multirow{3}{*}{$\begin{array}{l}\text { Glass } \\
\text { Fibre }\end{array}$} & 6 & 20 & 6 & 20 \\
\hline & & & & 40 & 100 & 55 & 100 \\
\hline & & & & 42 & 100 & 60 & 100 \\
\hline \multirow{3}{*}{7} & \multirow{3}{*}{ CP-RF } & \multirow{3}{*}{ 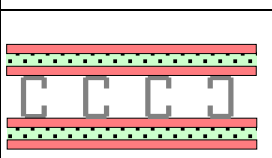 } & \multirow{3}{*}{$\begin{array}{l}\text { Rock } \\
\text { Fibre }\end{array}$} & 6 & 20 & 6 & 20 \\
\hline & & & & 55 & 100 & 60 & 100 \\
\hline & & & & 70 & 100 & 80 & 100 \\
\hline \multirow{3}{*}{8} & \multirow{3}{*}{$\mathrm{CP}-\mathrm{CF}$} & \multirow{3}{*}{ 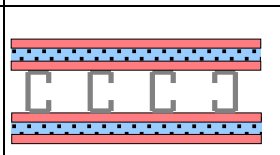 } & \multirow{3}{*}{$\begin{array}{l}\text { Cellulose } \\
\text { Fibre }\end{array}$} & 6 & 20 & 6 & 20 \\
\hline & & & & 45 & 100 & 60 & 100 \\
\hline & & & & 70 & 100 & 80 & 100 \\
\hline
\end{tabular}

W/C - Wall Configuration; HFT - Hot Flange Temperature; CFT - Cold Flange Temperature 
Table 3: Parameters Considered in the Finite Element Analyses of LSF walls

\begin{tabular}{|c|c|c|c|c|c|c|}
\hline \multirow{2}{*}{ Parameters } & \multirow{2}{*}{$\begin{array}{c}\text { FEA } \\
\text { Validation }\end{array}$} & \multicolumn{5}{|c|}{ FEA - Parametric Study } \\
\hline & & Case 1 & Case 2 & Case 3 & Case 4 & Case 5 \\
\hline $\begin{array}{l}\text { Yield } \\
\text { Stress } \\
(\mathrm{MPa})\end{array}$ & 569 & 500 & 500 & 500 & 250 & 250 \\
\hline $\begin{array}{l}\text { Elastic } \\
\text { Modulus } \\
(\mathrm{MPa})\end{array}$ & 213520 & 200000 & 200000 & 200000 & 200000 & 200000 \\
\hline $\begin{array}{l}\text { Thickness } \\
\text { (mm) }\end{array}$ & 1.15 & 1.15 & 1.15 & 1.15 & 1.15 & 1.95 \\
\hline $\begin{array}{c}\text { Screw } \\
\text { Spacing } \\
(\mathrm{mm})\end{array}$ & 300 & 300 & $\begin{array}{c}600 \text { and } \\
1200\end{array}$ & 300 & 300 & 300 \\
\hline $\begin{array}{c}\text { Plasterboard } \\
\text { Restraint }\end{array}$ & $\begin{array}{c}\text { Both } \\
\text { Flanges }\end{array}$ & $\begin{array}{c}\text { Both } \\
\text { Flanges }\end{array}$ & $\begin{array}{c}\text { Both } \\
\text { Flanges }\end{array}$ & $\begin{array}{l}\text { Cold } \\
\text { Flange } \\
\text { Only }\end{array}$ & $\begin{array}{c}\text { Both } \\
\text { Flanges }\end{array}$ & $\begin{array}{c}\text { Both } \\
\text { Flanges }\end{array}$ \\
\hline $\begin{array}{c}\text { Time- } \\
\text { Temperature } \\
\text { Profiles }\end{array}$ & Measured & Idealised & Idealised & Idealised & Idealised & Idealised \\
\hline
\end{tabular}


Table 4: Ultimate Loads of 1.15 mm G500 Steel Studs Lined on Both Sides by Two Layers of Plasterboard with Glass Fibre External Insulation

\begin{tabular}{|c|c|c|c|c|c|}
\hline & & & \multicolumn{3}{|c|}{ Ultimate Load (kN) } \\
\cline { 4 - 6 } Time & HFT & CFT & Screw & Screw & Screw \\
$($ min. $)$ & $\left({ }^{\circ} \mathrm{C}\right)$ & $\left({ }^{\circ} \mathrm{C}\right)$ & $\begin{array}{c}\text { Spacing } \\
\text { Spacing }\end{array}$ & $\begin{array}{c}\text { Spacing } \\
600 \mathrm{~mm}\end{array}$ \\
& & & $300 \mathrm{~mm}$ & $600 \mathrm{~mm}$ \\
\hline 0 & 20 & 20 & 70.80 & 68.70 & 60.90 \\
\hline 42 & 100 & 100 & 70.20 & 66.50 & 58.10 \\
\hline 50 & 127 & 100 & 62.70 & 62.30 & 54.30 \\
\hline 60 & 164 & 102 & 55.20 & 54.80 & 48.80 \\
\hline 70 & 204 & 124 & 51.30 & 50.60 & 45.30 \\
\hline 80 & 255 & 164 & 48.30 & 47.40 & 42.60 \\
\hline 90 & 323 & 222 & 44.10 & 42.70 & 38.60 \\
\hline 100 & 412 & 298 & 37.60 & 36.90 & 32.50 \\
\hline 110 & 530 & 392 & 27.30 & 26.30 & 23.90 \\
\hline 120 & 682 & 505 & 8.46 & 8.55 & 8.20 \\
\hline 125 & 773 & 568 & 4.60 & 4.46 & 4.37 \\
\hline
\end{tabular}

HFT - Hot Flange Temperature; CFT - Cold Flange Temperature 
Table 5: FEA Results of Steel Studs Lined on Both Sides by a Single Layer of Plasterboard

\begin{tabular}{|c|c|c|c|c|c|c|c|c|c|c|c|c|}
\hline \multirow[b]{2}{*}{$\begin{array}{l}\text { Time } \\
\text { (min.) }\end{array}$} & \multirow[b]{2}{*}{$\begin{array}{l}\text { HFT } \\
\left({ }^{\circ} \mathrm{C}\right)\end{array}$} & \multirow[b]{2}{*}{$\begin{array}{l}\text { CFT } \\
\left({ }^{\circ} \mathrm{C}\right)\end{array}$} & \multicolumn{2}{|c|}{ Case 1} & \multicolumn{2}{|c|}{ Case 2} & \multicolumn{2}{|c|}{ Case 3} & \multicolumn{2}{|c|}{ Case 4} & \multicolumn{2}{|c|}{ Case 5} \\
\hline & & & $\begin{array}{c}\text { UL } \\
(\mathrm{kN})\end{array}$ & LR & $\begin{array}{c}\text { UL } \\
(\mathrm{kN})\end{array}$ & LR & $\begin{array}{c}\mathrm{UL} \\
(\mathrm{kN})\end{array}$ & LR & $\begin{array}{c}\text { UL } \\
(\mathrm{kN})\end{array}$ & LR & $\begin{array}{c}\mathrm{UL} \\
(\mathrm{kN})\end{array}$ & LR \\
\hline 0 & & 20 & 70.80 & 10 & .70 & & 7.50 & & 3.60 & & 3.70 & 00 \\
\hline & & & & & & & & & & & .40 & \\
\hline & & & 0.00 & .71 & 9.30 & & 4.00 & & 34.10 & & 58.10 & .62 \\
\hline & & & 8.80 & & 37.80 & 0.5 & 25.90 & 5 & 26.50 & 0 . & 44.50 & .47 \\
\hline 40 & & & 1.40 & 0.2 & 30.30 & 0.44 & 18.70 & 0.44 & 16.30 & 0.37 & 27.70 & 0.30 \\
\hline 50 & & 390 & 18.80 & 0.27 & 18.70 & 0.27 & 10.90 & 0.27 & 11.80 & 0.27 & 20.00 & 0.21 \\
\hline 60 & & & 7.19 & 0.1 & 7.19 & 0.10 & 7.21 & 0.1 & 6.51 & 0.15 & 14.50 & 0.15 \\
\hline 70 & 725 & 725 & 4.93 & 0.07 & 4.92 & 0.07 & 4.91 & 0.07 & 4.19 & 0.10 & 9.06 & 0.10 \\
\hline
\end{tabular}

HFT - Hot Flange Temperature; CFT - Cold Flange Temperature; UL - Ultimate load;

$\mathrm{LR}-\mathrm{Load}$ ratio $=\mathrm{UL}$ at elevated temperatures/UL at ambient temperature 
Table 6: FEA Results of Steel Studs Lined on Both Sides by Two Layers of Plasterboard

\begin{tabular}{|c|c|c|c|c|c|c|c|c|c|c|c|c|}
\hline \multirow{2}{*}{$\begin{array}{c}\text { Time } \\
(\mathrm{min} .)\end{array}$} & \multirow{2}{*}{$\begin{array}{c}\mathrm{HFT} \\
\left({ }^{\circ} \mathrm{C}\right)\end{array}$} & \multirow{2}{*}{$\begin{array}{c}\text { CFT } \\
\left({ }^{\circ} \mathrm{C}\right)\end{array}$} & $\begin{array}{c}\text { Case 1 } \\
(\mathrm{kN})\end{array}$ & LR & $\begin{array}{c}\text { UL } \\
(\mathrm{kN})\end{array}$ & LR & $\begin{array}{c}\text { UL } \\
(\mathrm{kN})\end{array}$ & LR & $\begin{array}{c}\text { UL } \\
(\mathrm{kN})\end{array}$ & LR & $\begin{array}{c}\text { UL } \\
(\mathrm{kN})\end{array}$ & LR \\
\hline 0 & 20 & 20 & 70.80 & 1.00 & 68.70 & 1.00 & 37.50 & 1.00 & 43.60 & 1.00 & 93.70 & 1.00 \\
\hline 40 & 100 & 100 & 70.20 & 0.99 & 66.50 & 0.97 & 37.00 & 0.99 & 40.30 & 0.92 & 89.40 & 0.95 \\
\hline 50 & 158 & 100 & 56.20 & 0.79 & 55.60 & 0.81 & 37.20 & 0.79 & 37.70 & 0.86 & 66.60 & 0.71 \\
\hline 60 & 221 & 134 & 49.80 & 0.70 & 49.00 & 0.71 & 33.50 & 0.70 & 33.80 & 0.78 & 58.30 & 0.62 \\
\hline 70 & 285 & 195 & 47.10 & 0.67 & 46.10 & 0.67 & 30.70 & 0.67 & 31.40 & 0.72 & 55.10 & 0.59 \\
\hline 80 & 348 & 256 & 43.10 & 0.61 & 41.90 & 0.61 & 27.40 & 0.61 & 24.10 & 0.55 & 40.60 & 0.43 \\
\hline 90 & 412 & 316 & 38.30 & 0.54 & 37.20 & 0.54 & 23.60 & 0.54 & 18.30 & 0.42 & 31.20 & 0.33 \\
\hline 100 & 475 & 377 & 32.40 & 0.46 & 31.70 & 0.46 & 19.60 & 0.46 & 15.60 & 0.36 & 26.20 & 0.28 \\
\hline 110 & 539 & 438 & 25.50 & 0.36 & 25.00 & 0.36 & 14.80 & 0.36 & 13.00 & 0.30 & 21.80 & 0.23 \\
\hline 120 & 663 & 498 & 9.34 & 0.13 & 9.34 & 0.14 & 6.15 & 0.09 & 8.61 & 0.20 & - & - \\
\hline 130 & 784 & 559 & 4.21 & 0.06 & 4.19 & 0.06 & 2.89 & 0.04 & 3.35 & 0.08 & - & - \\
\hline
\end{tabular}

HFT - Hot Flange Temperature; CFT - Cold Flange Temperature; UL - Ultimate load; LR - Load ratio 
Table 7: FEA Results of Steel Studs Lined on Both Sides by Two Layers of Plasterboard with Glass Fibre Cavity Insulation

\begin{tabular}{|c|c|c|c|c|c|c|c|c|c|c|c|c|}
\hline \multirow[b]{2}{*}{$\begin{array}{l}\text { Time } \\
\text { (min.) }\end{array}$} & \multirow[b]{2}{*}{$\begin{array}{l}\text { HFT } \\
\left({ }^{\circ} \mathrm{C}\right)\end{array}$} & \multirow[b]{2}{*}{$\begin{array}{l}\text { CFT } \\
\left({ }^{\circ} \mathrm{C}\right)\end{array}$} & \multicolumn{2}{|c|}{ Case 1} & \multicolumn{2}{|c|}{ Case 2} & \multicolumn{2}{|c|}{ Case 3} & \multicolumn{2}{|c|}{ Case 4} & \multicolumn{2}{|c|}{ Case 5} \\
\hline & & & $\begin{array}{c}\mathrm{UL} \\
(\mathrm{kN})\end{array}$ & LR & $\begin{array}{c}\mathrm{UL} \\
(\mathrm{kN})\end{array}$ & LR & $\begin{array}{c}\mathrm{UL} \\
(\mathrm{kN})\end{array}$ & LR & $\begin{array}{c}\mathrm{UL} \\
(\mathrm{kN})\end{array}$ & LR & $\begin{array}{c}\mathrm{UL} \\
(\mathrm{kN})\end{array}$ & LR \\
\hline 0 & & & 70.80 & 1.00 & 68.70 & 1.00 & 37.50 & 1.00 & 43.60 & & 93.70 & \\
\hline & & & & & & & 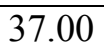 & & 30 & & & \\
\hline & & & & & & & & & 0 & & 1.30 & \\
\hline & & & .70 & & 392 & & 27.60 & $1=$ & 27.30 & & 6.10 & 49 \\
\hline & & & 1.00 & & 32.70 & & 20.50 & & 21.90 & & 7.10 & .40 \\
\hline & & & 5.20 & & 25.60 & & 15.10 & & 16.00 & & 27.70 & 0.30 \\
\hline 100 & & & 13.30 & 0.19 & 13.30 & 0.1 & 8.14 & 0.11 & 10.50 & 0.24 & 18.20 & 0.19 \\
\hline 110 & 739 & 409 & 7.04 & 0.10 & 7.04 & 0.10 & 5.15 & 0.07 & 6.07 & 0.14 & 11.70 & 0.12 \\
\hline
\end{tabular}

HFT - Hot Flange Temperature; CFT - Cold Flange Temperature; UL - Ultimate load; LR - Load ratio 
Table 8: FEA Results of Steel Studs Lined on Both Sides by Two Layers of Plasterboard with Rock Fibre Cavity Insulation

\begin{tabular}{|c|c|c|c|c|c|c|c|c|c|c|c|c|}
\hline \multirow[b]{2}{*}{$\begin{array}{l}\text { Time } \\
\text { (min.) }\end{array}$} & \multirow[b]{2}{*}{$\begin{array}{l}\text { HFT } \\
\left({ }^{\circ} \mathrm{C}\right)\end{array}$} & \multirow[b]{2}{*}{$\begin{array}{l}\text { CFT } \\
\left({ }^{\circ} \mathrm{C}\right)\end{array}$} & \multicolumn{2}{|c|}{ Case 1} & \multicolumn{2}{|c|}{ Case 2} & \multicolumn{2}{|c|}{ Case 3} & \multicolumn{2}{|c|}{ Case 4} & \multicolumn{2}{|c|}{ Case 5} \\
\hline & & & $\begin{array}{c}\mathrm{UL} \\
(\mathrm{kN})\end{array}$ & LR & $\begin{array}{c}\mathrm{UL} \\
(\mathrm{kN})\end{array}$ & LR & $\begin{array}{c}\text { UL } \\
(\mathrm{kN})\end{array}$ & LR & $\begin{array}{c}\mathrm{UL} \\
(\mathrm{kN})\end{array}$ & LR & $\begin{array}{c}\mathrm{UL} \\
(\mathrm{kN})\end{array}$ & LR \\
\hline 0 & 20 & & 70.80 & & 68.70 & 1.00 & 37.50 & 10 & 43.60 & 1.0 & 93.70 & 1.00 \\
\hline 52 & & & & & & & & & 30 & & 9. & \\
\hline 60 & & & & & 1.90 & & 5.50 & & 80 & & 1.90 & \\
\hline 70 & 70 & & 1.70 & 0.59 & 40.60 & 0.59 & 28.40 & 0.5 & 28.20 & 0.6 & 47.60 & 0.51 \\
\hline 80 & & & & & 34.40 & & 21.60 & & 23.10 & & 38.90 & 0.42 \\
\hline 90 & 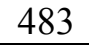 & & 3.40 & 0. & 27.50 & 0.40 & 17.20 & 0. & 18.00 & 0.41 & 30.80 & 0.33 \\
\hline 100 & 58 & 241 & 9.00 & 0. & 18.80 & 0. & 10.00 & 0. & 12.70 & 0.29 & 22.10 & 0.24 \\
\hline & & & 10.50 & & 10.50 & & 7.1 & & 8.3 & & 14.50 & 0.15 \\
\hline 120 & 789 & 322.2 & 5.44 & 0.08 & 5.48 & 0.08 & 4.69 & 0.07 & 4.28 & 0.10 & 8.06 & 0.09 \\
\hline
\end{tabular}

HFT - Hot Flange Temperature; CFT - Cold Flange Temperature; UL - Ultimate load; LR - Load ratio 
Table 9: FEA Results of Steel Studs Lined on Both Sides by Two Layers of Plasterboard with Cellulose Fibre Cavity Insulation

\begin{tabular}{|c|c|c|c|c|c|c|c|c|c|c|c|c|}
\hline \multirow{2}{*}{$\begin{array}{c}\text { Time } \\
(\mathrm{min} .)\end{array}$} & \multirow{2}{*}{$\begin{array}{c}\text { HFT } \\
\left({ }^{\circ} \mathrm{C}\right)\end{array}$} & \multirow{2}{*}{$\begin{array}{c}\text { CFT } \\
\left({ }^{\circ} \mathrm{C}\right)\end{array}$} & $\begin{array}{c}\text { Case } 1 \\
(\mathrm{kN})\end{array}$ & LR & $\begin{array}{c}\text { UL } \\
(\mathrm{kN})\end{array}$ & LR & $\begin{array}{c}\text { UL } \\
(\mathrm{kN})\end{array}$ & LR & $\begin{array}{c}\text { UL } \\
(\mathrm{kN})\end{array}$ & LR & $\begin{array}{c}\text { UL } \\
(\mathrm{kN})\end{array}$ & LR \\
\hline 0 & 20 & 20 & 70.80 & 1.00 & 68.70 & 1.00 & 37.50 & 1.00 & 43.60 & 1.00 & 93.70 & 1.00 \\
\hline 52 & 100 & 100 & 70.20 & 0.99 & 66.50 & 0.97 & 37.00 & 0.99 & 40.30 & 0.92 & 89.40 & 0.95 \\
\hline 60 & 176 & 100 & 53.00 & 0.75 & 52.40 & 0.76 & 35.60 & 0.75 & 35.80 & 0.82 & 62.10 & 0.66 \\
\hline 70 & 266 & 118 & 43.20 & 0.61 & 42.00 & 0.61 & 29.40 & 0.61 & 29.20 & 0.67 & 49.30 & 0.53 \\
\hline 80 & 355 & 156 & 36.70 & 0.52 & 35.50 & 0.52 & 22.90 & 0.52 & 24.60 & 0.56 & 41.50 & 0.44 \\
\hline 90 & 445 & 195 & 31.40 & 0.44 & 30.30 & 0.44 & 19.60 & 0.44 & 19.90 & 0.46 & 33.80 & 0.36 \\
\hline 100 & 534 & 233 & 24.90 & 0.35 & 24.50 & 0.36 & 13.80 & 0.35 & 14.90 & 0.34 & 25.80 & 0.28 \\
\hline 110 & 651 & 320 & 11.80 & 0.17 & 11.70 & 0.17 & 7.45 & 0.11 & 9.56 & 0.22 & 16.50 & 0.18 \\
\hline 115 & 750 & 405 & 6.63 & 0.09 & 6.63 & 0.10 & 5.00 & 0.07 & 5.63 & 0.13 & 10.90 & 0.12 \\
\hline
\end{tabular}

HFT - Hot Flange Temperature; CFT - Cold Flange Temperature; UL - Ultimate load; LR - Load ratio 
Table 10: FEA Results of Steel Studs Lined on Both Sides by Two Layers of Plasterboard with Glass Fibre External Insulation

\begin{tabular}{|c|c|c|c|c|c|c|c|c|c|c|c|c|}
\hline \multirow{2}{*}{$\begin{array}{c}\text { Time } \\
(\mathrm{min} .)\end{array}$} & \multirow{2}{*}{$\begin{array}{c}\mathrm{HFT} \\
\left({ }^{\circ} \mathrm{C}\right)\end{array}$} & \multirow{2}{*}{$\begin{array}{c}\text { CFT } \\
\left({ }^{\circ} \mathrm{C}\right)\end{array}$} & \begin{tabular}{c} 
Case 1 \\
\cline { 4 - 14 }$(\mathrm{kN})$
\end{tabular} & LR & $\begin{array}{c}\text { UL } \\
(\mathrm{kN})\end{array}$ & LR & $\begin{array}{c}\text { UL } \\
(\mathrm{kN})\end{array}$ & LR & $\begin{array}{c}\text { UL } \\
(\mathrm{kN})\end{array}$ & LR & $\begin{array}{c}\text { UL } \\
(\mathrm{kN})\end{array}$ & LR \\
\hline 0 & 20 & 20 & 70.80 & 1.00 & 68.70 & 1.00 & 37.50 & 1.00 & 43.60 & 1.00 & 93.70 & 1.00 \\
\hline 42 & 100 & 100 & 70.20 & 0.99 & 66.50 & 0.91 & 37.00 & 0.99 & 40.30 & 0.92 & 89.40 & 0.95 \\
\hline 50 & 127 & 100 & 62.70 & 0.89 & 62.30 & 0.80 & 39.90 & 0.89 & 40.10 & 0.92 & 76.10 & 0.81 \\
\hline 60 & 164 & 102 & 55.20 & 0.78 & 54.80 & 0.74 & 36.70 & 0.78 & 37.10 & 0.85 & 65.40 & 0.70 \\
\hline 70 & 204 & 124 & 51.30 & 0.72 & 50.60 & 0.69 & 34.50 & 0.72 & 34.80 & 0.80 & 60.20 & 0.64 \\
\hline 80 & 255 & 164 & 48.30 & 0.68 & 47.40 & 0.62 & 32.00 & 0.68 & 32.80 & 0.75 & 56.50 & 0.60 \\
\hline 90 & 323 & 222 & 44.10 & 0.62 & 42.70 & 0.54 & 28.50 & 0.62 & 27.70 & 0.64 & 47.30 & 0.50 \\
\hline 100 & 412 & 298 & 37.60 & 0.53 & 36.90 & 0.38 & 23.30 & 0.53 & 18.60 & 0.43 & 31.40 & 0.34 \\
\hline 110 & 530 & 392 & 27.30 & 0.39 & 26.30 & 0.12 & 15.10 & 0.39 & 13.30 & 0.31 & 22.50 & 0.24 \\
\hline 120 & 682 & 505 & 8.46 & 0.12 & 8.55 & 0.12 & 5.55 & 0.08 & 7.78 & 0.18 & 14.00 & 0.15 \\
\hline 125 & 773 & 568 & 4.60 & 0.06 & 4.46 & 0.06 & 3.11 & 0.04 & 3.76 & 0.09 & 8.17 & 0.09 \\
\hline
\end{tabular}

HFT - Hot Flange Temperature; CFT - Cold Flange Temperature; UL - Ultimate load; LR - Load ratio 
Table 11: FEA Results of 1.15 mm G500 Steel Studs Lined on Both Sides by Two Layers of Plasterboard with Rock Fibre External Insulation

\begin{tabular}{|c|c|c|c|c|c|c|c|c|c|c|c|c|}
\hline \multirow{2}{*}{$\begin{array}{c}\text { Time } \\
(\mathrm{min} .)\end{array}$} & \multirow{2}{*}{$\begin{array}{c}\text { HFT } \\
\left({ }^{\circ} \mathrm{C}\right)\end{array}$} & \multirow{2}{*}{$\begin{array}{c}\text { CFT } \\
\left({ }^{\circ} \mathrm{C}\right)\end{array}$} & \multicolumn{2}{c|}{ Case 1 } & \multicolumn{2}{c|}{ Case } & \multicolumn{2}{c|}{ Case 3 } & \multicolumn{2}{c|}{ Case 4 } & \multicolumn{2}{c|}{ Case 5 } \\
\hline 0 & 20 & 20 & 70.80 & 1.00 & 68.70 & 1.00 & 37.50 & 1.00 & 43.60 & 1.00 & 93.70 & 1.00 \\
\hline 70 & 100 & 100 & 70.20 & 0.99 & 66.50 & 0.97 & 37.00 & 0.99 & 40.30 & 0.92 & 89.40 & 0.95 \\
\hline 80 & 150 & 100 & 57.60 & 0.81 & 57.20 & 0.83 & 37.80 & 0.81 & 38.50 & 0.88 & 68.70 & 0.73 \\
\hline 90 & 207 & 133 & 51.90 & 0.73 & 51.30 & 0.75 & 34.60 & 0.73 & 35.00 & 0.80 & 61.00 & 0.65 \\
\hline 100 & 272 & 177 & 47.10 & 0.67 & 46.30 & 0.67 & 31.10 & 0.67 & 32.00 & 0.73 & 55.20 & 0.59 \\
\hline 110 & 343 & 233 & 42.30 & 0.60 & 40.90 & 0.60 & 27.20 & 0.60 & 25.70 & 0.59 & 43.20 & 0.46 \\
\hline 120 & 418 & 301 & 37.30 & 0.53 & 36.40 & 0.53 & 22.90 & 0.53 & 18.20 & 0.42 & 30.90 & 0.33 \\
\hline 130 & 497 & 381 & 30.40 & 0.43 & 29.70 & 0.43 & 17.80 & 0.43 & 14.70 & 0.34 & 24.70 & 0.26 \\
\hline 140 & 577 & 472 & 17.50 & 0.25 & 17.40 & 0.25 & 11.30 & 0.25 & 11.60 & 0.27 & 19.40 & 0.21 \\
\hline 150 & 659 & 575 & 8.70 & 0.12 & 8.53 & 0.12 & 6.44 & 0.09 & 8.16 & 0.19 & 14.30 & 0.15 \\
\hline 160 & 740 & 690 & 5.09 & 0.07 & 5.06 & 0.07 & 4.09 & 0.06 & 4.38 & 0.10 & 8.90 & 0.09 \\
\hline
\end{tabular}

HFT - Hot Flange Temperature; CFT - Cold Flange Temperature; UL - Ultimate load; LR - Load ratio 
Table 12: FEA Results of 1.15 mm G500 Steel Studs Lined on Both Sides by Two Layers of Plasterboard with Cellulose Fibre External Insulation

\begin{tabular}{|c|c|c|c|c|c|c|c|c|c|c|c|c|}
\hline \multirow{2}{*}{$\begin{array}{c}\text { Time } \\
(\mathrm{min} .)\end{array}$} & \multirow{2}{*}{$\begin{array}{c}\text { HFT } \\
\left({ }^{\circ} \mathrm{C}\right)\end{array}$} & \multirow{2}{*}{$\begin{array}{c}\text { CFT } \\
\left({ }^{\circ} \mathrm{C}\right)\end{array}$} & $\begin{array}{c}\text { Case 1 } \\
(\mathrm{kN})\end{array}$ & LR & $\begin{array}{c}\text { UL } \\
(\mathrm{kN})\end{array}$ & LR & $\begin{array}{c}\text { UL } \\
(\mathrm{kN})\end{array}$ & LR & $\begin{array}{c}\text { UL } \\
(\mathrm{kN})\end{array}$ & LR & $\begin{array}{c}\text { UL } \\
(\mathrm{kN})\end{array}$ & LR \\
\hline 0 & 20 & 20 & 70.80 & 1.00 & 68.70 & 1.00 & 37.50 & 1.00 & 43.60 & 1.00 & 93.70 & 1.00 \\
\hline 70 & 100 & 100 & 70.20 & 0.99 & 66.50 & 0.97 & 37.00 & 0.99 & 40.30 & 0.92 & 89.40 & 0.95 \\
\hline 80 & 175 & 101 & 53.20 & 0.75 & 52.60 & 0.77 & 35.80 & 0.75 & 36.00 & 0.83 & 62.50 & 0.67 \\
\hline 90 & 258 & 150 & 46.60 & 0.66 & 45.20 & 0.66 & 31.20 & 0.66 & 31.70 & 0.73 & 54.00 & 0.58 \\
\hline 100 & 346 & 216 & 41.00 & 0.58 & 39.80 & 0.58 & 26.60 & 0.58 & 26.20 & 0.60 & 44.10 & 0.47 \\
\hline 110 & 437 & 299 & 35.20 & 0.50 & 34.10 & 0.50 & 21.50 & 0.50 & 17.40 & 0.40 & 29.50 & 0.31 \\
\hline 120 & 526 & 398 & 27.70 & 0.39 & 26.90 & 0.39 & 15.50 & 0.39 & 13.50 & 0.31 & 22.70 & 0.24 \\
\hline 130 & 623 & 515 & 10.80 & 0.15 & 10.70 & 0.16 & 7.60 & 0.11 & 9.96 & 0.23 & 16.60 & 0.18 \\
\hline 140 & 713 & 648 & 6.18 & 0.09 & 6.21 & 0.09 & 4.84 & 0.07 & 5.45 & 0.13 & 11.00 & 0.12 \\
\hline
\end{tabular}

HFT - Hot Flange Temperature; CFT - Cold Flange Temperature; UL - Ultimate load; LR - Load ratio 
Table 13: FEA Failure Times of LSF Wall Panels with Different Plasterboard Restraints

\begin{tabular}{|c|c|c|c|c|c|}
\hline \multirow{3}{*}{ Index } & \multirow{3}{*}{$\begin{array}{l}\text { Load } \\
\text { Ratio }\end{array}$} & \multicolumn{4}{|c|}{ Failure Time (min.) } \\
\hline & & \multirow{2}{*}{$\begin{array}{c}\text { Both } \\
\text { Flanges } \\
\text { Restrained }\end{array}$} & \multicolumn{3}{|c|}{$\begin{array}{c}\text { CF Restrained; } \\
\text { HF Temperature Limit }\end{array}$} \\
\hline & & & $600^{\circ} \mathrm{C}$ & $550^{\circ} \mathrm{C}$ & $500^{\circ} \mathrm{C}$ \\
\hline \multirow{3}{*}{$1 \times 1$} & 0.7 & 20 & 20 & 20 & 20 \\
\hline & 0.4 & 42 & 42 & 42 & 42 \\
\hline & 0.2 & 54 & 54 & 48 & 48 \\
\hline \multirow{3}{*}{$2 \times 2$} & 0.7 & 61 & 61 & 61 & 61 \\
\hline & 0.4 & 106 & 106 & 106 & 102 \\
\hline & 0.2 & 117 & 116 & 116 & 111 \\
\hline \multirow{3}{*}{ CI-GF } & 0.7 & 62 & 62 & 62 & 62 \\
\hline & 0.4 & 87 & 87 & 87 & 83 \\
\hline & 0.2 & 99 & 97 & 97 & 91 \\
\hline \multirow{3}{*}{ CI-RF } & 0.7 & 63 & 63 & 63 & 63 \\
\hline & 0.4 & 90 & 90 & 90 & 90 \\
\hline & 0.2 & 106 & 104 & 98 & 98 \\
\hline \multirow{3}{*}{$\mathrm{CI}-\mathrm{CF}$} & 0.7 & 64 & 64 & 64 & 64 \\
\hline & 0.4 & 95 & 95 & 95 & 92 \\
\hline & 0.2 & 108 & 106 & 106 & 100 \\
\hline \multirow{3}{*}{ CP-GF } & 0.7 & 76 & 76 & 76 & 76 \\
\hline & 0.4 & 109 & 109 & 109 & 104 \\
\hline & 0.2 & 117 & 116 & 116 & 111 \\
\hline \multirow{3}{*}{ CP-RF } & 0.7 & 95 & 95 & 95 & 95 \\
\hline & 0.4 & 132 & 132 & 131 & 131 \\
\hline & 0.2 & 144 & 143 & 139 & 139 \\
\hline \multirow{3}{*}{$\mathrm{CP}-\mathrm{CF}$} & 0.7 & 86 & 86 & 86 & 86 \\
\hline & 0.4 & 119 & 119 & 119 & 113 \\
\hline & 0.2 & 128 & 127 & 127 & 122 \\
\hline
\end{tabular}

HF - Hot Flange; CF - Cold Flange 
Table 14: Predicted Failure Times for 1.15 mm G500 Steel Studs Lined on Both Sides by Plasterboard

\begin{tabular}{|c|l|c|c|c|c|c|c|c|}
\hline \multirow{3}{*}{ Index } & \multicolumn{7}{|c|}{ Failure Time (min.) } \\
\cline { 2 - 10 } & \multicolumn{3}{|c|}{ LR $=0.2$} & \multicolumn{3}{c|}{ LR $=0.4$} & \multicolumn{2}{c|}{ LR $=0.7$} \\
\cline { 2 - 10 } & Test & FEA & Eqn. & Test & FEA & Eqn. & FEA & Eqn. \\
\hline $1 \times 1$ & $53^{*}$ & 54 & 57 & - & 42 & 41 & 20 & 21 \\
\hline $2 \times 2$ & $111^{*}$ & 117 & 121 & - & 106 & 106 & 61 & 65 \\
\hline CI-GF & $101^{*}$ & 99 & 103 & - & 87 & 86 & 62 & 62 \\
\hline CI-RF & $107^{*}$ & 106 & 107 & - & 90 & 89 & 63 & 63 \\
\hline CI-CF & $110^{*}$ & 108 & 110 & - & 95 & 93 & 64 & 64 \\
\hline CP-GF & 118 & 117 & 116 & 108 & 109 & 108 & 76 & 77 \\
\hline CP-RF & $136^{\#}$ & 144 & 144 & 134 & 132 & 131 & 95 & 95 \\
\hline CP-CF & $124^{*}$ & 128 & 129 & - & 119 & 117 & 86 & 88 \\
\hline
\end{tabular}

(*) - Tests conducted by Kolarkar [13]; (\# ) - Earlier failure time due to lack of space for thermal expansion; LR - Load ratio 
Table 15: Predicted Failure Times for 1.15 mm G250 Steel Studs Lined on Both Sides by Plasterboard

\begin{tabular}{|c|c|c|c|c|c|c|}
\hline \multirow{3}{*}{ Index } & \multicolumn{6}{|c|}{ Failure Time (min.) } \\
\cline { 2 - 7 } & \multicolumn{2}{|c|}{ LR $=0.2$} & \multicolumn{2}{c|}{ LR $=0.4$} & \multicolumn{2}{c|}{ LR $=0.7$} \\
\cline { 2 - 7 } & FEA & Eqn. & FEA & Eqn. & FEA & Eqn. \\
\hline $1 \times 1$ & 56 & 55 & 39 & 40 & 25 & 25 \\
\hline $2 \times 2$ & 120 & 117 & 93 & 96 & 71 & 68 \\
\hline CI-GF & 104 & 104 & 88 & 87 & 66 & 66 \\
\hline CI-RF & 109 & 109 & 91 & 90 & 67 & 67 \\
\hline CI-CF & 111 & 111 & 95 & 95 & 68 & 68 \\
\hline CP-GF & 118 & 117 & 102 & 104 & 84 & 83 \\
\hline CP-RF & 148 & 147 & 122 & 125 & 102 & 100 \\
\hline CP-CF & 133 & 131 & 110 & 112 & 92 & 92 \\
\hline
\end{tabular}

LR - Load ratio 
Table 16: Predicted Failure Times for 1.95 mm G250 Steel Studs Lined on Both Sides by Plasterboard

\begin{tabular}{|c|c|c|c|c|c|c|}
\hline \multirow{3}{*}{ Index } & \multicolumn{6}{|c|}{ Failure Time (min.) } \\
\cline { 2 - 7 } & \multicolumn{2}{|c|}{ LR $=0.2$} & \multicolumn{2}{c|}{ LR $=0.4$} & \multicolumn{2}{c|}{ LR $=0.7$} \\
\cline { 2 - 7 } & FEA & Eqn. & FEA & Eqn. & FEA & Eqn. \\
\hline $1 \times 1$ & 52 & 52 & 34 & 33 & 19 & 18 \\
\hline $2 \times 2$ & 117 & 114 & 83 & 82 & 51 & 56 \\
\hline CI-GF & 99 & 100 & 80 & 79 & 59 & 59 \\
\hline CI-RF & 104 & 104 & 82 & 81 & 59 & 59 \\
\hline CI-CF & 108 & 109 & 85 & 84 & 59 & 59 \\
\hline CP-GF & 114 & 114 & 96 & 96 & 60 & 66 \\
\hline CP-RF & 141 & 142 & 115 & 114 & 84 & 86 \\
\hline CP-CF & 126 & 126 & 105 & 103 & 79 & 81 \\
\hline
\end{tabular}

LR - Load ratio 
Table 17: Comparison of Failure Times for Externally Insulated Wall Panels with Non-insulated Wall Panels

\begin{tabular}{|c|c|c|c|c|c|c|c|c|c|}
\hline \multirow{3}{*}{ External } & \multicolumn{10}{|c|}{ \% increase } \\
\cline { 2 - 11 } Insulation & \multicolumn{1}{|c|}{$1.15 \mathrm{~mm}$ G500 } & \multicolumn{1}{|c|}{$1.15 \mathrm{~mm}$ G250 } & \multicolumn{1}{c|}{$1.95 \mathrm{~mm}$ G250 } \\
\cline { 2 - 11 } & LR & LR & LR & LR & LR & LR & LR & LR & LR \\
& 0.2 & 0.4 & 0.7 & 0.2 & 0.4 & 0.7 & 0.2 & 0.4 & 0.7 \\
\hline Glass fibre & 0 & 3 & 25 & -2 & 8 & 24 & 3 & 16 & 18 \\
\hline Rock fibre & 23 & 25 & 56 & 23 & 29 & 49 & 21 & 39 & 65 \\
\hline Cellulose fibre & 9 & 12 & 41 & 10 & 16 & 37 & 8 & 27 & 55 \\
\hline
\end{tabular}

LR - Load ratio 
Table 18: FEA Failure Temperatures of LSF Wall Panels

\begin{tabular}{|c|c|c|c|c|c|c|c|c|c|c|}
\hline & \multicolumn{10}{|c|}{ Failure Temperature $\left({ }^{\circ} \mathrm{C}\right)$} \\
\cline { 2 - 11 } Index & \multicolumn{2}{|c|}{ Load Ratio $=0.2$} & \multicolumn{2}{c|}{ Load Ratio $=0.4$} & \multicolumn{3}{c|}{ Load Ratio $=0.7$} \\
\cline { 2 - 11 } & G500 & G250 & G250 & G500 & G250 & G250 & G500 & G250 & G250 \\
& $\begin{array}{c}\mathrm{t}=1.15 \\
\mathrm{~mm}\end{array}$ & $\begin{array}{c}\mathrm{t}=1.15 \\
\mathrm{~mm}\end{array}$ & $\begin{array}{c}\mathrm{t}=1.95 \\
\mathrm{~mm}\end{array}$ & $\begin{array}{c}\mathrm{t}=1.15 \\
\mathrm{~mm}\end{array}$ & $\begin{array}{c}\mathrm{t}=1.15 \\
\mathrm{~mm}\end{array}$ & $\begin{array}{c}\mathrm{t}=1.95 \\
\mathrm{~mm}\end{array}$ & $\begin{array}{c}\mathrm{t}=1.15 \\
\mathrm{~mm}\end{array}$ & $\begin{array}{c}\mathrm{t}=1.15 \\
\mathrm{~mm}\end{array}$ & $\begin{array}{c}\mathrm{t}=1.95 \\
\mathrm{~mm}\end{array}$ \\
\hline $1 \times 1$ & 611 & 626 & 597 & 497 & 457 & 398 & 202 & 266 & 173 \\
\hline $2 \times 2$ & 626 & 660 & 583 & 513 & 432 & 369 & 227 & 292 & 165 \\
\hline CI-GF & 620 & 672 & 621 & 485 & 488 & 399 & 207 & 248 & 168 \\
\hline CI-RF & 643 & 678 & 630 & 484 & 494 & 399 & 207 & 248 & 167 \\
\hline CI-CF & 630 & 672 & 623 & 487 & 489 & 402 & 208 & 248 & 167 \\
\hline CP-GF & 636 & 656 & 597 & 518 & 438 & 378 & 234 & 285 & 163 \\
\hline CP-RF & 608 & 645 & 588 & 510 & 435 & 378 & 239 & 289 & 173 \\
\hline CP-CF & 603 & 648 & 589 & 519 & 437 & 387 & 221 & 277 & 167 \\
\hline
\end{tabular}




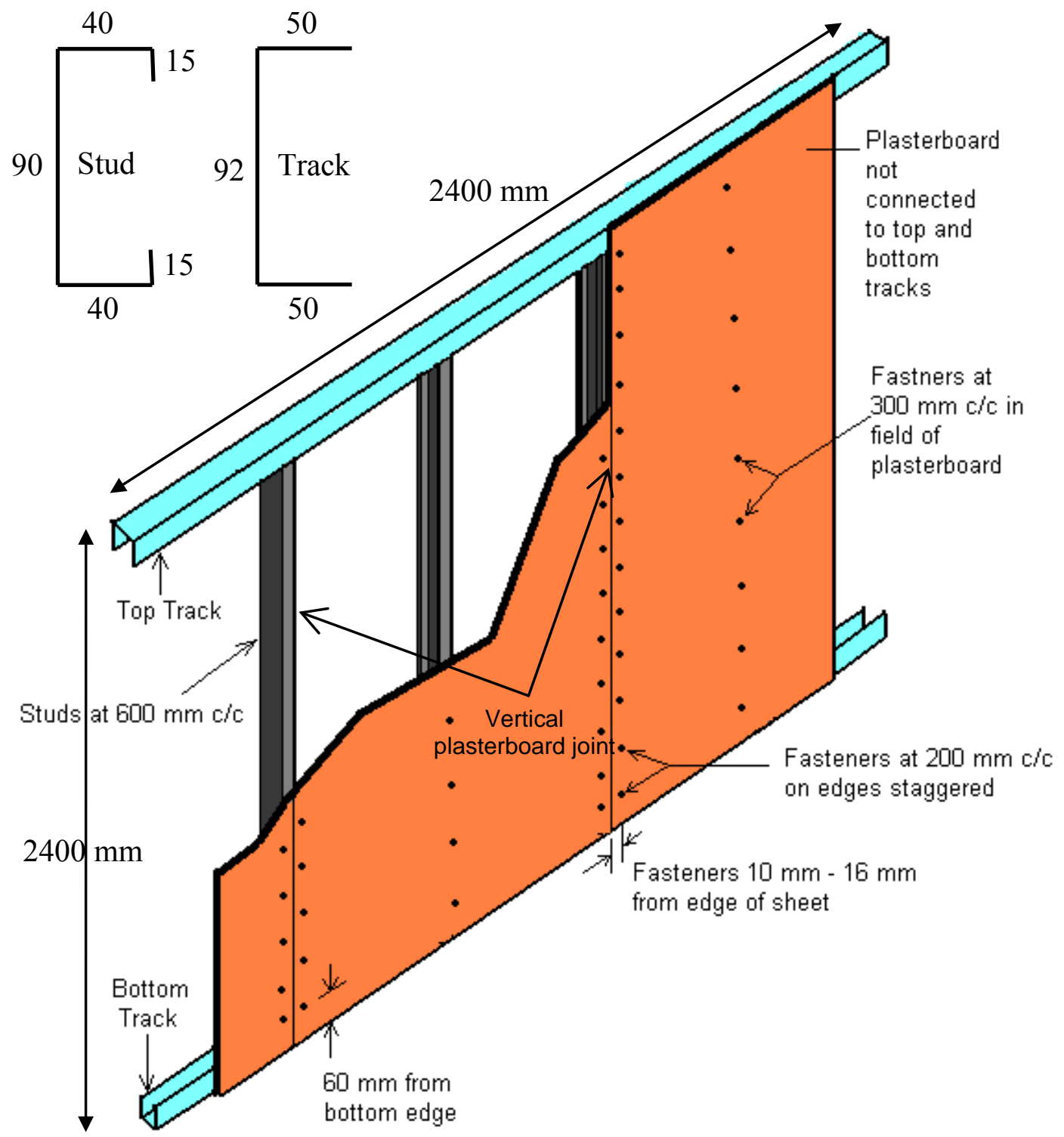

Figure 1: LSF Wall Panel 


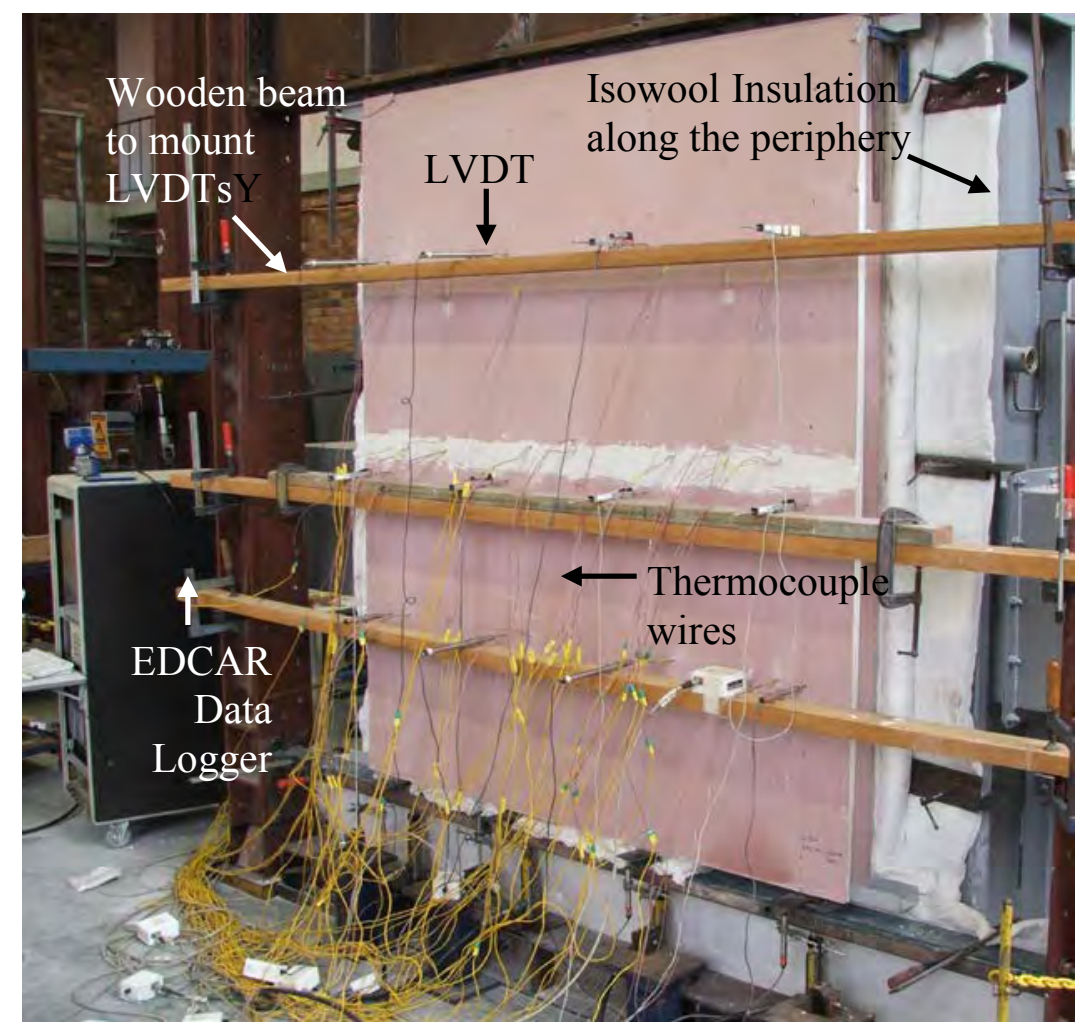

(a) Test specimen before testing
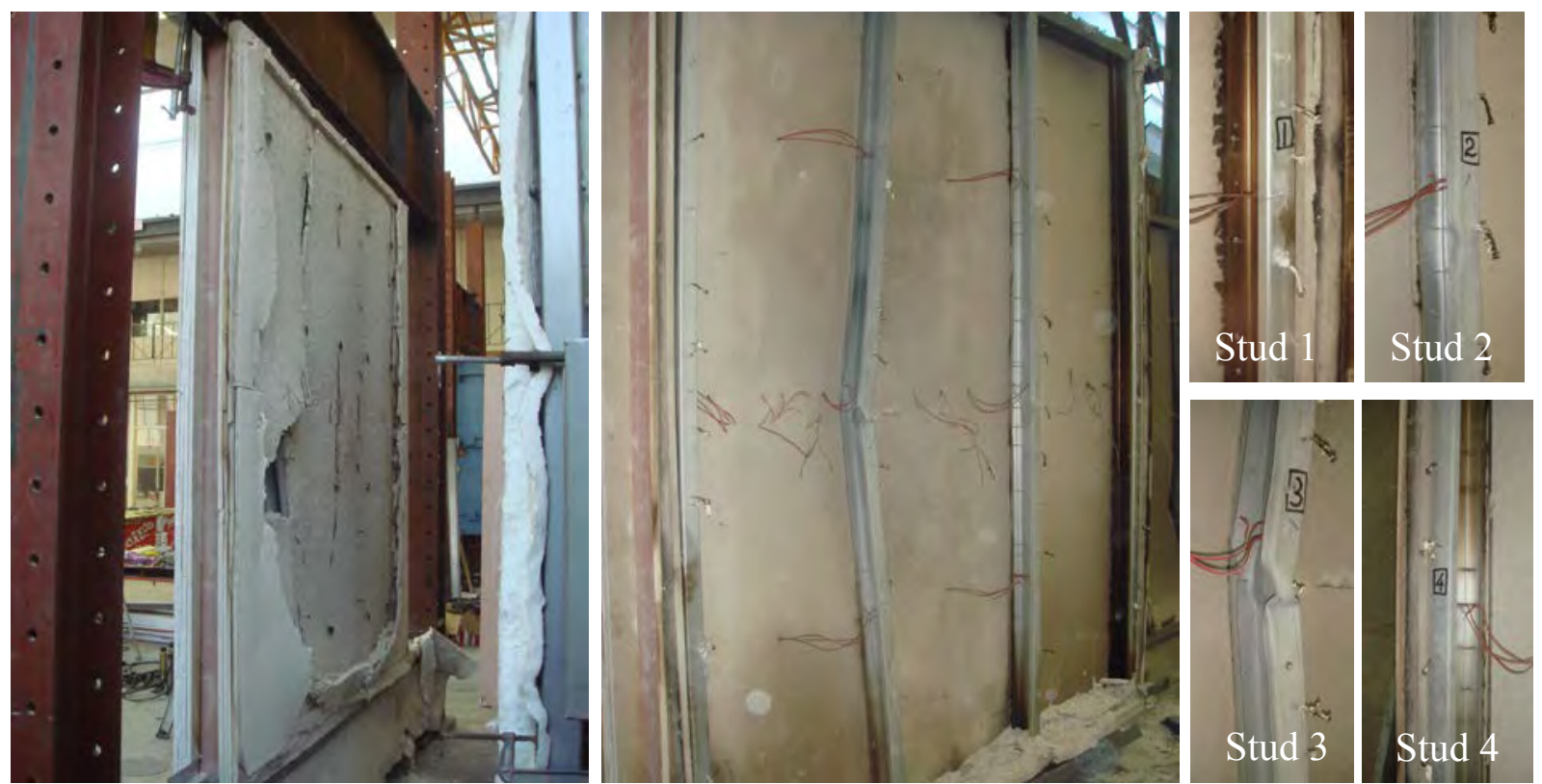

(b) Test specimen after failure

Figure 2: Experimental Study 
(a) $1 \times 1$
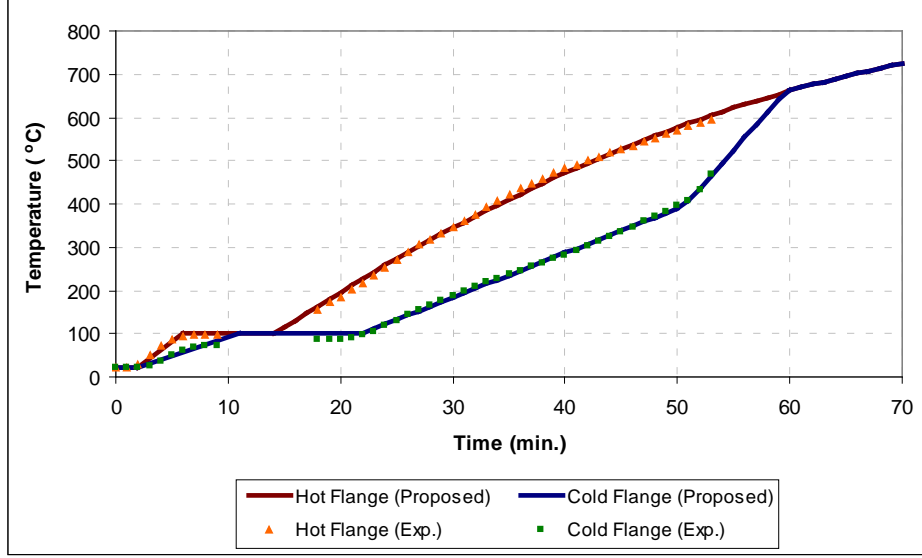

(b) $2 \times 2$

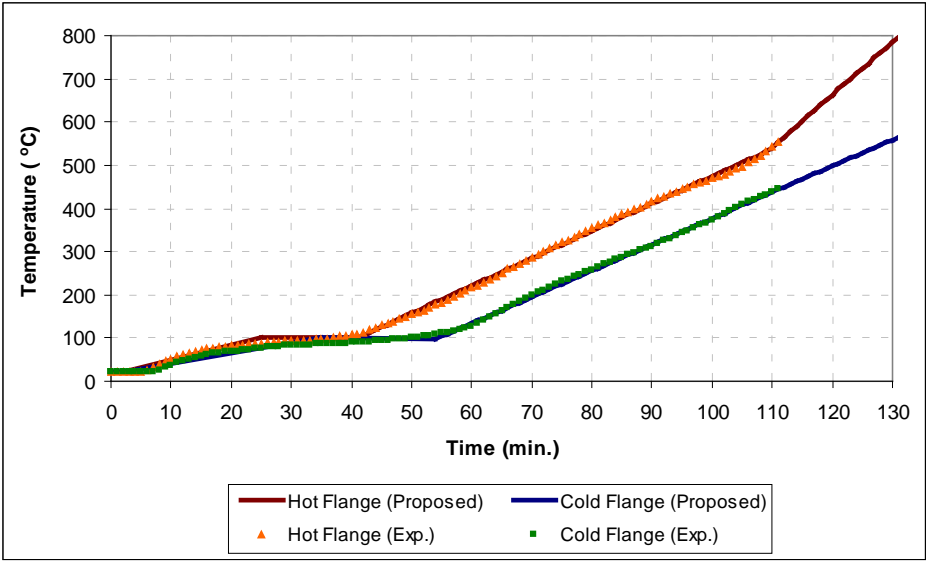

(c) CI-GF
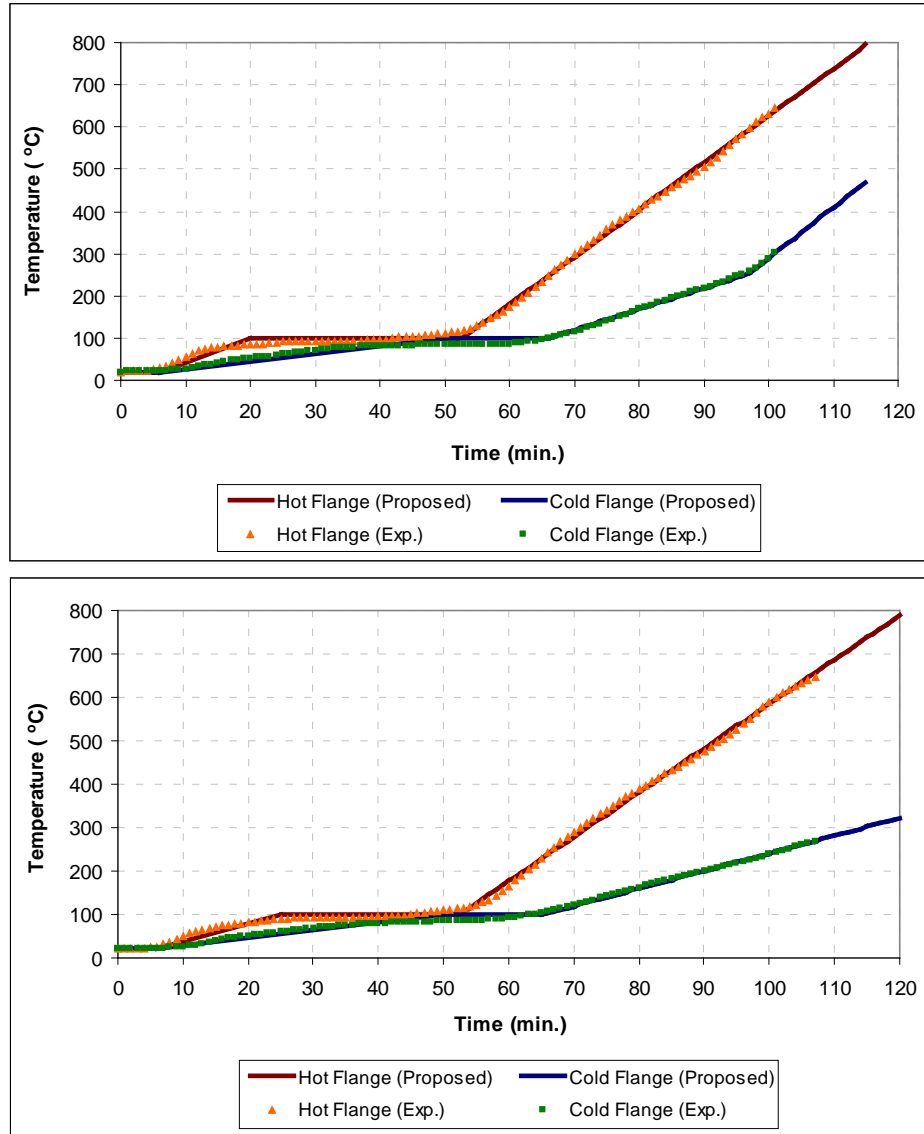

Figure 3: Idealised Time - Temperature Profiles for LSF Walls 
(e) CI-CF
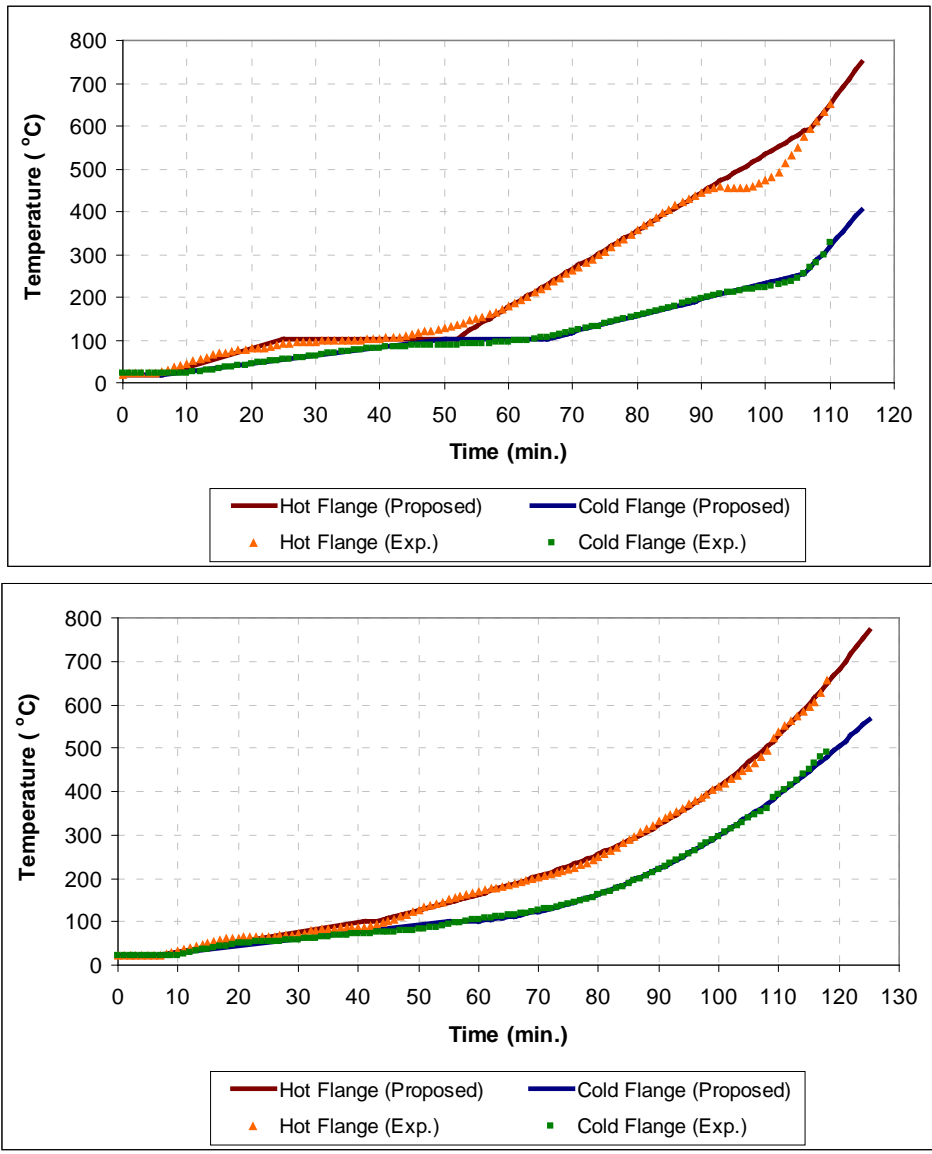

(f) $\mathrm{CP}-\mathrm{GF}$

(g) CP-RF
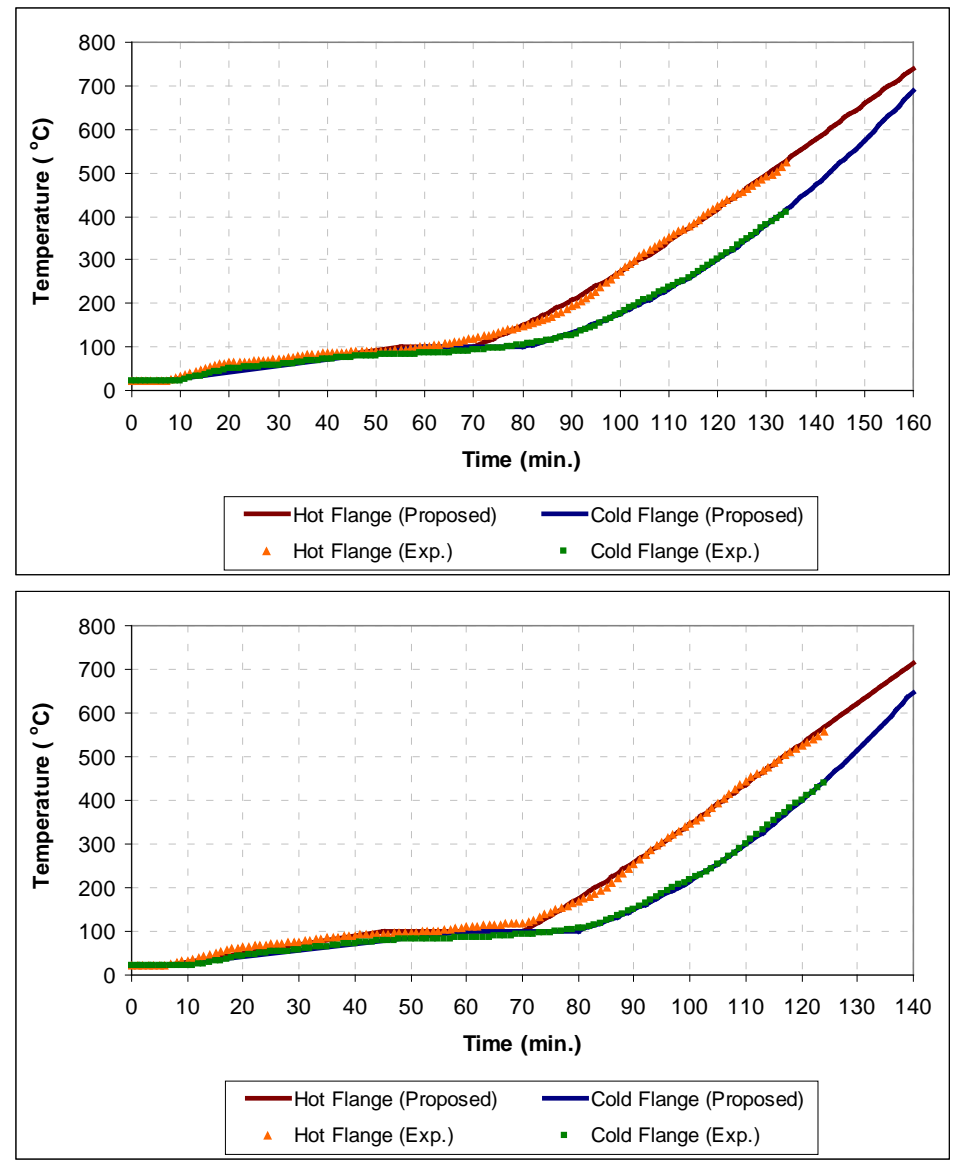

Figure 3: Idealised Time - Temperature Profiles for LSF Walls 


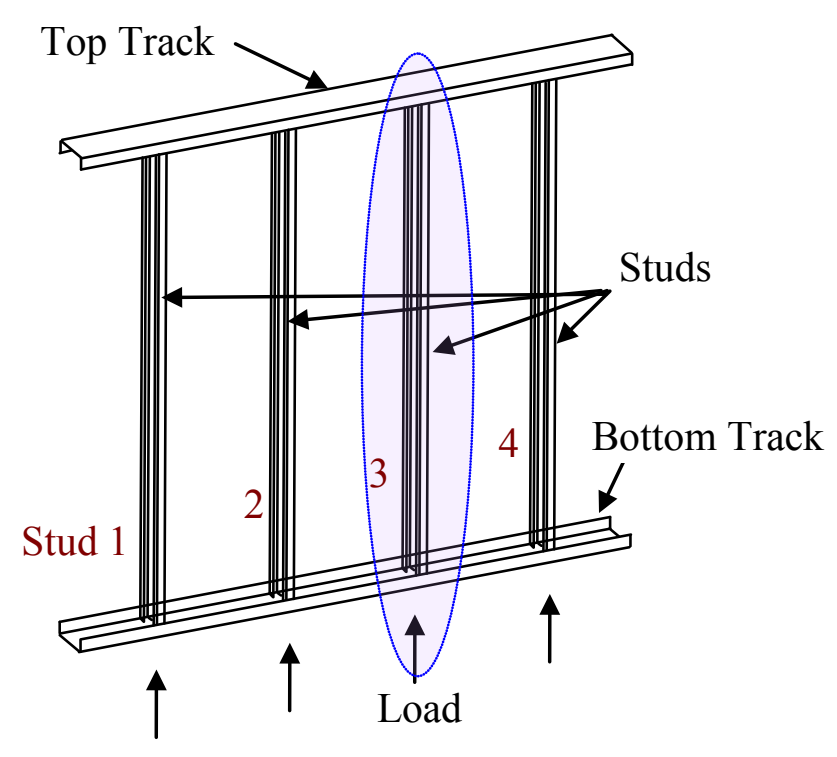

(a) LSF

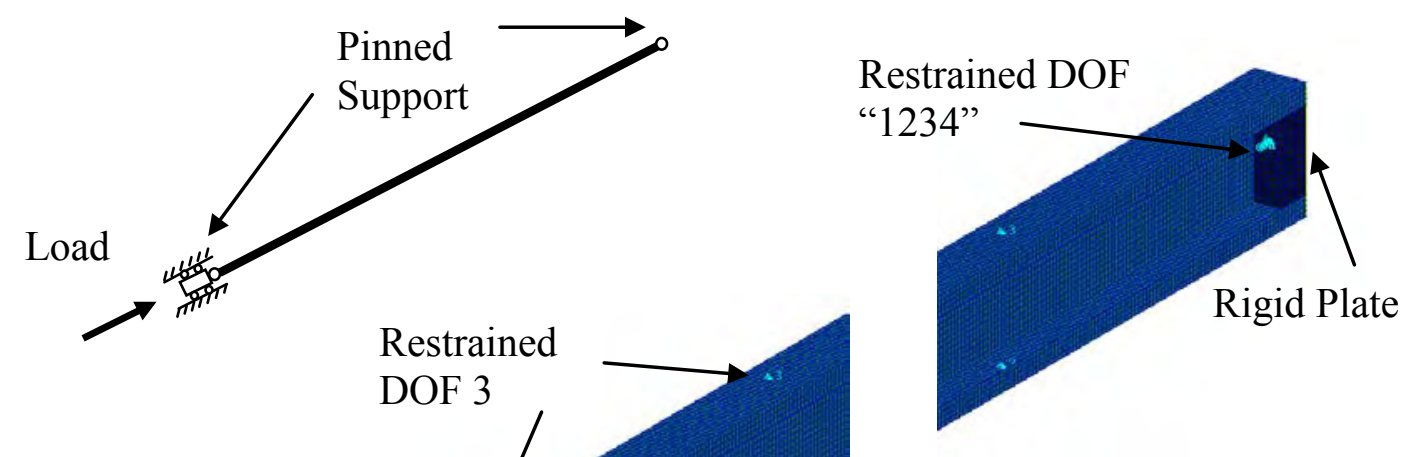

Stud

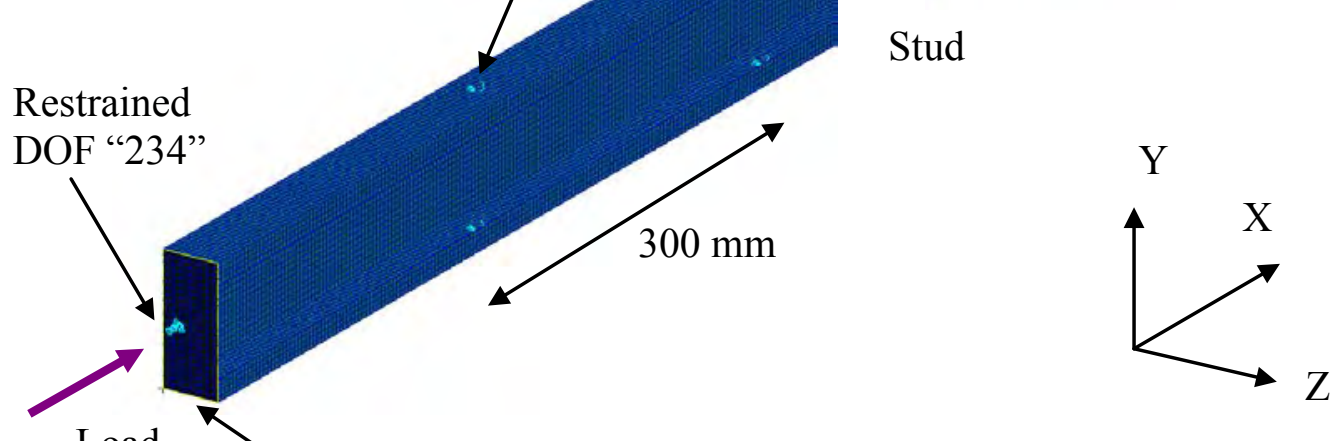

Load Rigid Plate

(b) Boundary conditions
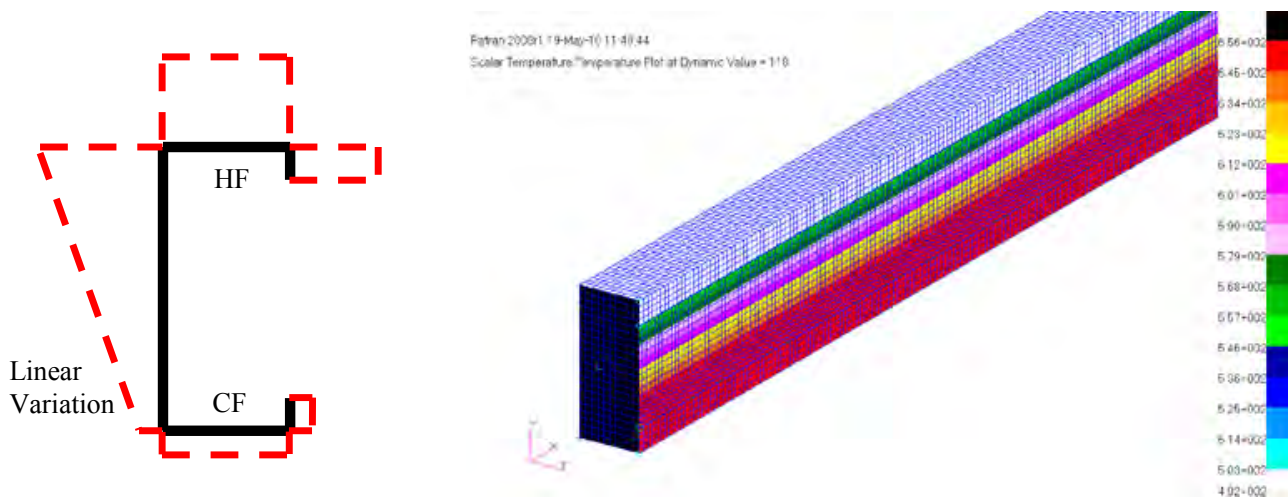

(c) Non-uniform temperature distribution

Figure 4: Finite Element Analyses 


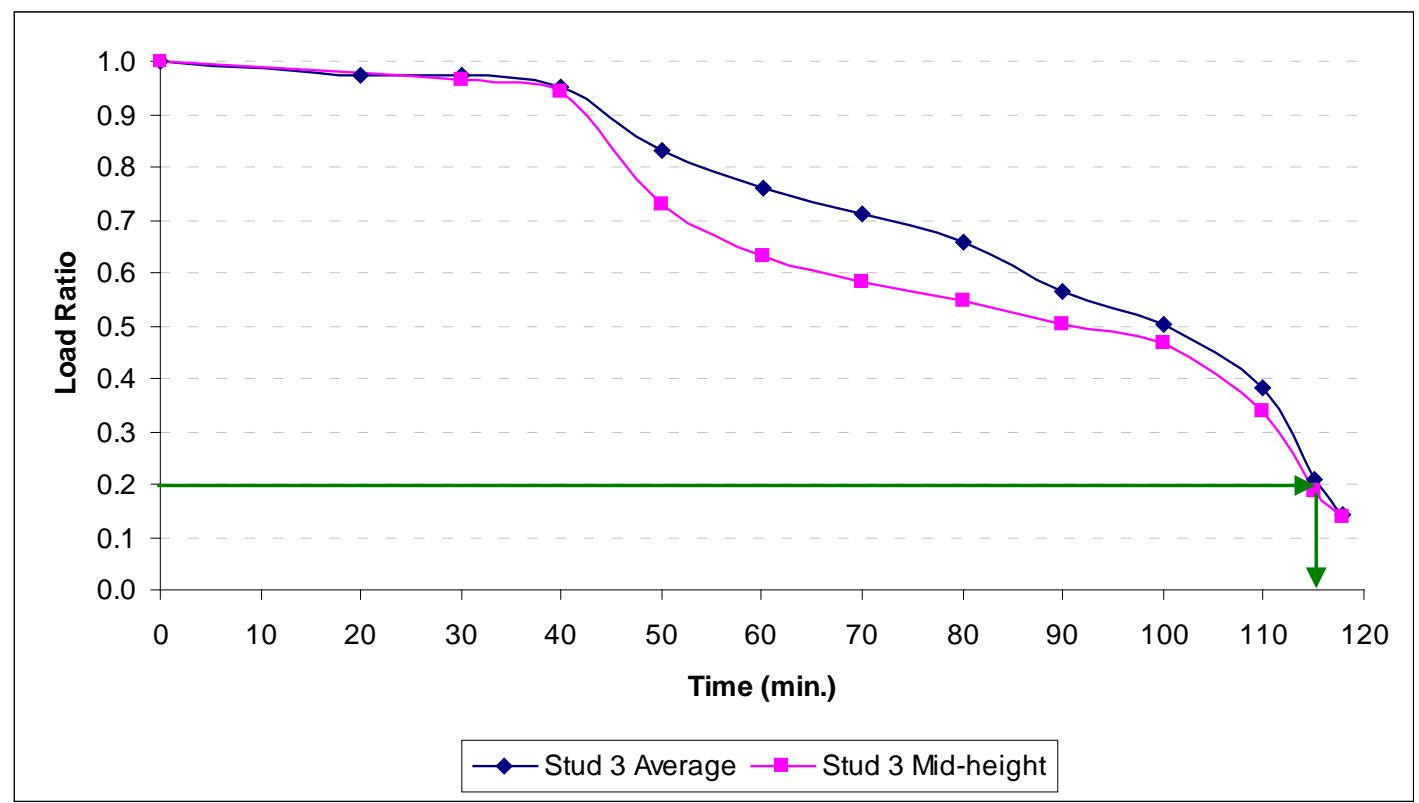

(a) Variation of load ratio with time

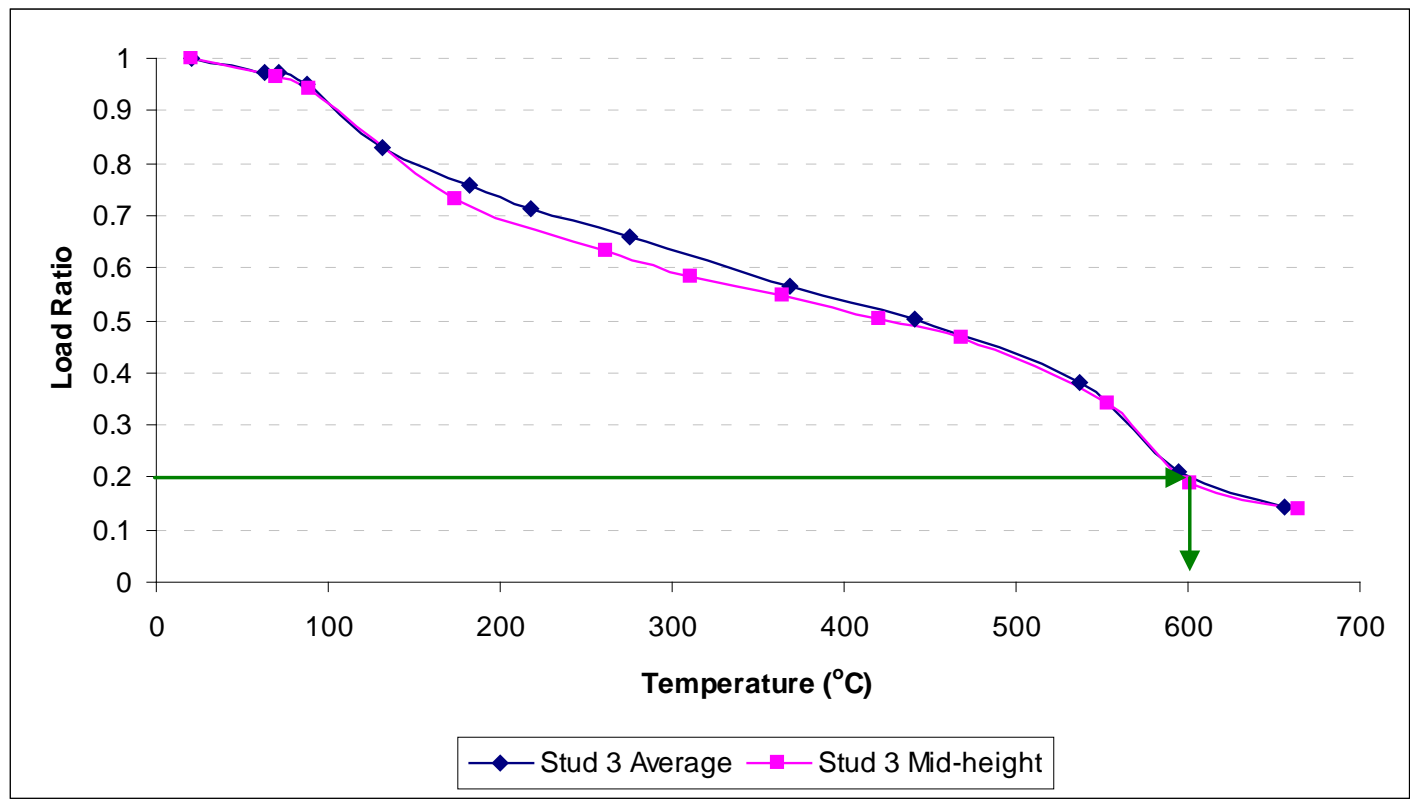

(b) Variation of load ratio with hot flange temperature

Figure 5: FEA Results for Stud 3 of Test 1 under Steady State Conditions 
Patran 2008r1 13-May-11 12:22:17

Fringe: cict11 10load, Step2, TotalTime=1.2102, Stress, Components, von Mises, At SECTION_POINT_1 Deform: cicft110load, Step2,TotalTime=1.2102, Deformation, Displacements,

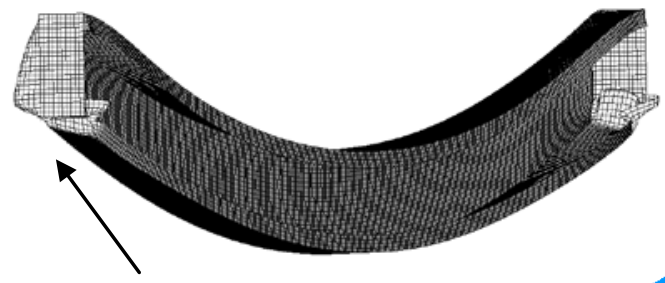

Local buckling

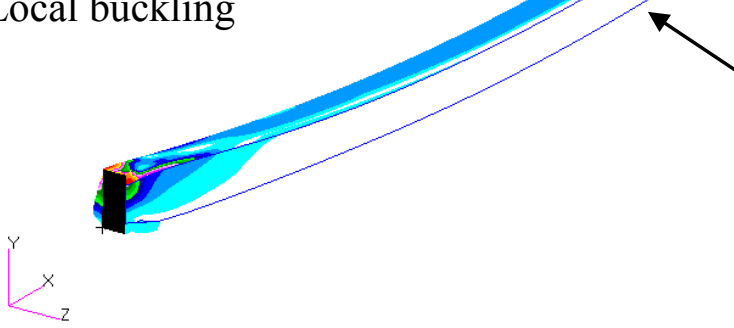

Thermal bowing

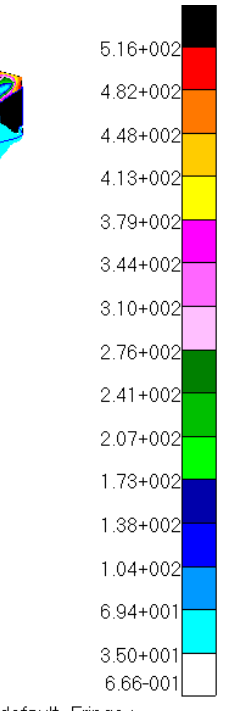
Max5.16+002@Nd 30055 Min 6.66-001@Nd 4822 default_Deformation

(a) Screw spacing of $300 \mathrm{~mm}$

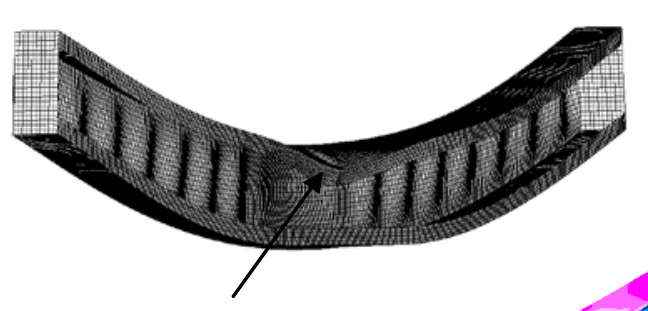

Local buckling

(b) Screw spacing of $1200 \mathrm{~mm}$

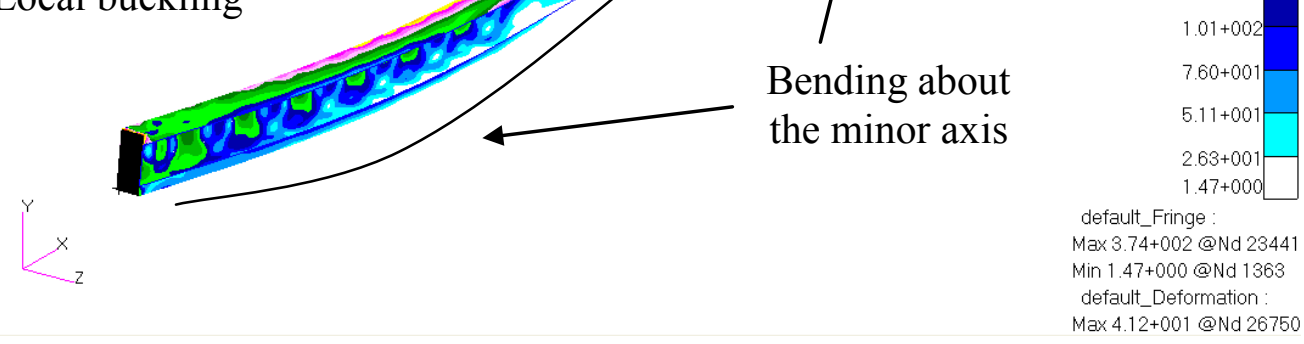

Figure 6: Ultimate Failure Modes of LSF Wall Studs with Different Screw Spacings 


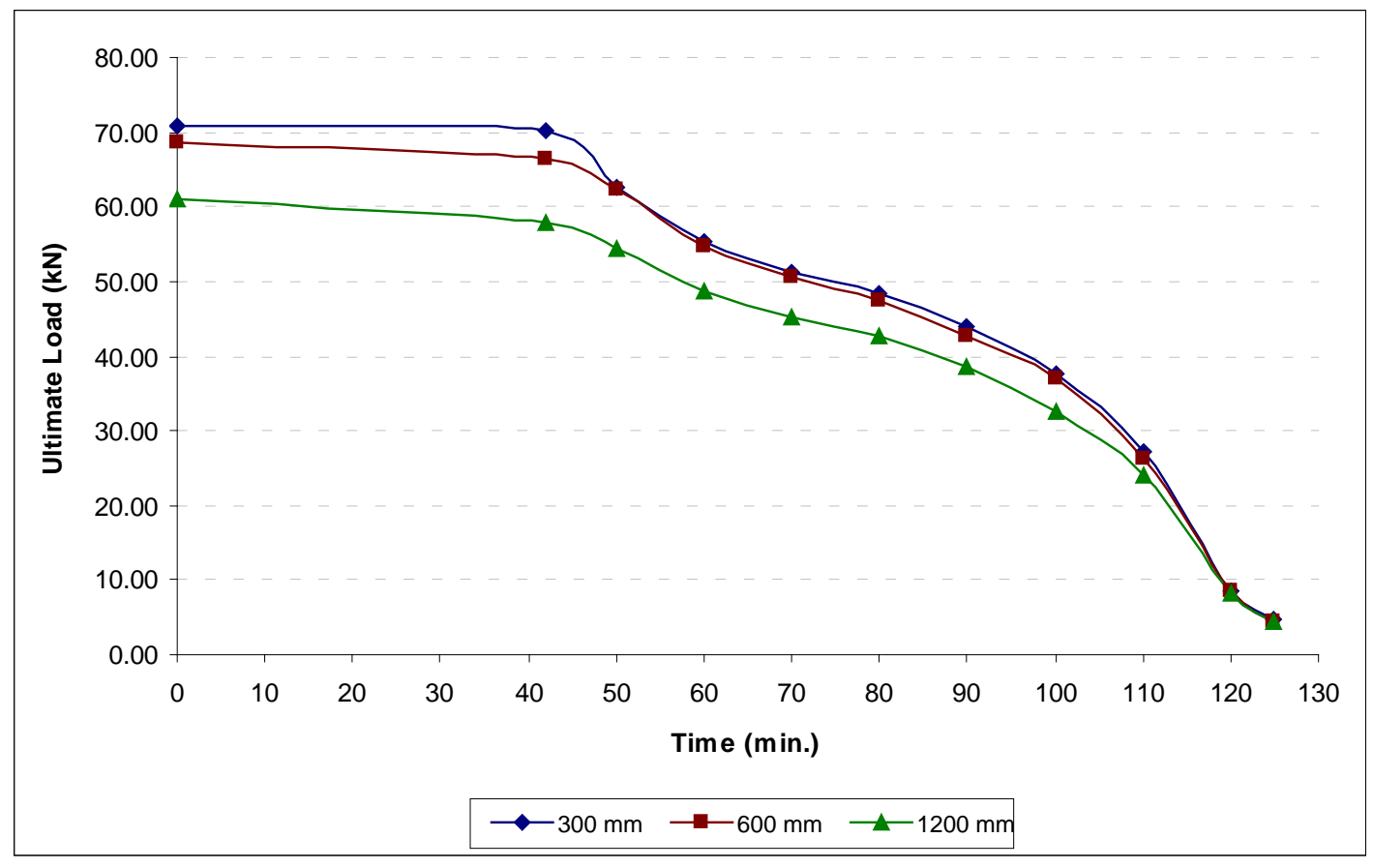

Figure 7: Ultimate Load Variation with Time for 1.15 mm G500 Steel Studs Lined on Both Sides by Two Layers of Plasterboard with Glass Fibre External Insulation 
(a) $1 \times 1$

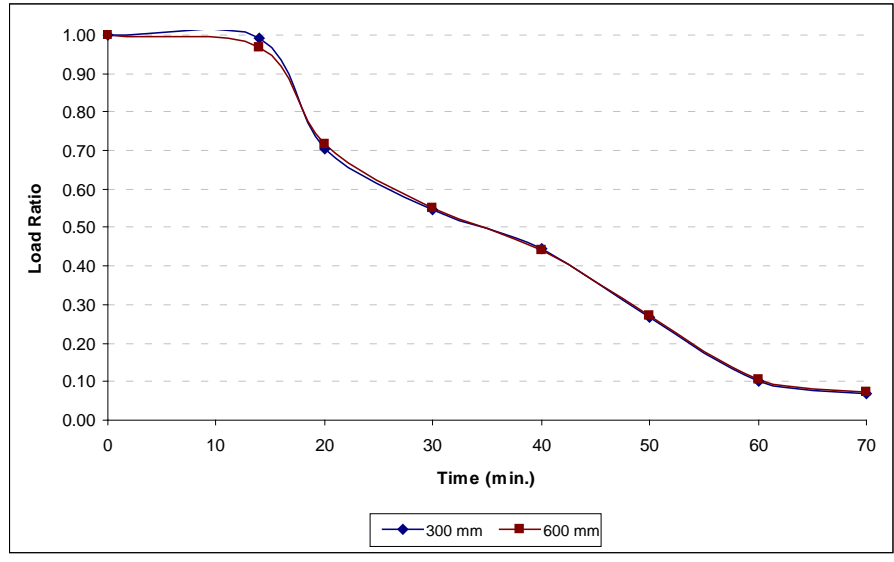

(b) $2 \times 2$

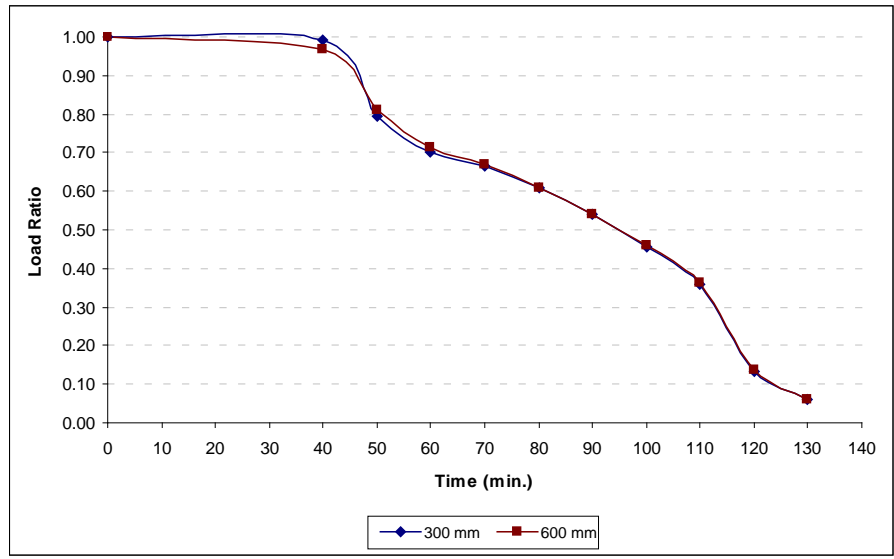

(c) CI-GF

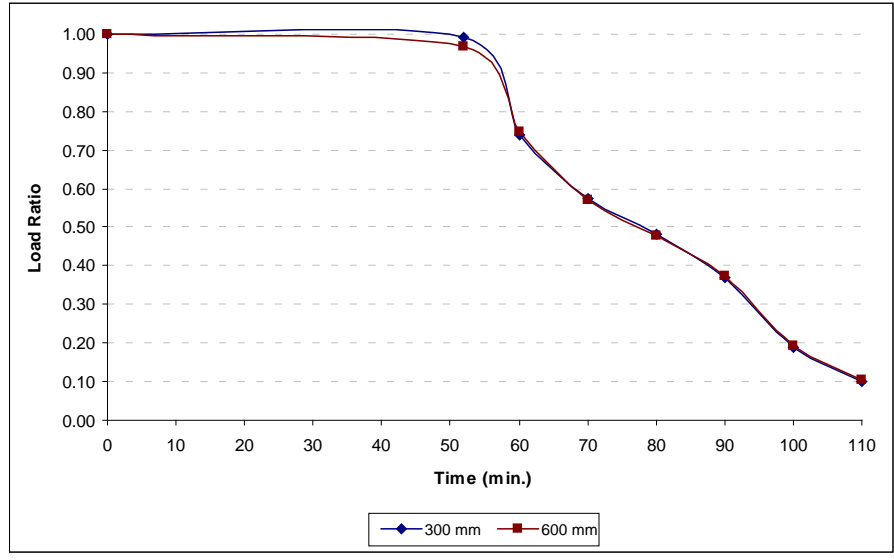

(d) CI-RF

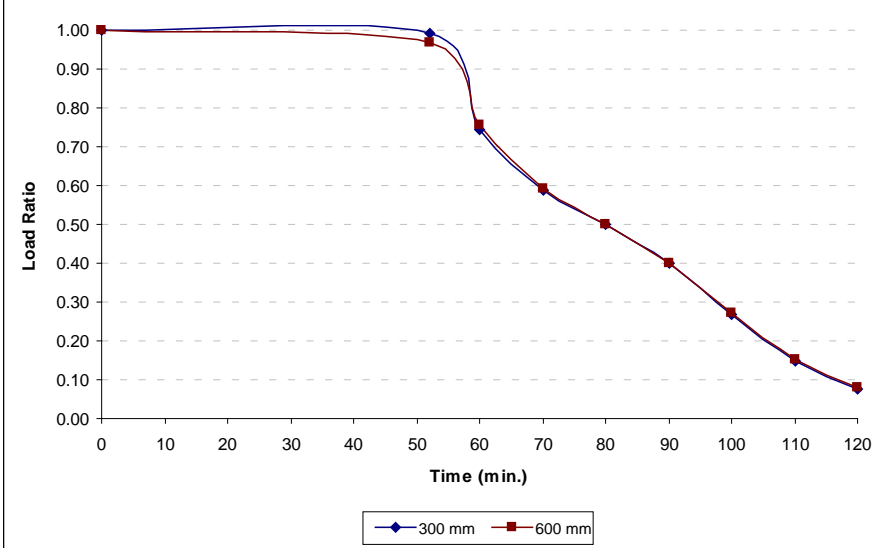

Figure 8: FEA Results for 1.15 mm G500 Steel Studs with Different Screw Spacings 
(e) $\mathrm{CI}-\mathrm{CF}$

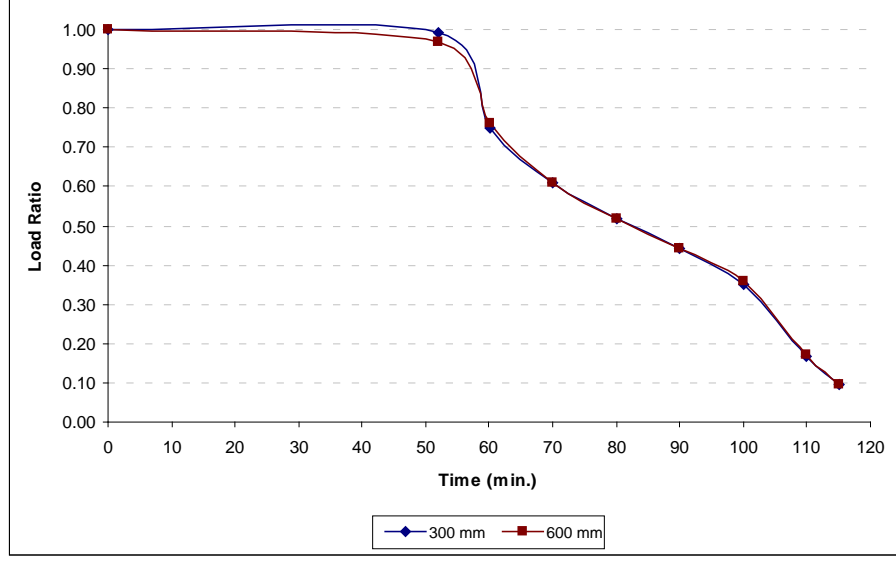

(f) $\mathrm{CP}-\mathrm{GF}$

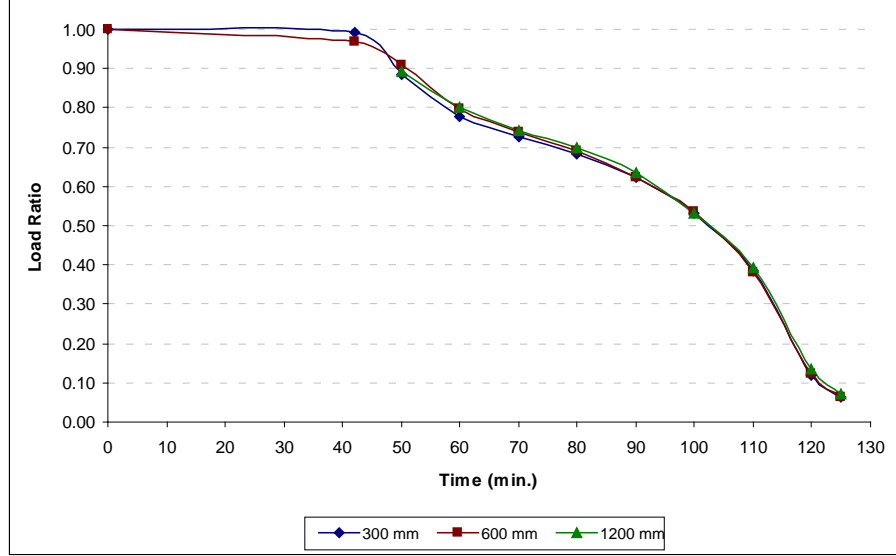

(g) CP-RF

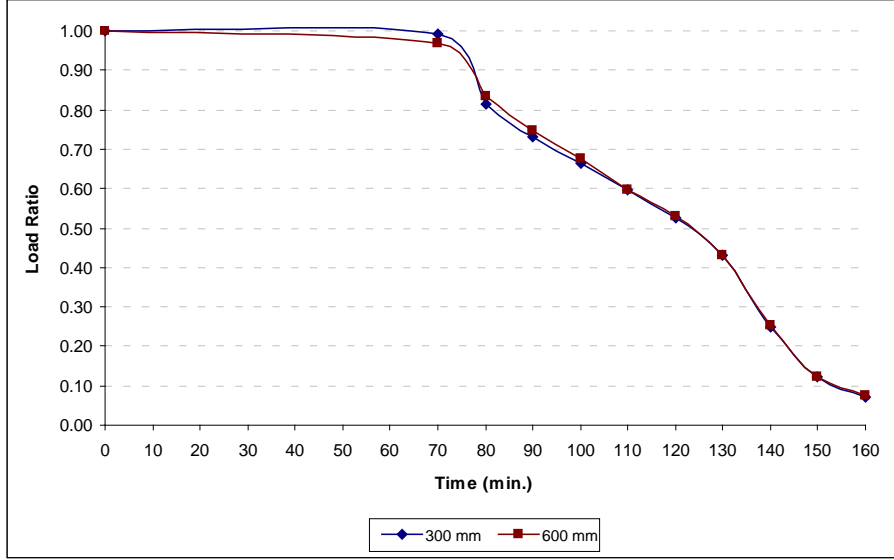

(h) $\mathrm{CP}-\mathrm{CF}$

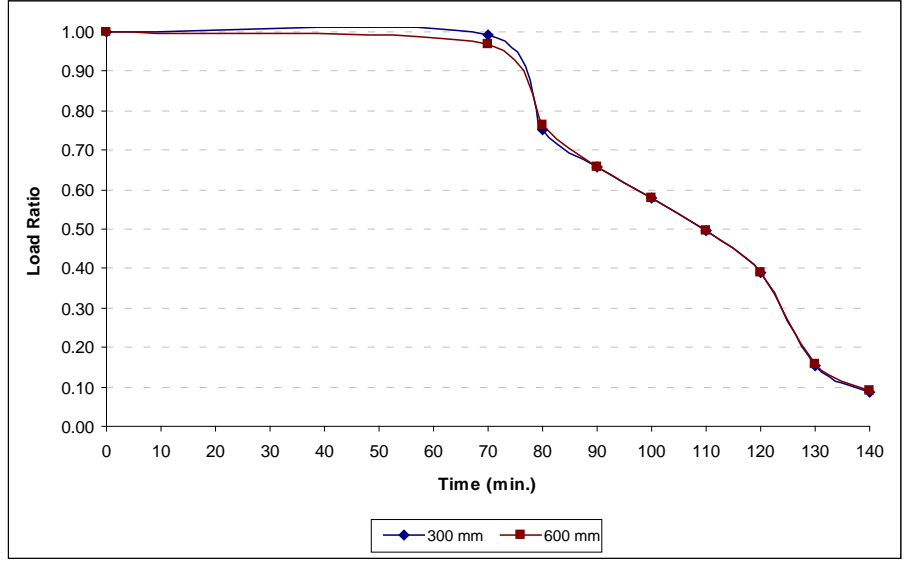

Figure 8: FEA Results for 1.15 mm G500 Steel Studs with Different Screw Spacings 
Patran 2008r1 13-May-11 12:22:17

Fringe: cicft1 10load, Step2,TotalTime=1.2102, Stress, Components, von Mises, At SECTION_POINT_1

Deform: cicft1 10load, Step2,TotalTime=1,2102, Deformation, Displacements.

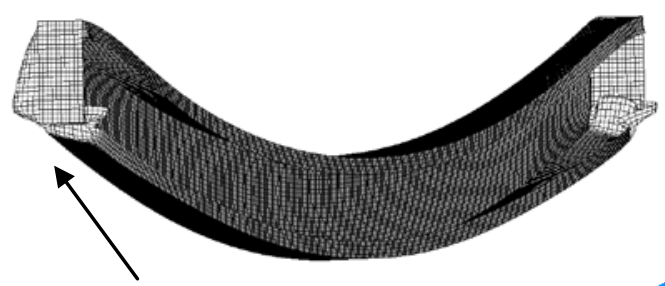

Local buckling
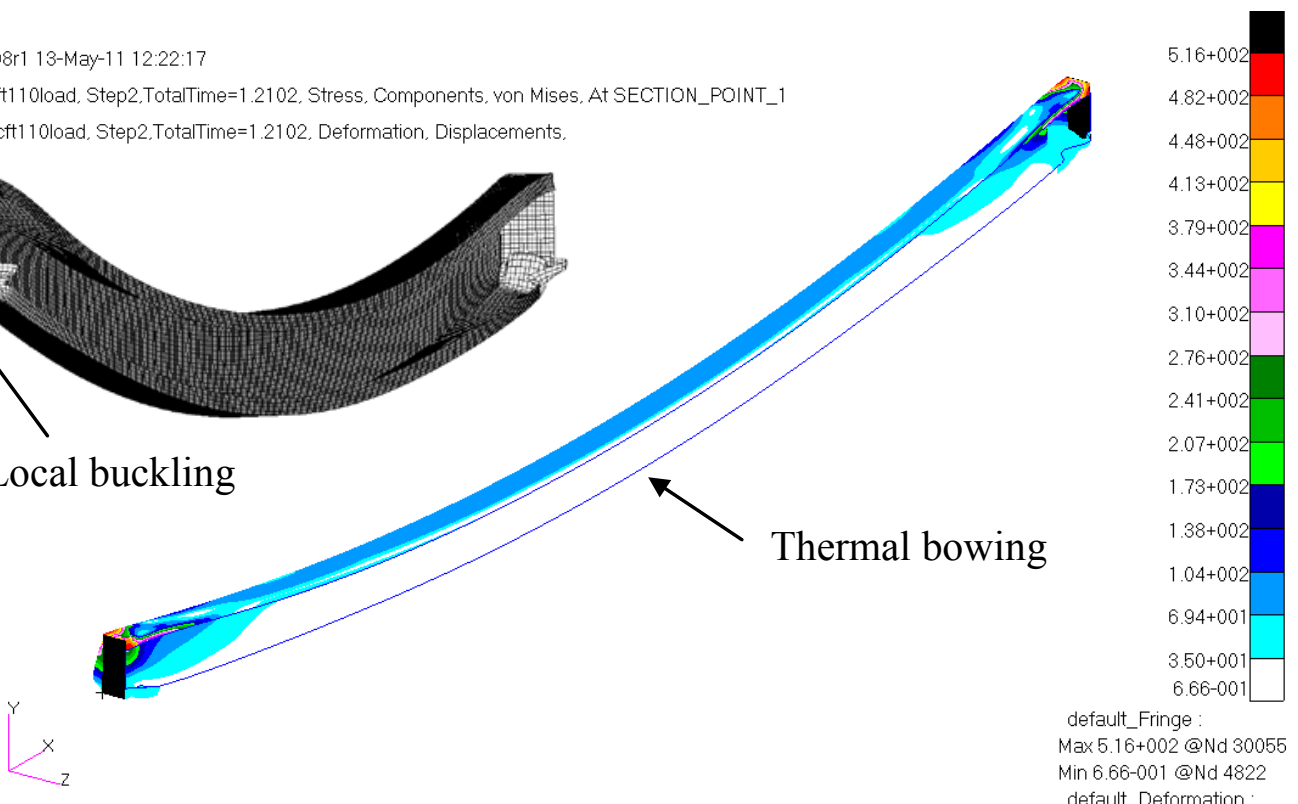

default_Fringe

Max 5.16+002@Nd 30055

Min 6.66-001@Nd 4822

default_Deformation

(a) Both flanges are restrained

Patran 2008r1 13-May-11 12:39:14

Fringe: cirft1 10load, Step2,TotalTime=1.5511, Stress, Components, von Mises, At SECTION_POINT_1

Deform: cirft110load. Step2,TotalTime=1.5511, Deformation, Displacements,
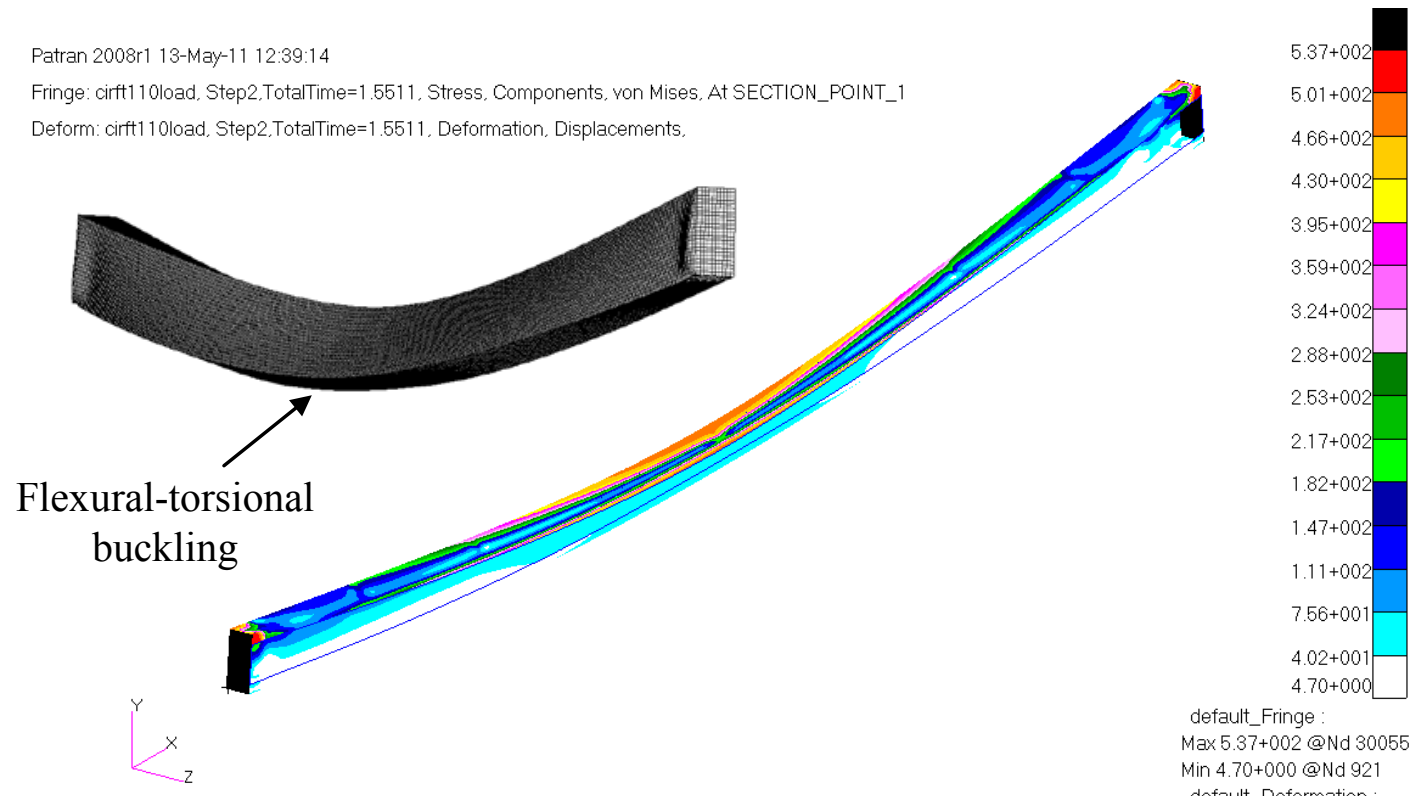

default_Fringe:

Max 5.37+002@Nd 30055

Min 4.70+000@Nd 921

default_Deformation :
Max $1.81+002 @ N d 26750$

(b) Only the cold flange is restrained

Figure 9: Ultimate Failure Modes of LSF Wall Studs with Different Plasterboard Restraints 
(a) $1 \times 1$

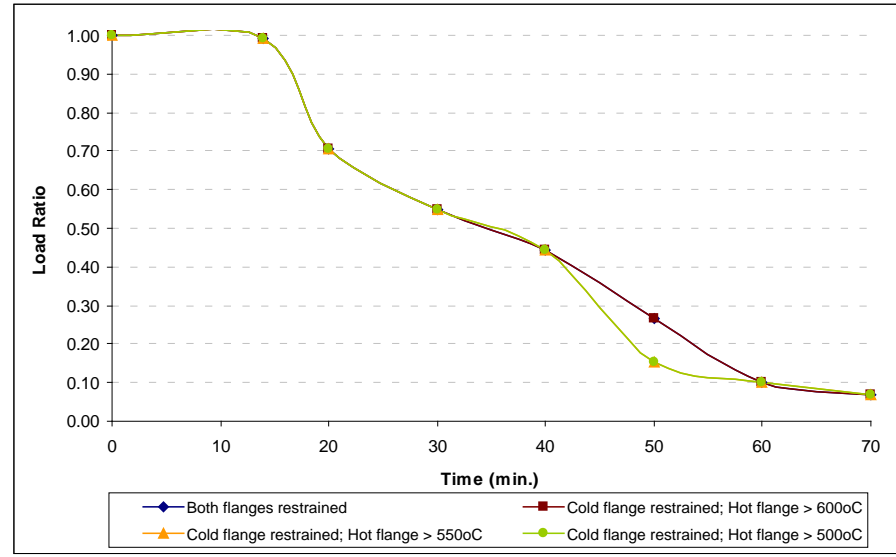

(b) $2 \times 2$

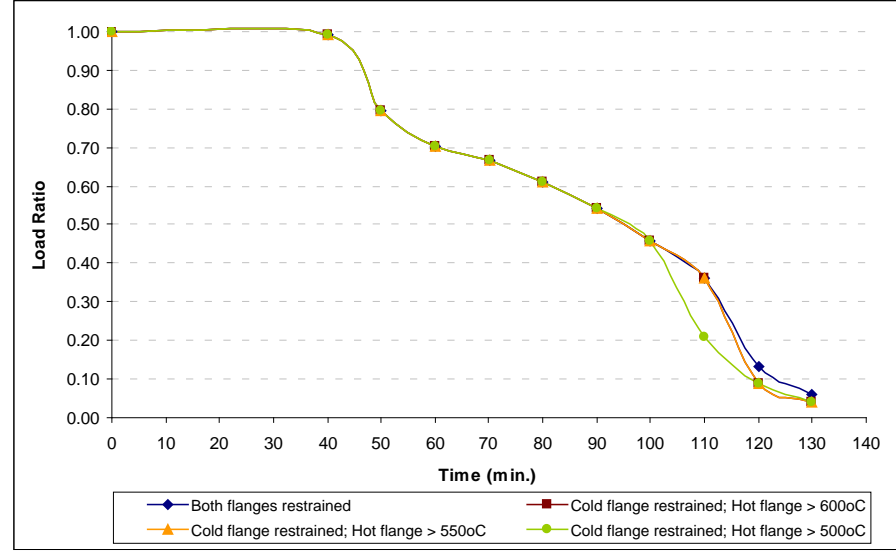

(c) CI-GF

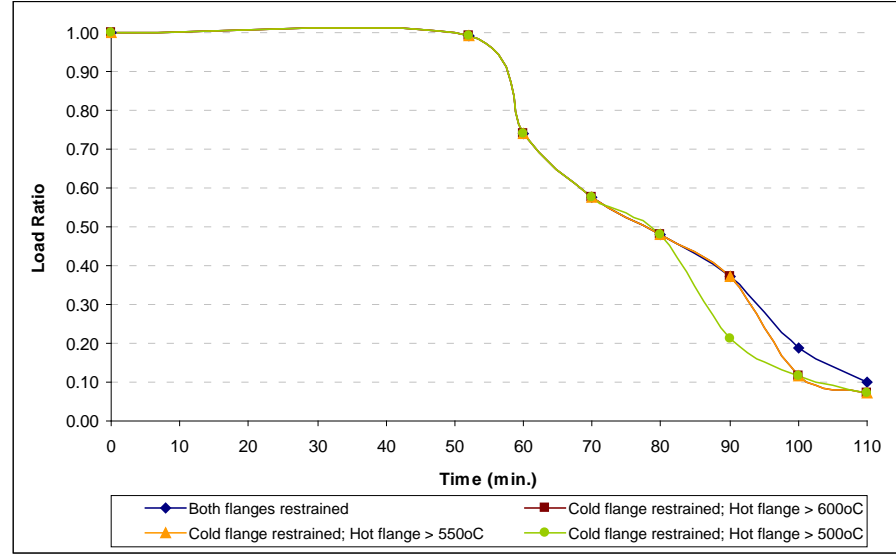

(d) CI-RF

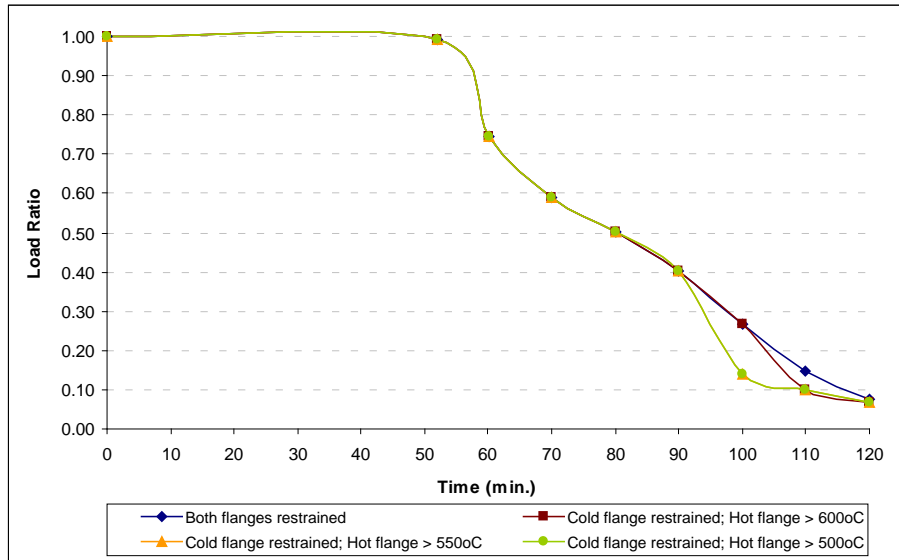

Figure 10: FEA Results for 1.15 mm G500 Steel Studs at 300 mm Screw Spacing 
(e) CI-CF

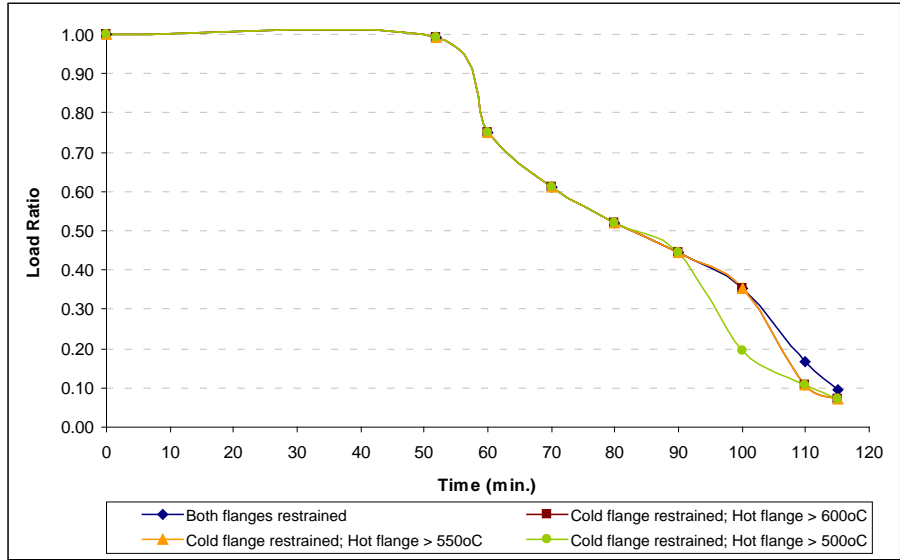

(f) $\mathrm{CP}-\mathrm{GF}$

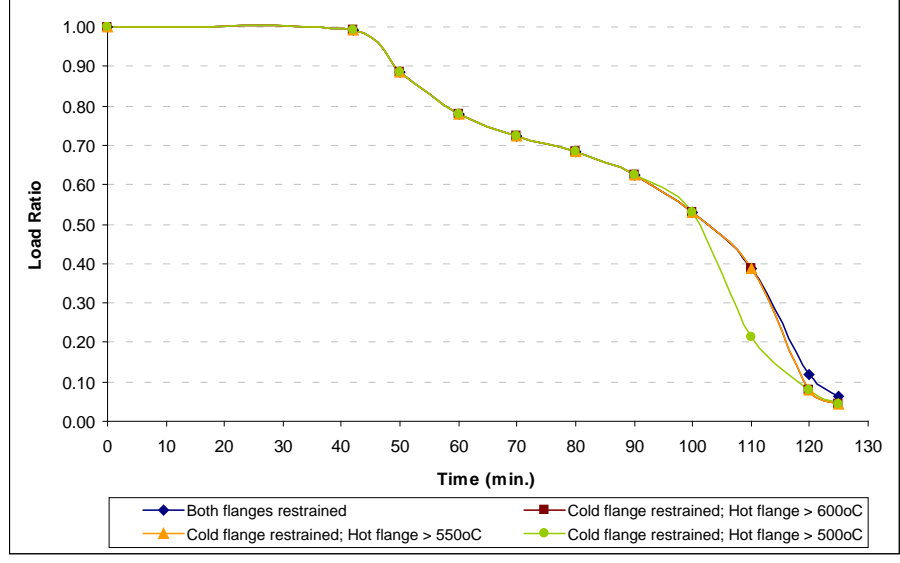

(g) CP-RF

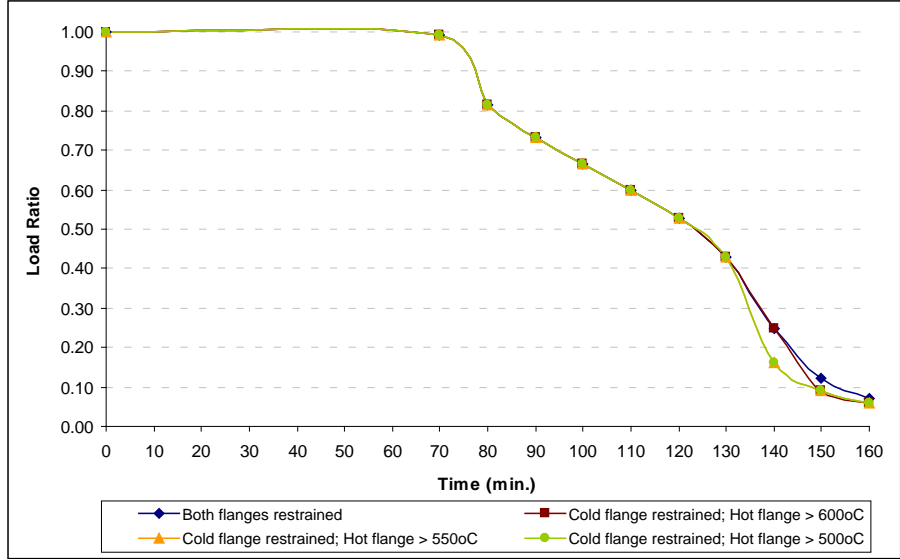

(h) $\mathrm{CP}-\mathrm{CF}$

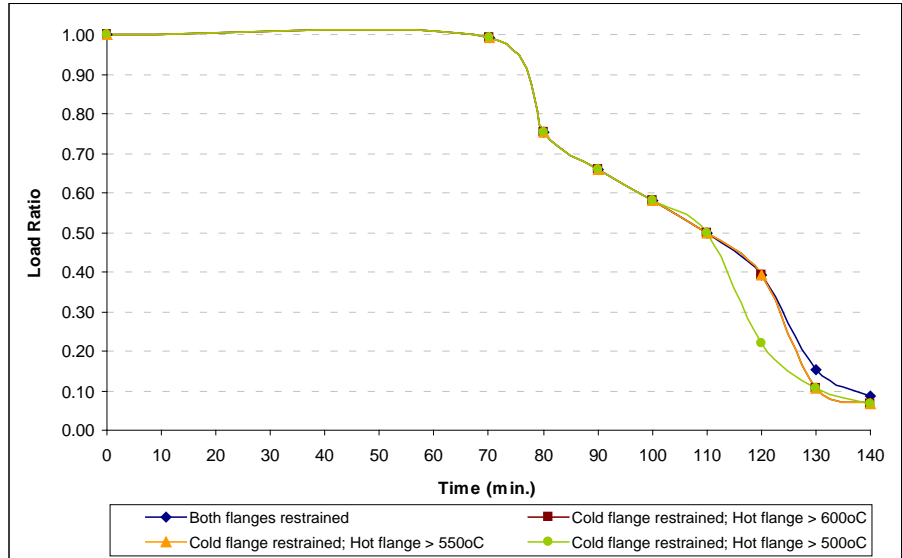

Figure 10: FEA Results for 1.15 mm G500 Steel Studs at $300 \mathrm{~mm}$ Screw Spacing 
(a) $1 \times 1$

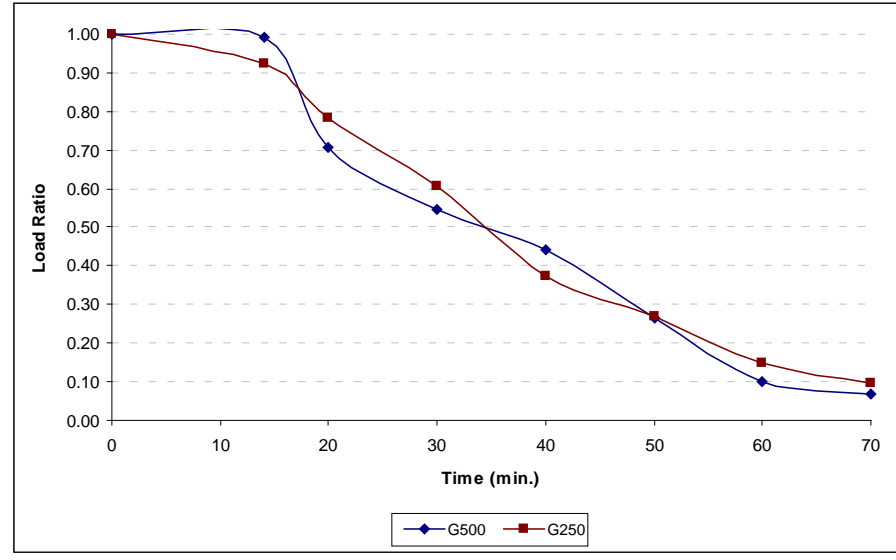

(b) $2 \times 2$

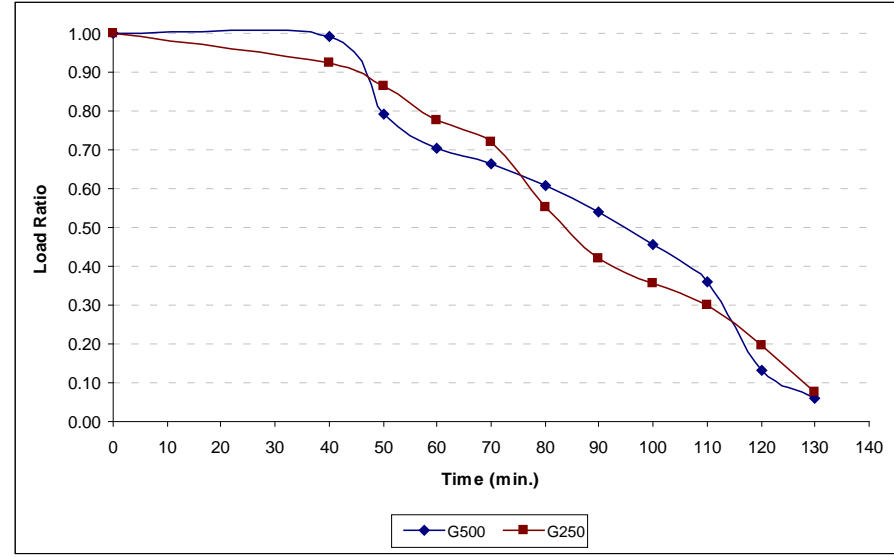

(c) $\mathrm{CI}-\mathrm{GF}$

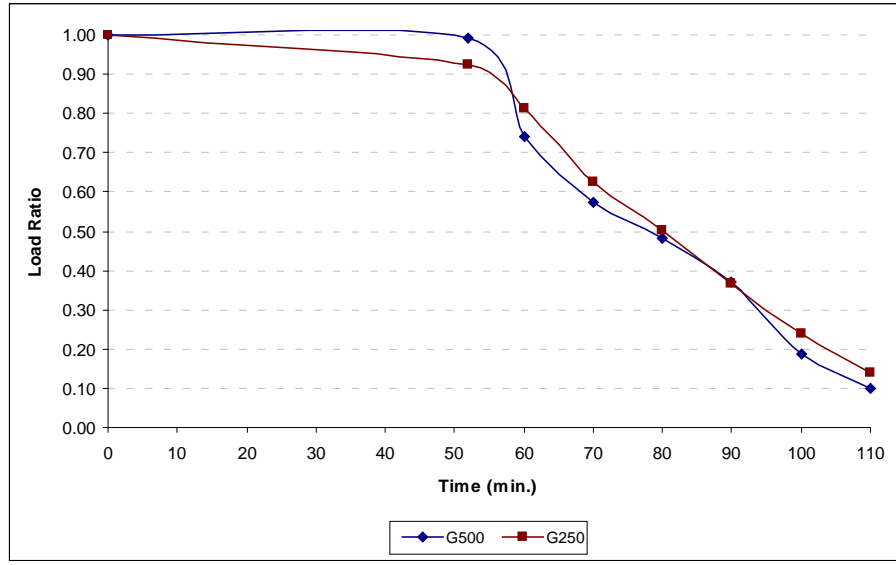

(d) CI-RF

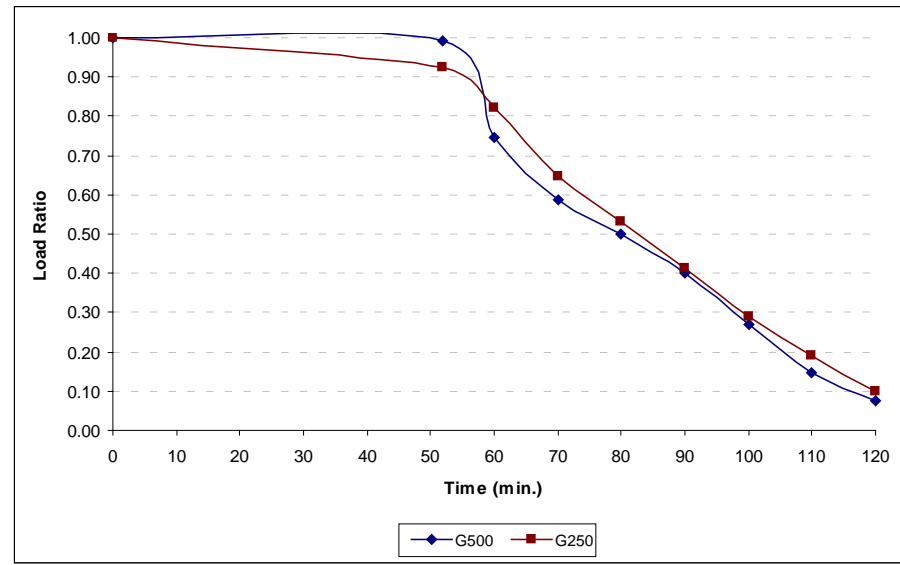

Figure 11: FEA Results for $1.15 \mathrm{~mm}$ G500 and G250 LSF Wall Studs at $300 \mathrm{~mm}$ Screw Spacing 
(e) CI-CF

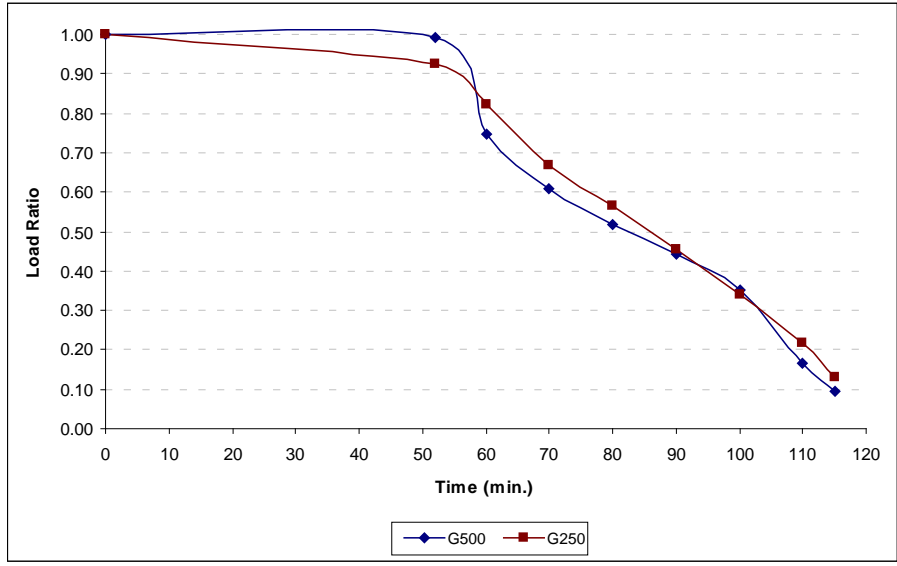

(f) $\mathrm{CP}-\mathrm{GF}$

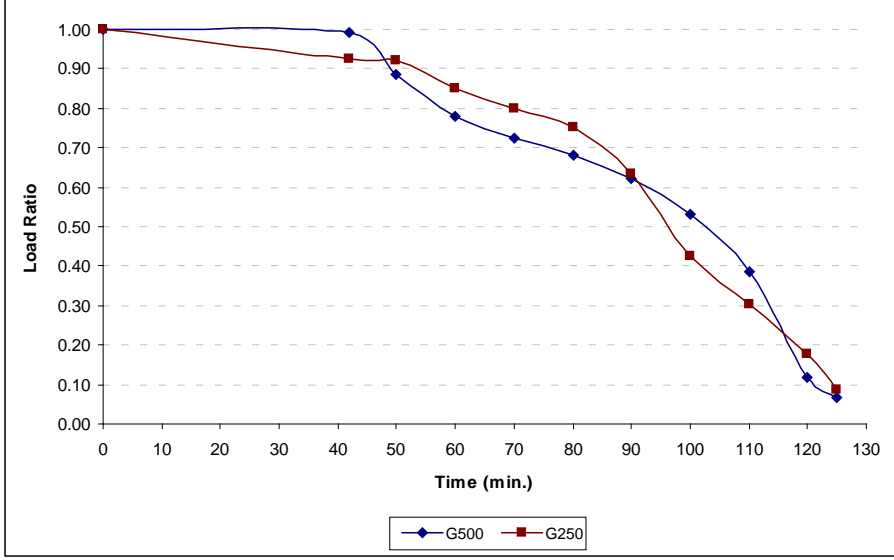

(g) CP-RF

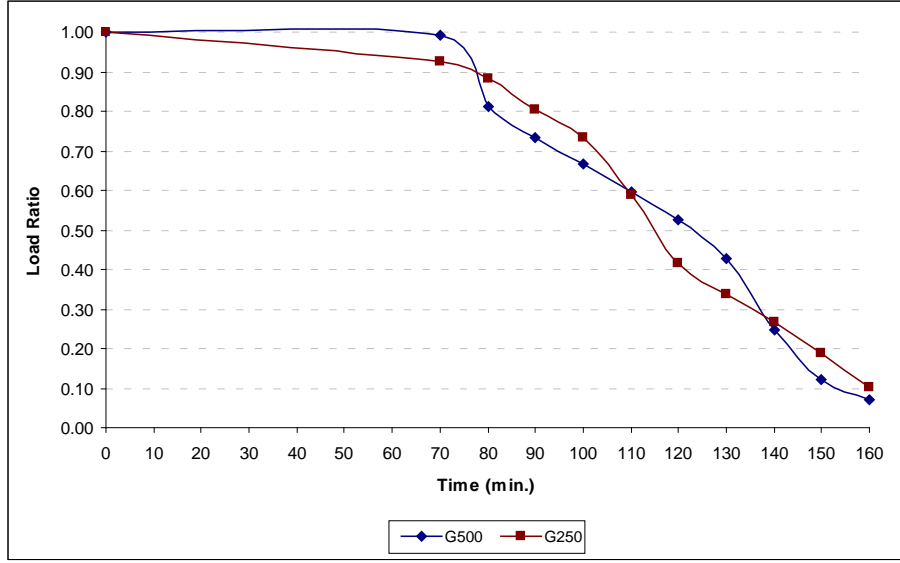

(h) $\mathrm{CP}-\mathrm{CF}$

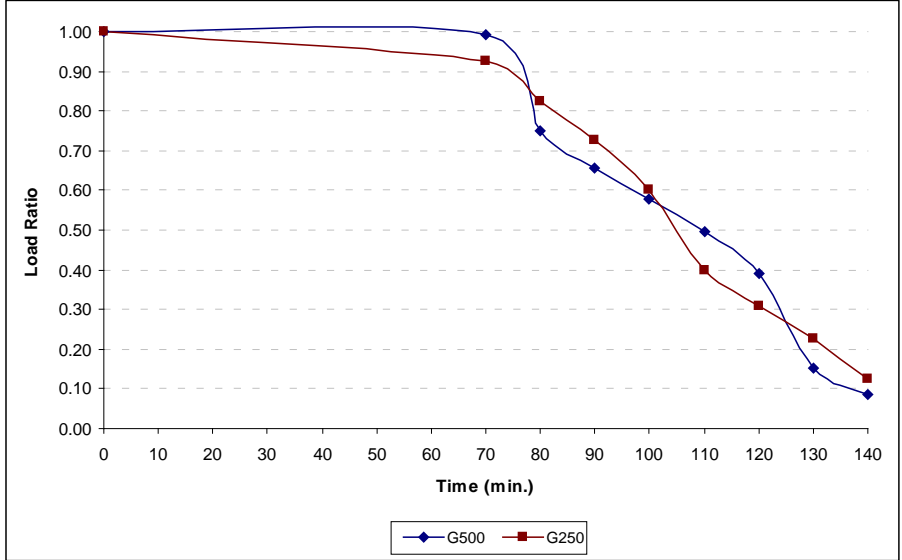

Figure 11: FEA Results for $1.15 \mathrm{~mm}$ G500 and G250 LSF Wall Studs at $300 \mathrm{~mm}$ Screw Spacing 
Patran 2008r1 13-May-11 12:22:17

Fringe: cicft1 1 0 load, Step2,TotalTime=1.2102, Stress, Components, von Mises, At SECTION_POINT_1

Deform: cicft110load, Step2,TotalTime=1.2102, Deformation, Displacements

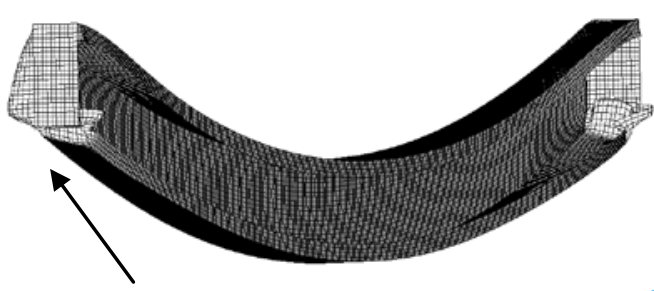

Local buckling
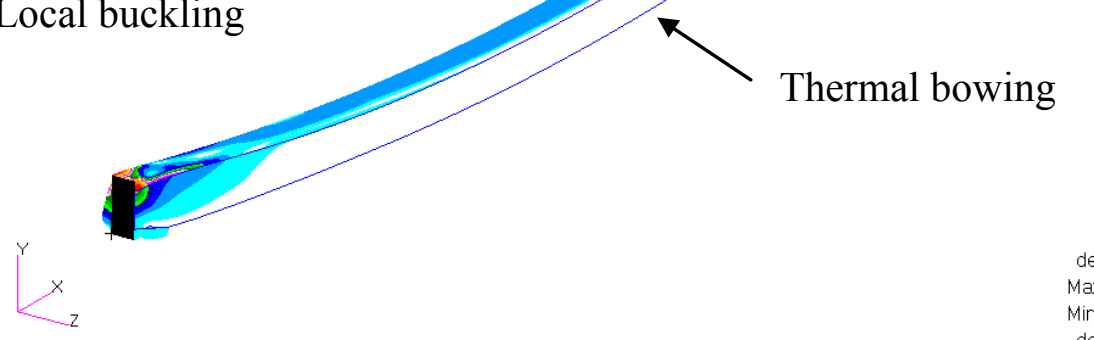

(a) Steel thickness of $1.15 \mathrm{~mm}$

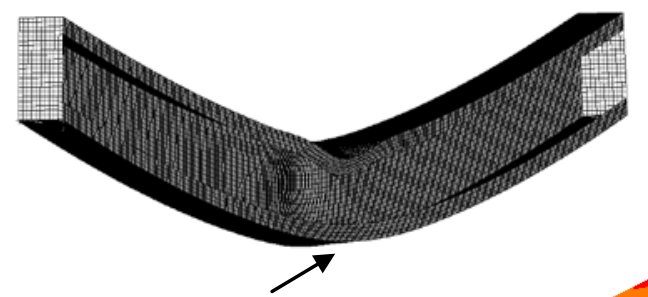

Flexural buckling

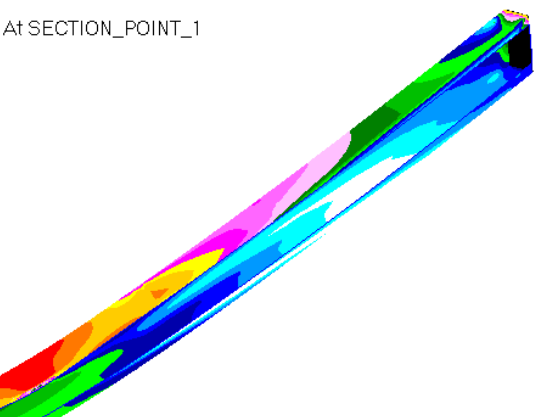

(b) Steel thickness of $1.95 \mathrm{~mm}$

Figure 12: Ultimate Failure Modes of LSF Wall Studs Made of Different Thicknesses 
(a) $1 \times 1$

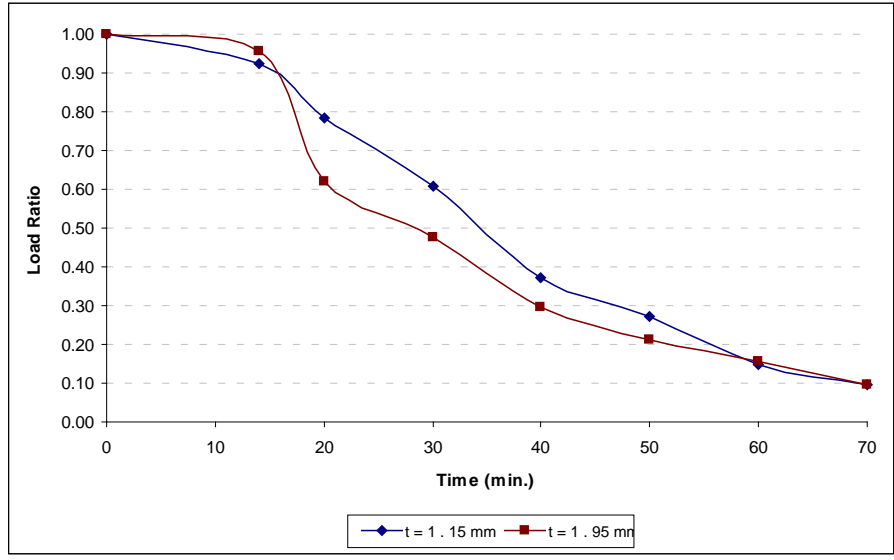

(b) $2 \times 2$

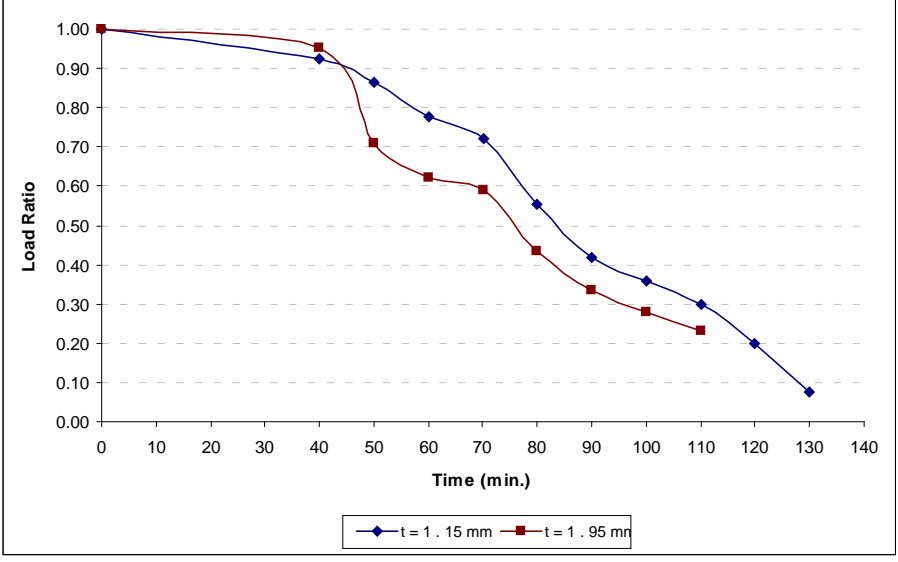

(c) CI-GF

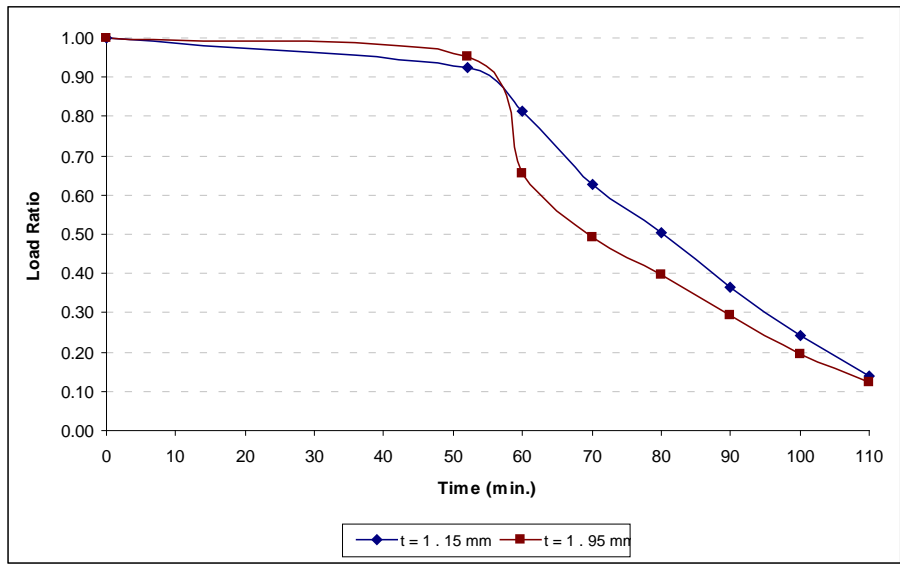

(d) CI-RF

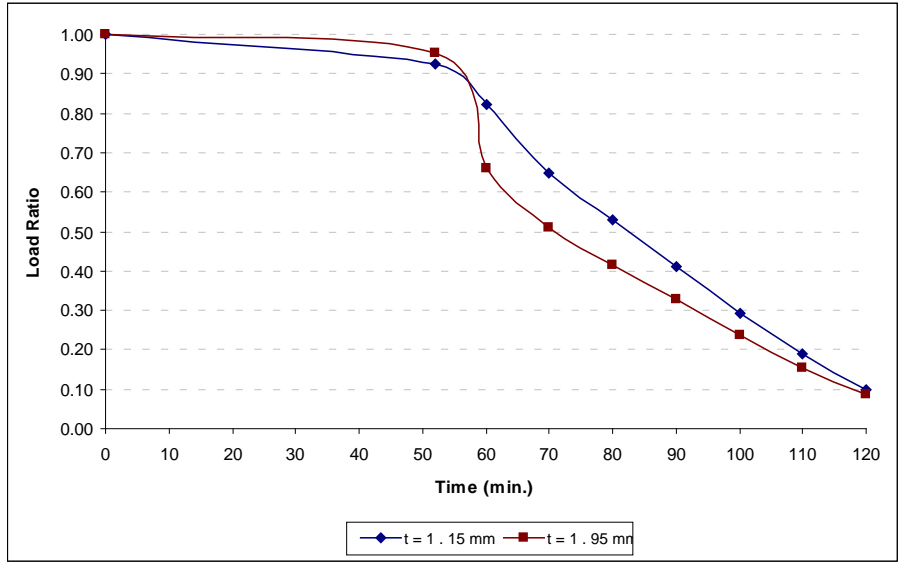

Figure 13: FEA Results for G250 Steel Studs with Different Thicknesses 
(e) CI-CF

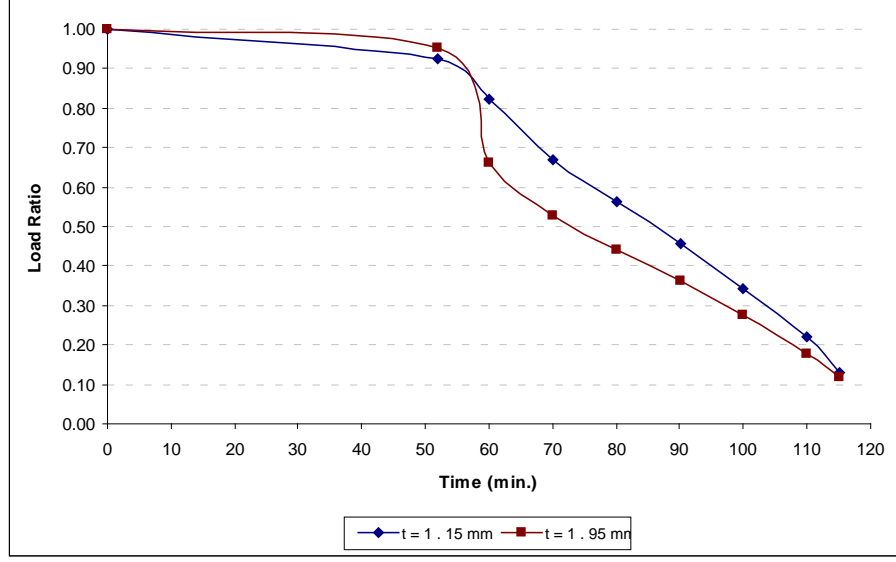

(f) $\mathrm{CP}-\mathrm{GF}$

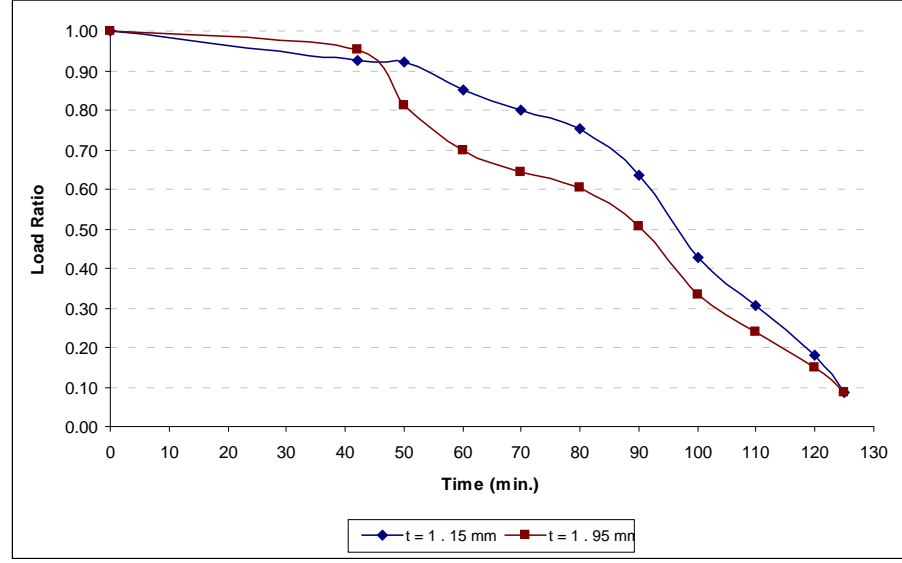

(g) $\mathrm{CP}-\mathrm{RF}$

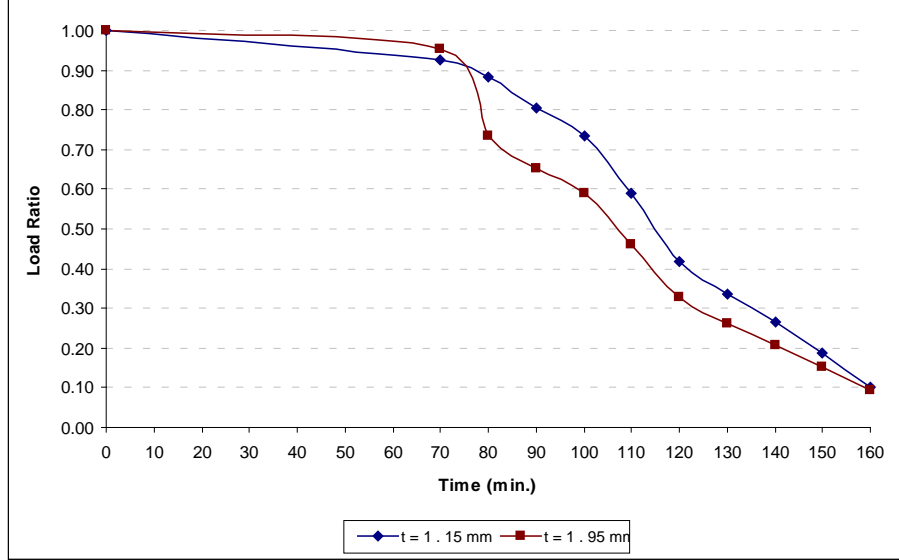

(h) $\mathrm{CP}-\mathrm{CF}$

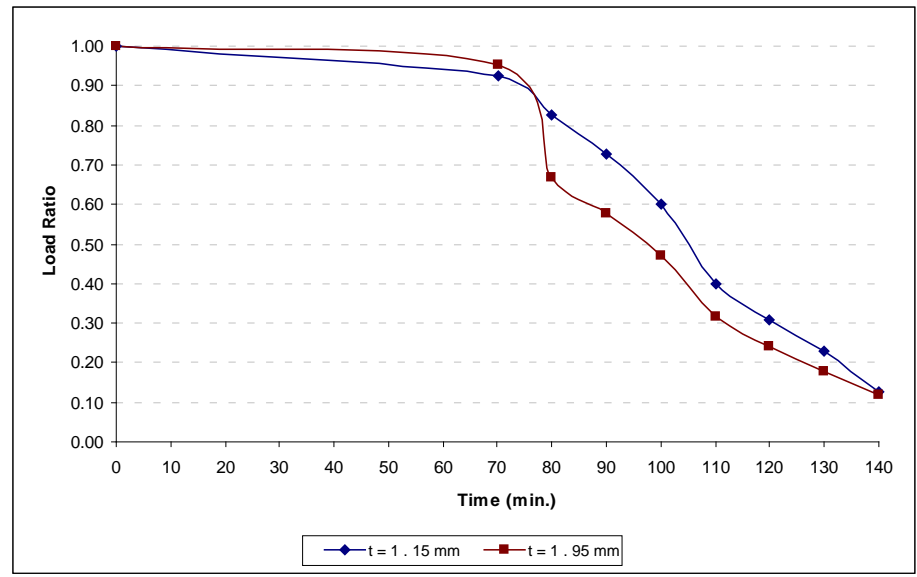

Figure 13: FEA Results for G250 Steel Studs with Different Thicknesses 
(a) $1 \times 1$

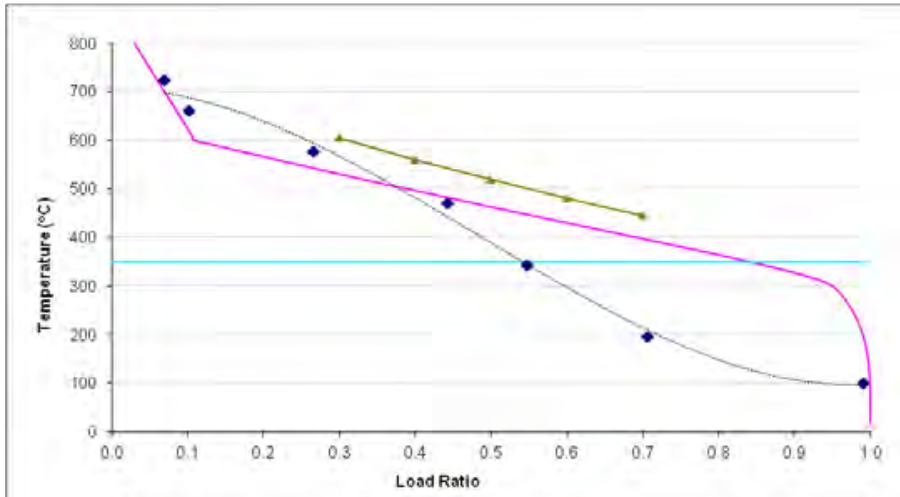

(b) $2 \times 2$

- FEA — Kolarkar (2010) —- Lawson (1993) ——ECSPat 12 -..-...- Poly \{FEA

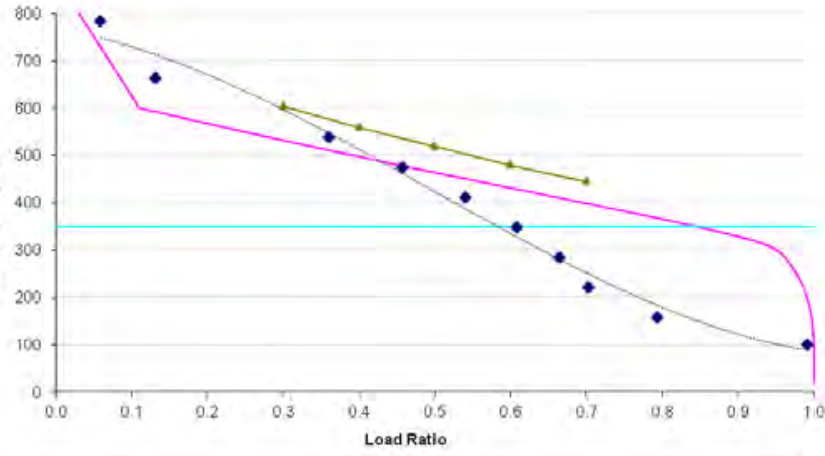

- FEA — Kolarkar (2010) - Lawson (1993) - ECS Part1.2-Poly. (FEA)

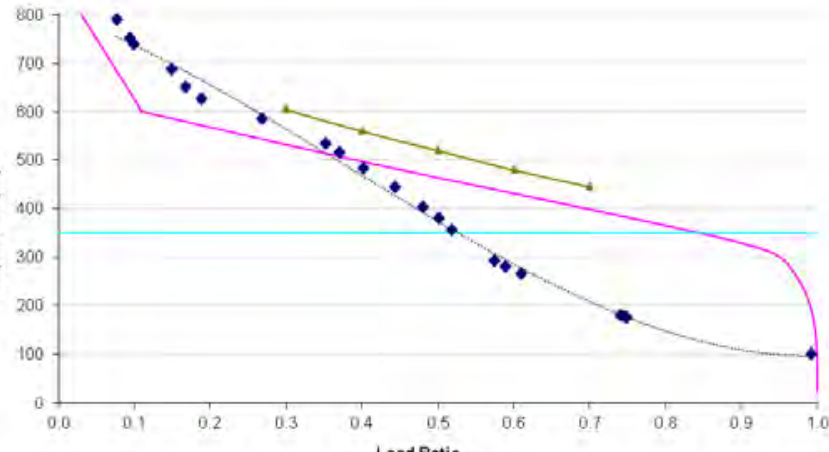

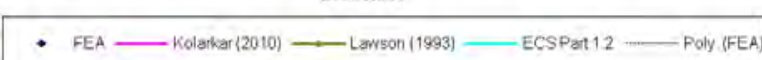

(c) $\mathrm{CI}$

(d) $\mathrm{CP}$

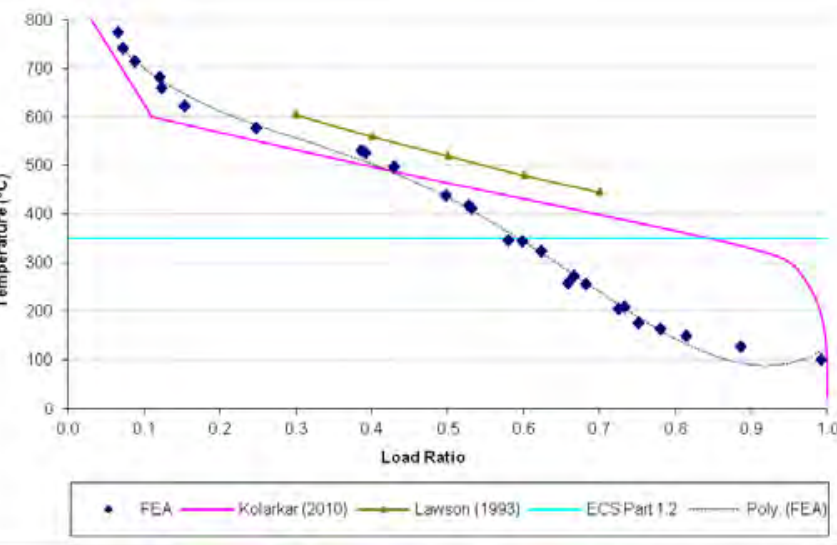

Figure 14: Comparison of FEA Results for 1.15 mm G500 Steel Studs 
(a) $1 \times 1$

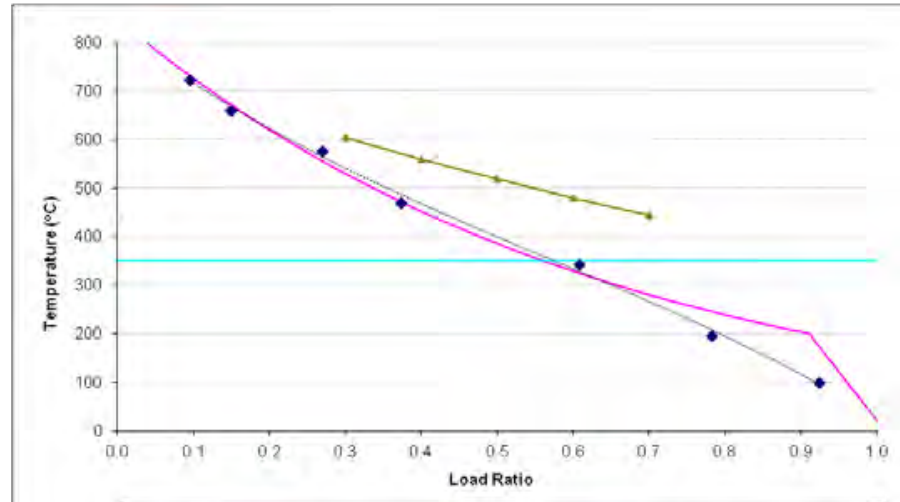

- FEA — Kolarkar(2010)—Lawson (1993)—ECSPart $12 \ldots-\ldots-\ldots$ Poly (FEA)

(b) $2 \times 2$

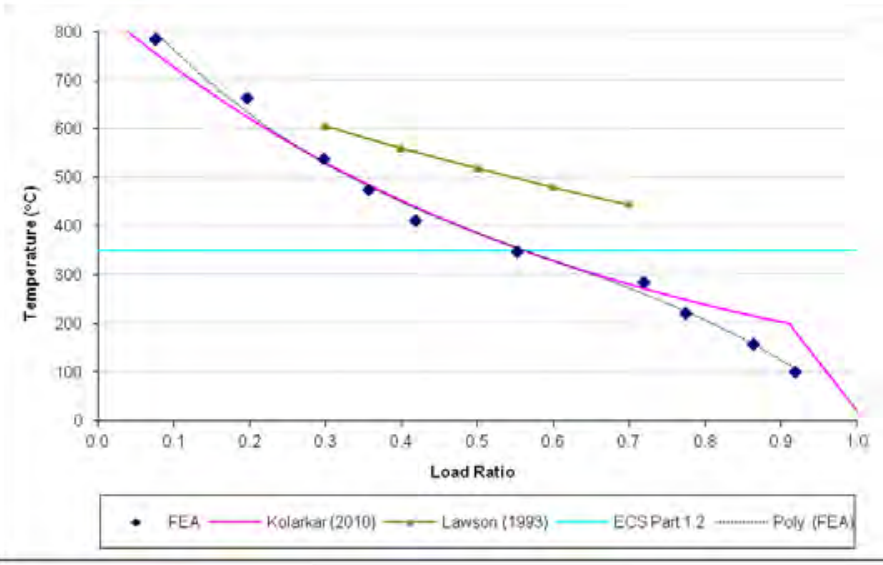

(c) $\mathrm{CI}$

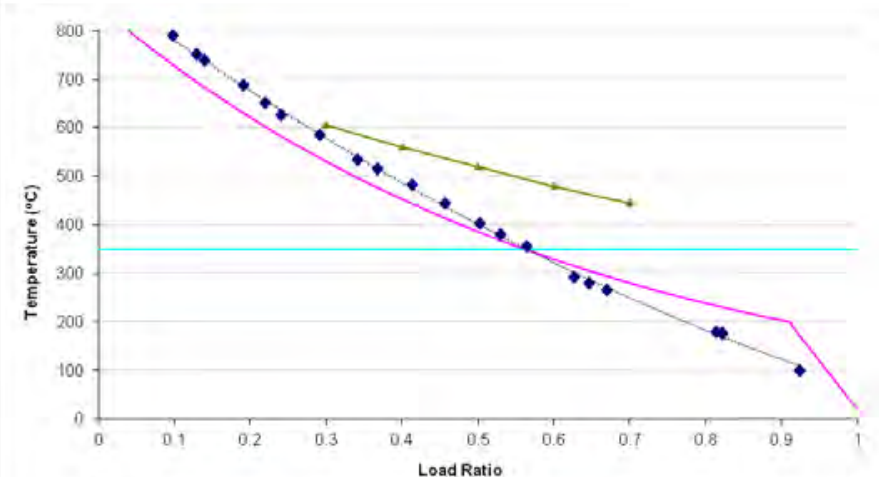

- FEA — Kolarkar (2010) —- Lawson (1995) — ECSPart 12 -... Poly (FEA)

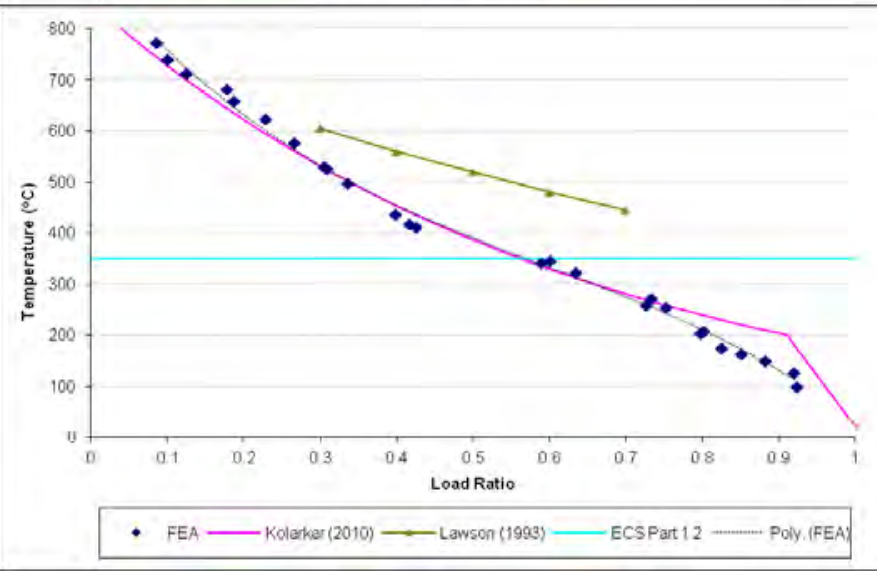

Figure 15: Comparison of FEA Results for 1.15 mm G250 Steel Studs 
(a) $1 \times 1$

(b) $2 \times 2$

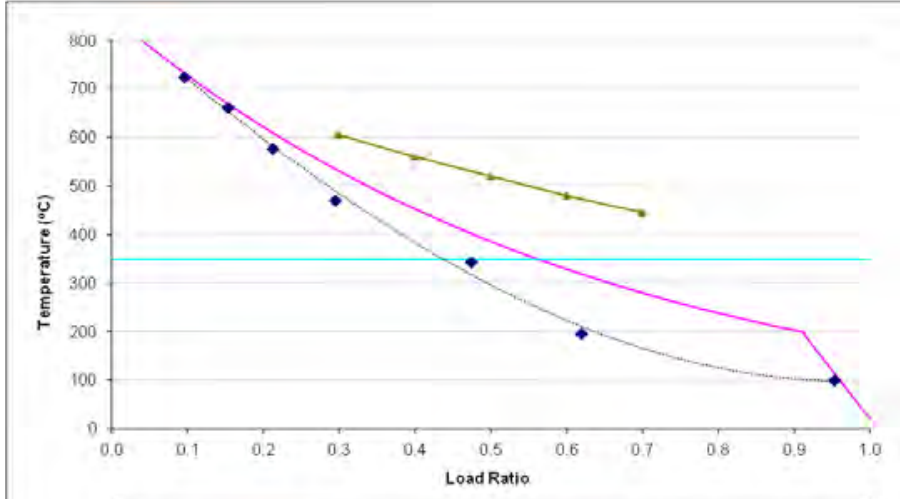

- FEA — Kolarkar (2010) —- Lamson (1993) — ECSPart 1.2 —... Poly. (FEA)

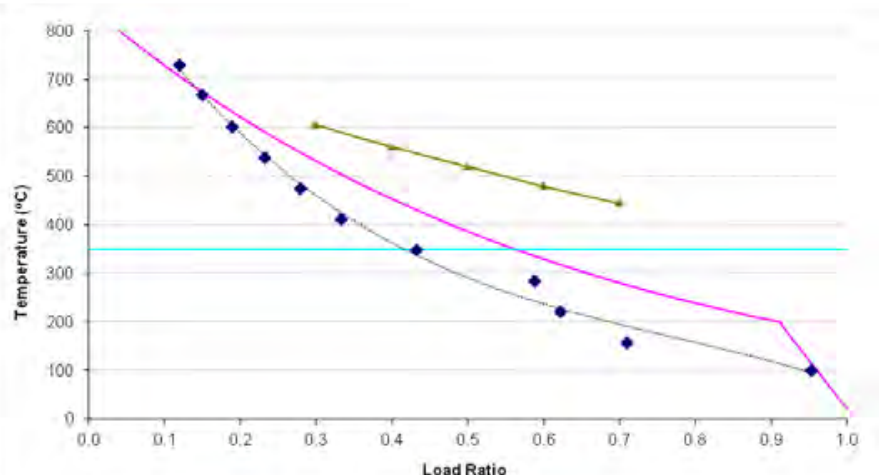

- FEA — Kolarkar (2010) - Lawson (1993) —-ECSPart $12 \longrightarrow$ Poly (FEA)

(c) $\mathrm{CI}$

(d) $\mathrm{CP}$

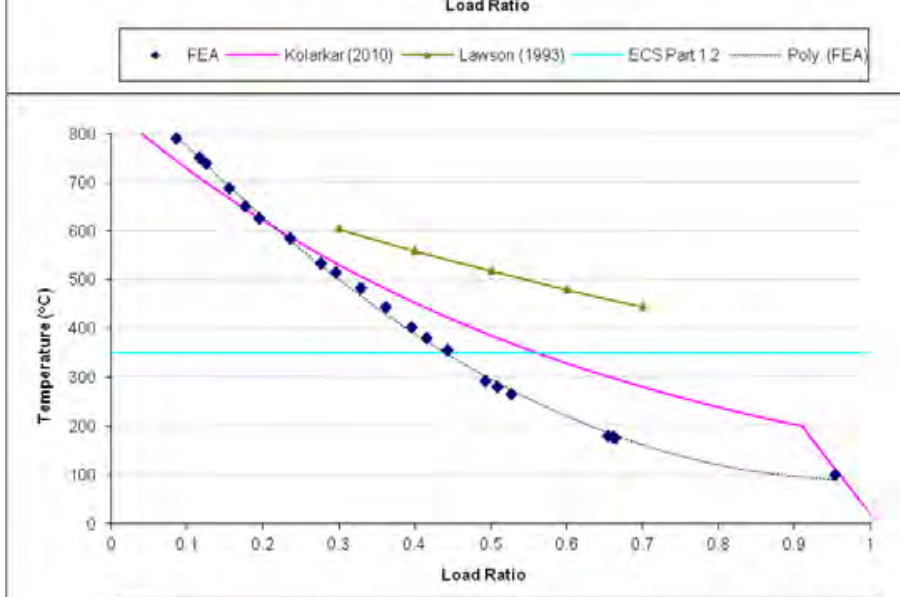

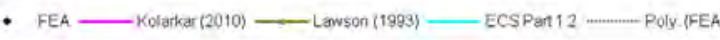

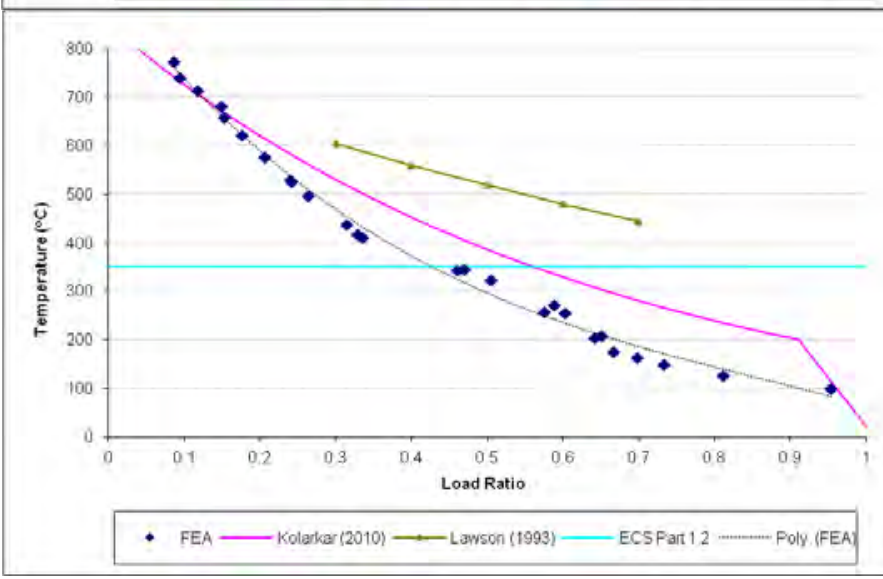

Figure 16: Comparison of FEA Results for 1.95 mm G250 Steel Studs 


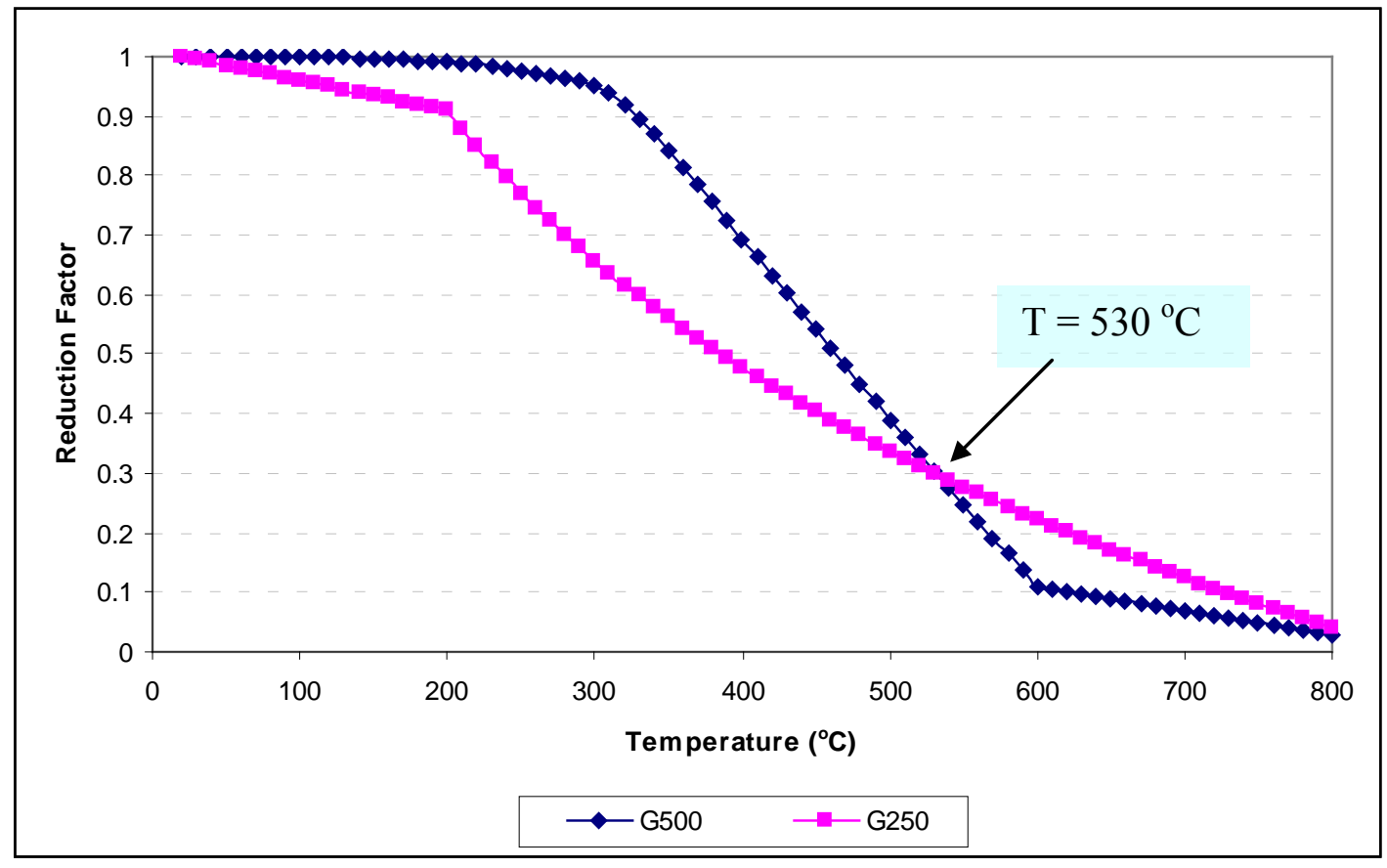

Figure 17: Reduction Factors for Yield Strength at Elevated Temperatures 